NBSIR 88-3729

\title{
A Collection of Technical Studies Completed for the Computer-aided Acquisition and Logistic Support (CALS) Program Fiscal Year 1987 Volume 4 of 4
}

Thomas Wright, Editor

U.S. DEPARTMENT OF COMMERCE National Bureau of Standards Institute for Computer Sciences and Technology Information Systems Engineering Division Gaithersburg, MD 20899

March 1988
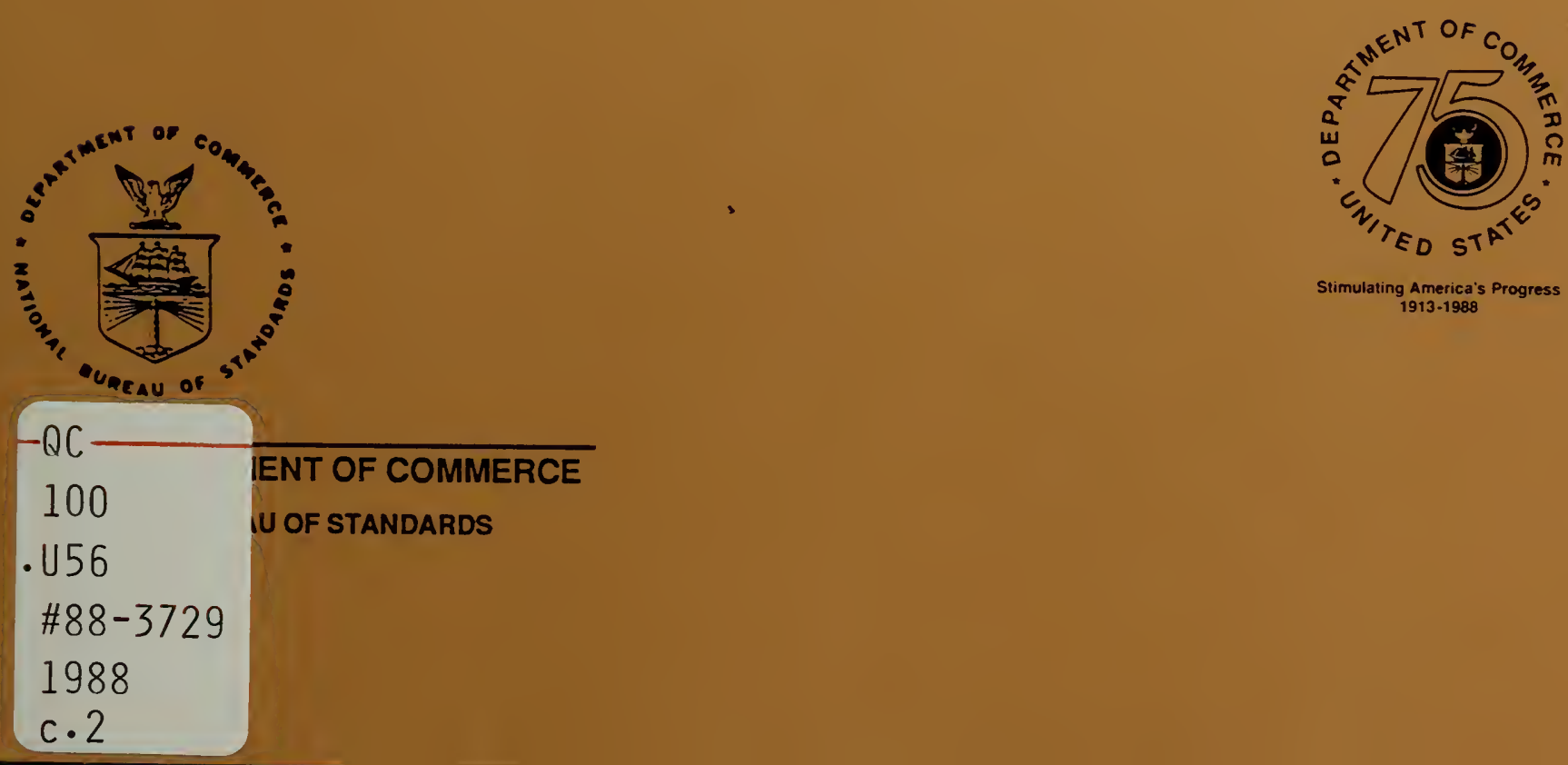

Stimulating America's Progress 1913-1988 



\section{A COLLECTION OF TECHNICAL STUDIES COMPLETED FOR THE COPUTER-AIDED ACQUISITION AND LOGISTIC SUPPORT (CALS) PROGRAM}

\section{FISCAL YEAR 1987} VOLUME 4 OF 4

Thomas Wright, Editor

U.S. DEPARTMENT OF COMMERCE

National Bureau of Standards Institute for Computer Sciences and Technology Information Systems Engineering Division

Gaithersburg, MD 20899

March 1988

U.S. DEPARTMENT OF COMMERCE, C. William Verity, Secretary NATIONAL BUREAU OF STANDARDS, Ernest Ambler, Director 



\section{EIECUTIVE SUMMARY}

The overail objective of the Department of Defense Computer-aided Acquisition \& Logistic supp:=t (CAIS) Irogram is to interrate the cesign, manufacturing, and logistic functions through the efficient application of computer technology. CALs is a program to $\bar{c}_{\text {fply }}$ existing and emerging communications and computer-aided technologies in DOD and incustr:

- Intesrate and improve äesign, manufacturing, and logistic functions; thereby briging existing "islands of automation."

- Actively influence the design process to produce weapor systems that are more reliable and easier to support anc maintain.

- Shift from current paper-intensive weapon support processes to a highly autcmated mode of operazion, basec on a unified DOD interface with industry for exchange of logistic technical information in digital form.

The CALS program was established by the Deputy secretary of Defense in september 1985 to implement the recommendations of a joint Industry/DoD Task Force. Management is provided by a DoD Eteering Group, an OSD CAIS Policy office, and their counterpazts in each Military Department and the Defense zogistics Agency. The CA.IS Policy office has obtained the support of the Natioral Bureau of standarcs in the selection and implementation $0=$ cl. Is standards. An Industzy steering Group has also been established to focus the work of key industrial associations and the defense contractor community in CALS implementation.

The Bureau has been furded since spzing 1986 to recommend a suitee of industry standards for system integration and digizal ciata transfer, and to accelerate their implementation. NBS activizies during 1506 were primarily aimed at:

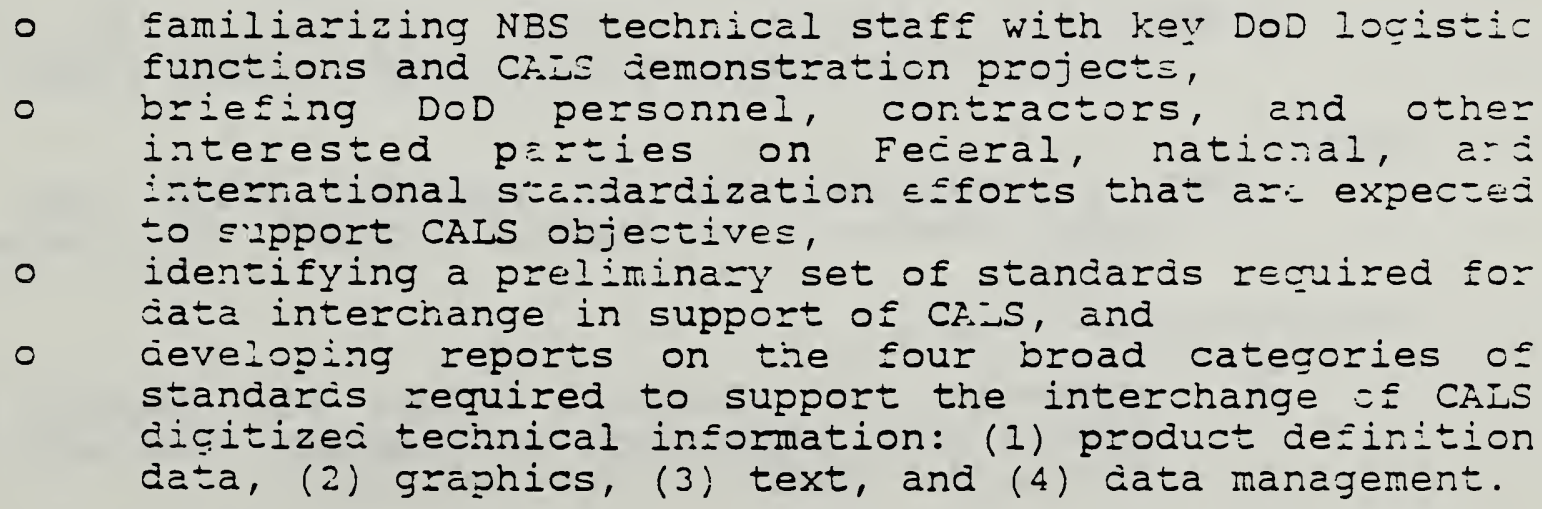

R.s a resuit of these efforts, NES made a preliminary identification of several high-priority standards implementations 
neecied for CAIs data interchange arj access.l Euilding on hnswledge and experience giined during FY86, NBS fo...sed on the following activizies in FY87: developing a CALS Framework, DEvel: me: = Flan and Core Requirements Packaçe; providing technical support fer standarss develogment and implementation; c it conducting workshors and meetirgs fo promote dialogue with =nt Services, the Defense Logistics Agency, and industry.

A riajor FY87 thrust was the completion of initial documentision of the high-prisrity stindards required in the CA:s environment. Some of tiese standards (e.f., SGML, IGES) reouired tailaring o enhancem:nt. Other standaras zrouirei a "push" (e.g., cEEM) for their development in a timely fishion. These four volumes are a collection of ths final reports presented to the CiLs Policy office. 2 The collection is divided as follows:

\section{VOLUME I:}

Text

Evalliation of Text Interchange Methods

Plan for Conformance Testing for DoD Implementation of SGML

Guidelines for the Development of Tags for SGMI

The NBS FIPS - SGMI VIIidation suite

The NBS FIPS - SGNI Reference Parser

Using SGMI - Application Guidelines

ODA/ODIF Implementation Agreement a Dccumen= RDplication Profile

Data Nanagement

Ci.js Report on Data Management Standards

Suppcrting Logistic support Analysis (ISA) USing =ie In Eormation Resource jictionary system (IRDS)

Medía

ICST Pecommendations or optical Disks and In:E Refiireme::s for Planned EDMICS Procurement, Einal Report

1 Kemmerer, S., Editor, "Final NBS Report for C:Is, F:86," U.S. Department of Commerce, National Bureau of Standazds, NBSIP. 8T-2566, MaY 198?.

2 The pubiishing of this crilection of reports does not imply the CALS PaIic: office has erdorsed the conclusions and recommenciations presented. 
Raster Compress ior.

Report on Raster Graphics

Tiled Raster Interchange Fommat, TEIF Version 1.0, Rev. 1.2 Confortince Testing

NES Plan for Vaidiation (Confomaride Testing) of computer Products in Support of the CAIS Program

VOLUNE 2:

Graphics

Raster-to-Vects= Conversion: A State-of-the-Art Assessment

Development of CGM VaIidation Routines

CAIS Application Profile for CGM

CALS Requirements Reflected in the Extended CGM (CGEM) Standaras Effort

A Reference Implementation for CGM, Functional Recuirements and Conceptual Design

IGES to CGM Translator Design Specification

VOLOME 3:

Graphics

CGM Registration For CALS Requirements

VOIUME 4:

Product Data

Guidelines for Testing IGES Translators

Guidelines for IGES Application subse:s 
The followin= are additional deliverables completed by : 35 during FY87 but uncer separate cover. They are available througt. the CAIS Policy office.

CAIS Core Requirements, Phase I.0

$C i$ is Framework:

CAIS Program Integräion ct Logistic Support Analysis and Feliability and Maintainability Data Deliverables

CAIS Current State of Digital Technology (Phase I.0)

CALS Workshoy Proceecings:

Graphi=s Data Interface for Engineering Design and Tecinica: Publication Systems (January 13;14)

Introduction to the Core Fequizements Package (April 23)

MIISTD-1840A, Automated Intercnenge of Technical Information

MILSPEC-D-28000, Digital Representation for Communication of Product Data: Application Subsets

MIISPE:-M-28001, Manuais, Techr: III: Mazkup Requizements and G.:E:ic style specificatior for Electronic Printed output and Exchange 


\section{C.PNTRIBITIONS}

NBS would like to acknowledge the major technical contributors to this volume. In alphabetical order they are:

Jesse Crusey

Clarence Jonnson

Bradford Smith

Thomas Wright 


\section{.}




PP.ODUCT DATA

GUIDELINES FOR TESTING IGES TRANSLATORS

GUIDELINES FOR IGES APPLICATION SUBSETS 


IGES TRANSLATOR TESTING

TABLE OF CONTENTS

1. Introduction

2. Reference Model for CAD Data Exchange

3. Error Sources in CAD Data Exchange

Error sources from sencing system

Error sources from receiving system Summary

4. The Hierarchy of IGES Translator Testing

5. Verification Level Testing

6. Application Level Testing

7. Acceptance Level Testing

8. Software Tools to Support Translator Testing

APPENDICES 
1. Introduction: This report presents results from the $F: 87$ project $c^{-}$ digizal product data undertaken by tie En:-nee:ing CAD/CAM Group at tite National Bureau of Standards (NBS). The work wis sponsored by the

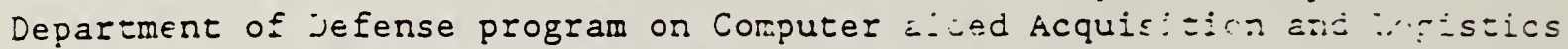
(AIS) and concerns the development of methods for testing ::e qui:: ty and completeness of Computer aided Desigr (AD) cata e:. alange throur the Initial Graphics Exchange Specification ; : ES).

CALS resources were used to augment and a-celerate the NBS-leci, volunta:.: IGES/PDES Orgar.ization involving over 600 experts from 200 companies. The goal of the FY $\varepsilon ;$ CALS sponsored program was uo estaitish a National Testing Program for IGES translators. The CALS fundirg Froduced significant deliverables in the development of testing methodology for IGES translacors and in the development of the IGES applicarion suinse: concept and its incorporation into a forma: military specif: ateion fo: procurement of datasets.

The resting methodo:ogy being developed by the IGES/PDES :-gari:zanion comnittees recognizes three inter-related leveis of inanslator testing:

\begin{tabular}{|c|c|}
\hline erification Testing & $\begin{array}{l}\text { - The testing } c \text { vendor claims and conformance } \\
\text { of IGES transiators to the IGES Specification } \\
\text { through individual entity tests. }\end{array}$ \\
\hline Application Testing & $\begin{array}{l}\text { - The testing of functionality in } \\
\text { specific application areas tr:ough entizy- } \\
\text { entity and er.ity-atzibute interactions. }\end{array}$ \\
\hline Acceptance Iesting & $\begin{array}{l}\text { - liser testing that assesses }=\text { e degree } \\
\text { of compatibility of diffezt: CAD/CAM systems } \\
\text { in. the users' shop and operationai } \\
\text { environment. }\end{array}$ \\
\hline
\end{tabular}

The CALS objective in the verification zask is zo establish a liational f:ansiato: Testing Program under the dizection of the jociety of

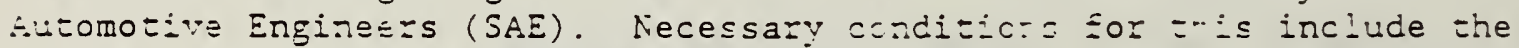
exister.ve of comprehersive LestinE provedures ap zoved $\cdots$ the IGES/DDES Organization, the trairing of knowiedgeable test teams, and the development of $w=11$ docimented test cases. The first was developec ly NE: uncer the CALS prog:am and is retorted here as the "Quickstart" prograr. T:-is effort, presented in June 1987, integrated divergent "iews in several IEES Committees and moved the organization towards consensus. The approach $\because$ cs next rejined and extensive-y tested undez the name of zr: "Juisksta: $:="$ proszam. The methodolosy is presently uiewec is E: :shec and $: \equiv a d y$ Eor use by the Sriz in the tzial phase testing program.

The verification methocology was thozougrily tested in the "Ouiristur= $j z "$ progtam agains four CA.D systems. Eresentations of the methicolog: to the various zesting comriztees and outside obstzvers zesulzed in im:-rovements to the tes: scheme and its impienertuzion. During a live 
demonstration of the verification two test incidents were encountered that caused an error report to be sent to one vendor.

1.1. Background: To the greatest extent possible, this cocument represenss both the philosophy and intent of the IGES Organization and the NBS Center for Manufacturing Engineering. Readers are reminded that future progress in the implementation of the methodology as well as mutual deve:opment with the International Standards Organization committee IC $184 /$ SC4 testing effort make the material herein subject to change and refinement.

The work has benefited from the collective experience in IGES testing developed at companies participating in the voluntary effort. Three important contributors were: 1) the Department of Energy DOEDEF project, 2) the General Motors Testing Program, and 3) the British effort at the University of Leeds. Active discussions with representatives of these projects continue to identify and incorporite the best features of each program.

In 1986 the IGES Testing Committee determined that in order to achieve its mission goals in a reasonable time Erame, it needed to reorganize into six separate IGES committees:

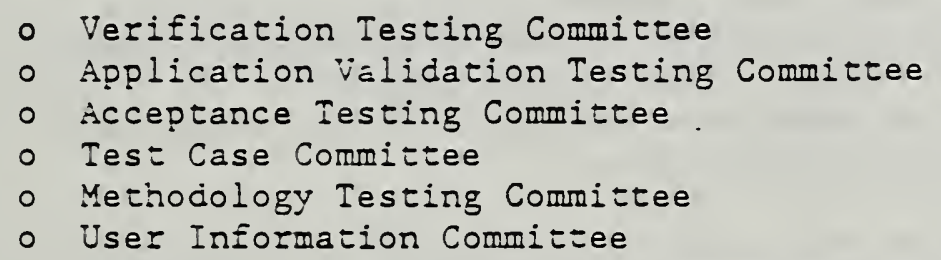

These six committees now comprise a formal IGES testing project. This Eives the IGES organizazion four projects 1.- IGES, 2.-PDES, 3.- Testing Methodology, and 4. - ISO activities.

NBS is working intensively with the committees in an effort to accelerate the development of the methodologies and initiate a National IGES Izanslator Testing Program under the control of the Society of Automozive Eng-neers.

Other work of the Testing Methodology Project includes or will include the IGES Version 4.0 and 5.0 entities into the Verification Testing program, development of Application Testing Programs, generation of Acceptance Testing Guidelines, and PDES testing.

1.2. Status: Verification testing requires both a methodology for performing the test and test cases to be used for specific CAD systems. While developing and validating the methodology is a manageable sask, the development of test cases for all possible entities, form numbers and attributes would require years of concentrated work. Clearly, this is 
unacseptable fo- DOD, NBS, and the If:S community. To avo:c this protien, the NBS IGES office developec a plan to put in plice a simplified National Testing Program dur-ng the first quarter of 1988. This plin, calleci "Quicksta:=", is complete in terms of th.e methodology and p:ocedures, anc makes use of a sujset of test cases capable of s:porting CAD systems and app!:za=ion st., sets in eypical use today.

The "Quickstar=" approach was designed to verify those IGES entities selected from the prcposed DOD appilcatior subsets (Technical Pubiication. Illustrations, Engineering Drawings and Electrical/Electronic

Applications). The effort developec anc used the same testing frocedures that will be used by the Society of Automotive Engineers. This ailo:-d the testing effort to "shake out" the system with a re tuced load of entities and readily achirvable goals.

The "Quickstart jr." appro.zch was infiated in iuly wi:h the insent to produce the detailed procedures required by the Society of Autototive Engineers, (SAE), anc their testing agencies. To accomplish this, five IGES tes = cases, a set of formal preprocessor and postpzocessor tes= procedures, four sepirate $C A D$ systems and different CAD users were used to define and develop the testirf process. The results of this work are ciscussed at length in this document.

Future testing activities will concentrate on developing and documenting the complete set of test cases needed by the SAE. Attempes bill alsc be made to reconcile and utilize the efferss from DOEDEF, Genera- Notors and the University of Leeds. The testing program at the University Leecs is of pazicular importance because of their established bise oi tes $i n g$ g $00 \mathrm{is}$ and testing experience.

Accilional efforts will be aimed at initiating the SAE testing program stadilizing the testing procedures, generating test cases for IGES $\because \equiv$ sion 4.0 entilies, acquirins testing tools, and designing an incormazior. system for manipli-ating the tes = resulzs. 
2. A Reference Model for CAD-Based Data Exchange: When dealirie with the issues of data exchange, it is usually beneficial to define a universe of discourse in order to establish a common frame of reference. To that end, the reference model shown in Figure 1 was created. The mode! was designed in the context of current IGES usage. That is, knowledg:abie human intervention is a prerequisite for the information transfer process. Human intervention is manifested in establishing local site procedures for design control, user conventions for application-oriented constructs, and the use of "common sense" to interpret the intended part functiona:ity.

The reference model uses boxes to represent information formats such as the IGES format and the native CAD database formats. Arrows represent the flow of information between these representations. Identifiers enciosed in small circles are used to indicate the significant functions of the model.

Shown at the top of Figure 1 is the representation known as product data. Product data is assumed to be a fuzzy concept that requires the agency of a knowledgeable human to translate its imprecise representation into that of a local CAD system. The representation of product data is in the domain of PDES and is beyond the scope of this effort.

2.1. A Trpical IGES Data Exchange: The model shows the CAD data exchange process to be a nearly symmetrical sequence of representations and interface processes. The first element, labeled 1, represents the designer, engineer, or CAD operator. It designates the iterative processing performed by a user to translate the concepts embodied by the part model into a valid CAD representation. The actions of the users are governed by design goals, application conventions, local procedures, and the interface capabilities of the CAD system.

Element number 2 in the model symbolizes the local CAD database representation, its support systems, and general capability. CAD representation and functionality is of parzicular concern for acceptance testing. Users need a good understanding of what functionality they require and how that functionality is represented internaily. These issues will be discussed later in this report.

The third element identifies the conversion process from the native CAD representation of the originating system to the IGES format. This process, know as IGES preprocessing, may be an integrated module of CAD system or a separate stand-alone utility.

The fourth element is the data representation defined by the IGES specification "as seen by the sending system". The IGES representation was designed to be a neutral format, rich in data elements to encompass all CAD-related applications. However, due to application conventions, different methods of encoding information, and ambiguity in the IGES 
enclose

figure 1 
specification, there can be multiple, correct interpretations of the information contained in an IGES file. For example, at one site the conventions may dictate using connected line segments to indicate fluid flow. At another site with different conventions, this information may be lost. For this reason the IGES representation as seen by sending and receiving system are separated. The difference in IGES usage is often referred to as "flavoring".

The fifth element is the transmission of the IGES file from the sending to a receiving system. The manner of transmission is unspecified. It can be via magnetic media, optical disk, local area networks, or telephone link. Typically an error detection and correction scheme is utilized to ensure data integrity.

Elements six through nine are reflections of elements one through four. Item six is the representation of an IGES file as seen "by the receiving system". For reasons previously stated, the IGES neutral format can be interpreted differently by the sending and receiving systems.

Element seven designates the IGES postprocessing step which converts the IGES format into that of the receiving CAD system. There is one significant difference between the interactions of elements two and three versus the interactions between elements seven and eight. For the preprocessing step, the software implementors will typically have a firm conceptual grasp on the information to be translated to the IGES format. It then becomes a matter of finding the most appropriate data elements in IGES to do the job. On the other hand, designers of the postprocessors need to be ready for a wide variety of entities, forms, and

functionalities.

The final element identifies the operations of a CAD operator who inspects the CAD database and assesses its correctness. Errors are fixed according to the operators interpretation of the CAD database and value is added to the part data. Again as in element one, local application conventions and site procedures are applied. 
3. Error Sources in Data Exchange: Errors in data exchange can be thought of as the failure to accurately transfer information from a sending system to a receiving system. The fallures can be caused by errors of commission and errors of omission on the part of implementors and users of CAD systems. They can also be caused by ambiguities in the standards used to encode and transfer the data such as IGES and the data media protocols.

The reference model illustrated in Figure 1 is particulary useful in looking at error sources. All errors can be associated with the representation of data or the communication processes between the representations. Representation errors arise from ambiguity, logical errors, and incompleteness. Process and interface errors can be procedural errors, software bugs, and human misunderstanding. These error sources will now be expanded from the point of view of the sending and receiving systems.

3.1. Error Sources from Sending system: Error sources on the sending side can be thought of as origination errors. They include software bugs, design flaws, improper local design conventions, and errors induced by tolerancing and precision problems. Most of the error sources in this class, especially those concerned with engineering and design practices, are not within the scope of data exchange errors.

3.1.1. Human errors: Human errors as described in the model shown in Figure 1 are errors introduced by human mistakes. These include errors in the local site conventions, misuse of the software and the inability to represent part model information through the CAD system interface. Some of these errors are subtle and not really errors in their own right. For example, a local site convention may use a particular set of geometric elements and associativities to describe a high pressure steam pipe. When transferred as a series of drawings to another site, this information is lost and requires human interprezation to reconstruct iss intent. Because the operator on the receiving must guess, a possible error source is introduced because the original intent has become unclear.

3.1.2. CAD Representation errors: CAD representations present us with another error source. There are of course software bugs, which when found, can be fixed. Other problems of a more difficult nature involve, change control, inadequate representation functionality, and missing functionality. As mentioned before, these latter error sources are not necessarily errors on the part of the CAD system. They arise due to a mismatch of expectations between the sending and receiving CAD users and sending and receiving CAD implementors.

Change control error sources occur when a system is modified and an unexpected change in functionality occurred. An example occurred when a vendor changed his text handling technique. Normally this would be a 
trivial concern, except that in one application a small position shift occurred on the lettering of a printed circuit board. At the new position, the lettering shorted out two conducting paths which, in turn, caused a board fallure.

Missing, inadequate, and mismatched functionality occurs when a user cannot represent desired part functionality in the CAD database. It can also occur when the functionality inherent in the database cannot be transferred either to IGES or to the receiving CAD system. Mismatched functionality occurs when the representation forms on the sending and receiving systems are sufficiently different so that identical functionalities can not be transferred. Examples of this have recently surfaced on two systems that had different conventions for handing level and color information. One popular CAD system associates color and level so that only one color can be defined for a given level. While this is not an error, test cases designed to transfer information to a level using colored entities were not successful.

3.1.3. IGES preprocessing: The IGES translators are the most obvious and most often cited sources of error. Historically, this was caused by the general poor quality of translator software and the lack of support given to IGES translators by the CAD companies. Modern translators are vastly improved over their predecessors and are undeserving of their poor reputations. What this discussion will show is that many of the errors occurring in the exchange process are introduced by differences in expectations on the receiving and sending systems and not due to faulty sof tware.

Errors introduced by preprocessing include: improperly constructed IGES files, poor choice of entity mappings, and the inability to represent native functionality in the IGES format.

3.1.4. IGES format errors: As stated previously, element four identifies the IGES format as seen by the sending system. The class includes generic IGES problems such as erroneous and ambiguous specifications. These problems have received a great deal of attention in the user community and will not be elaborated. A second source of error occurs because there are multiple, correct IGES representations for a given CAD database element. When compounded across the entire CAD database, a very large set of correct IGES files can be generated to represent the same part. In a data exchange, the implementor of a preprocessor has the advantage of knowing the intent of the native database. To him, having multiple representations will be seen as flexibility. He will merely choose the IGES entities which most closely match his native entities. The implementor of the postprocessor does not have this advantage and must make assumptions about the intent of the file. Thus, a possible error source is introduced.

3.1.5. Transmission Errors: Transmission error occurs when data files 
transmitted from the sending system do not match the data files received. These errors are of two types, transmission and interpretation. Transmission errors are usually induced by noise or device malfunction. It can include magnetic media failure, improper head alignment on a floppy disk drive or a lightning burst over a telephone line. With current error correcting protocols and modern device drivers, these are usually not a problem. Errors are more likely to occur through the misinterpretation of the file structure of the correct data files.

Each computer operating system has its own definition of what a file should look like. Larger systems will have several choices of file types to choose from. When files are transferred to other systems (electronic bulletin boards, local area networks, and magnetic media), a file structure change can occur that is invisible to the user. This was dramatically demonstrated during IGES testing at NBS when valid IGES files could not be postprocessed. Fortunately, when the file type is misused, the error is so severe that it cannot remain undetected.

3.2. Error Sources from Receiving Systems: The list of possible error sources from a receiving system accurately mirrors the error sources from the sending system. The major difference between the two sides is that the sender, knowing what to communicate, must select a representation to capture his intent. The receiving system has an open-ended task. From a large set of choices, all reasonable constructs must be interpreted and higher orders of information associated.

3.2.1. Transmission Errors: As mentioned in section 2.1.5, transmission error occurs when data files transmitted from the sending system do not match the data files received. The errors are of two types, transmission and interpretation. Transmission errors are usually induced by noise or device malfunction. It can include magnetic media failure, improper head alignment on a floppy disk drive or a lightning burst over a telephone line.

Interpretation errors typically occur because of differing expectations of file and carriage control. Interpretation errors can be induced by either the operating system or application programs.

\subsubsection{IGES format errors: This identifies error sources inherent in} the IGES format as seen by the receiving system. Included are the generic IGES problems such as erroneous and ambiguous specifications and those induced by multiple correct representations of CAD functionality.

3.2.3. IGES Postprocessing: The IGES postprocessor and preprocessor share the dubious distinction of being the best known and most often cited error source. As with many examples of "common knowledge" this may be untrue. Development of this representational model has shown that most exchange errors may occur at the logical level. However, this 
assertion of this needs to backed up facts and such facts are not available.

Errors introduced by postprocessing include: improperly constructed IGES files, no support for specific entities, and the inability to represent all entity functionality inherent in the IGES construct.

3.2.4. CAD Representation errors: Error sources for CAD representations on the receiving system include software bugs, inadequate representation functionality, and missing functionality. As mentioned before, most arise due to a mismatch of expectations between the sending and receiving $C A D$ users and sending and receiving $C A D$ implementors.

\subsubsection{Human errors: Human errors are mainly derived from} misinterpretations and errors associated with site specific and application specific conventions. When human intervention is necessary to correct or restore a part model, the operator must detect those items that require change and modify them. Since this is an iterative process, the operator mirrors the originator of the part. Consequently, he must follow local conventions and be subject to the same error sources.

3.3. Conceptual Grouping: As with any complex process, there are multiple ways to classify its behavior. The error sources discussed so Ear have been presented along sequential and functional lines of daca Elow. If viewed conceptionally, another useful grouping of error sources emerges with the concept of functional intent.

Functional intent can be defined as the process of transferting the original design intent from one system to another. This involves the use of a representational form and a translation to and from the form as shown below.

This process occurs between each representational form. From figure 1 , these are the product data model, the sending and receiving CAD databases, the human operators internal modeling, and the IGES format. Errors can now be collected into these five catagories for each operation. in the data exchange process. However, since two of these five catagories deal with functional intent and another two deal with 
translation choices we can reduce the errors groupings to three error classes. A functionality class including error sources that derive from the capabilities of the $C A D$ systems to capture the intent of the original part model, a translation class that includes errors generated by translation and interpretation, and finally a representation class that includes error sources induced by the representational format.

For completeness, a fourth class is added to include general operational errors. This includes human error, software configuration management errors, and transmission noise and media fallure. The following table summarizes these error sources by class. 
4. The Hierarchy of IGES Translator Testing: Before starting to use IGES as a mechanism for CAD data exchange for production quality information, it is prudent to test the translators that will be used. As has been the case with General Motors, Boeing, Hugnes, the Seawolf project, and others, testing is a laborious and demanding task. The task is also extremely complex and if approached without a formal plan, will consume tremendous amounts of manpower.

4.1. Three Level Strategy: The IGES/PDES Testing Methodology project has developed a three level strategy for translator testing that produces detailed test results with a minimum of resources. It is based upon a division of workload into portions that are generic to all users and CAD systems, portions that are common to a specific application, and portions that can only be tested in the user's own system environment. As previously defined, the strategy divides testing into three levels:

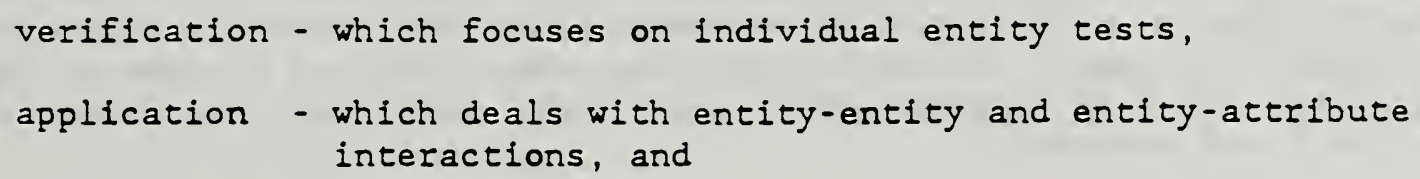

Each level builds upon work done at the lower levels. For instance, the application level testing cannot proceed unless verification testing has been completed on each entity and form number that is in the application subset. Furthermore, this three level strategy allows the common aspects of all testing to be done at a single site and thus supports all users of the IGES translation. Such a site is the envisioned SAE national testing program to do verification level testing. Test results from the SAE can be used by all application level testing and those in turn are used in acceptance level testing.

4.2. Gathering Data on CAD Error Sources: A comprehensive data gathering effort must be looked at from several different perspectives. The first, and the basic building block for the others, is gathering data on specific CAD systems. Specific error sources induced by specific systems need to be cataloged in both preprocessor and postprocessor modes. This is the verification test which includes a comprehensive approach for intra-system testing and data gathering to accurately characterize the features of a given system and check those features for conformance with the IGES Specification. At this time, these tests are being developed and tested. Specifics of the "Quickstart" implementation will be discussed in the next section on verification level testing with the actual results presented in Appendix $C$.

The second front for data gathering is in the area of application level testing. IGES application subsets have been defined for three candidate applications. It is expected that as the necessary information models become available and usage guides written, error analysis will begin. 
The final front is concerned with errors generated on specific systems at specific test sites. Data gathering and analysis of inter-system data exchange is the subject of acceptance testing. This process is the most important to the end user because it will show what errors he can expect in his own shop and provide guidance for avoiding them. Error detection and correction lies at the heart of the acceptance testing concept. Consequently, it will be discussed with the acceptance testing section in this report.

The verification test is a very important component of the acceptance test. Basic operations done during the verification process must also be performed for the acceptance test, (the derivation and testing of the entity map being the most significant). Without the verification results, the end user would have to design his own site specific verffication test to gage IGES performance and characterize his CAD systems prior to investigating inter-system data exchange. This burdensome function would be further duplicated at other sites that are attempting to come to terms with their CAD data exchange needs. Acceptance testing is discussed in Section 6 and Appendix E. 
5. Verification Level Testing: Verification Testing is the first part of a three part process aimed at improving the quality of digital product data transfer. It addresses the concept of vendor claims, the correctness of individual entities read into and written from CAD/CAM systems, and overall conformance to the IGES specification.

5.1. Approach: The goal of the Verification Testing effort is to establish an independent, national program to test IGES translators. The trial phase of the program, which will be run by the Society of Automotive Engineers will help establish a defined level of quality for IGES translators.

A key concept in Verification Testing is that of the vendor claim. Unlike most standards, IGES is not designed to be fully implemented by system implementors. This circumstance arises from the richness and application-specific entities in the IGES specification. System designers implement those entities which are meaningful for their application areas. As a consequence, it is necessary to determine what an IGES translator supports and what restrictions are placed on its use. To capture this information, the concept of the vendor claim was developed. It consists of the following.

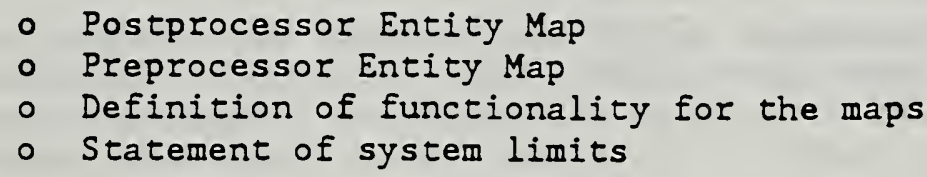

It is the objective of the Verification Test to take the vendor claims and "verify" that they are correct through the use of the IGES test library and analytical comparisons. The actual tests will be run by a testing agency selected by the SAE.

Results from the testing agency will be reviewed by the IGES Verification Panel, which is made up of IGES members, IGES users, and industry representatives. The panel will evaluate the results of the tests and produce its findings. If necessary, a 30-day review period will be granted for negotiations with the vendor and retesting. Following that period, a verification report is issued stating the claims that have been verified. The Verification Panel will be under the jurisdiction of the SAE Review Board which monitors the activity of the testing program.

The Verification program will have to ramp up for complete Version 3.0 testing over a period of two years. Over two thousand test cases and test scripts with accompanying documentation and expected results must be produced. This will clearly take time and effort. Since it is unreasonable to delay the start of testing until all IGES capabilities can be evaluated, a phased approach will be used. An initial selection of Phase I entities has been chosen from the DOD Technical Publication, Engineering Drawing, and Printed Circuit Board application subsets. 
The different phases of the tesing program are defined below. The Preliminary Phase and Phase I. are described in detall by the appendices. This approach allows for a trial testing period during Phase I., which will accommodate the need for internal testing and debugging.

Preliminary Establish the testing program and develop supporting documentation and test cases. This phase is running now and will continue through the end of calendar 1987.

Phase I

Start program in "trial mode" and add increasing levels of testing complexity. Most testing will be manual. Phase will run all of calendar 1988.

Phase II

Add software tools to do more complete analysis of ICES processors. Begin adding Version 4.0 entities. Phase will run all of calendar 1989.

Phase III Begin automating the testing sequences. Add Version 5.0 entities and new tools for analyzing surfaces. Phase will run through 1990.

5.2. Methodology Development: The basic concepts of Verification testing have been in place since 1986. The next step required that these concepts be expanded and translated into detalled instructions for those persons performing the test. To this end, two projects were undertaken to develop and test these procedures. They have since been dubbed "Quickstart" and "Quickstart jr."

5.2.1. "Ouickstart": The "Quickstart" approach was defined so that a National Verification Program could be started in the near future. This approach, led to the development of the material in Appendix $A$.

"Quickstart" broke verification testing into smaller problem domains and created a time table for addressing unresolved technical issues.

It is important to recognize that the "Quickstart" approach did not replace the existing testing methodologies. It produced an implementation strategy for those methodologies. Furthermore, even though subsets were used to defined the initial set of entities to be tested, "Quickstart" testing must not be confused with application subset testing.

5.2.2. "Quickstart ir.": The SAE program requires clear and detailed instructions to guide its testing. Creating and testing these verification procedures on real systems was the subject of the three month effort called "Quickstart jr."

The purpose of "Quickstart jr." was to provide a validation of all the relevant material on testing methodology developed for the planned SAE Test Program and to assess its completeness and technical quality on a narrow set of entity types. Once the methodology was proven using a few 
test cases, the full breadth of test cases needed for a national testing program could be developed.

Specific tasks accomplished in the "Quickstart fr." project included:

- Production of a detalled overview of entire verification process.

- Creation of detalled step-by-step pre and postprocessor testing plans.

- Production of five complete test cases with documentation, construction scripts, and verification criteria - line, arc, general note, angular dimension and subfigure.

- Tests of procedures on 4 CAD systems.

- Production of a prototype SAE Verification Report.

- Presentation of results to IGES testing committees

The project produced a detailed set of step-by-step procedures for testing both preprocessors and postprocessors as well as suggestions for revising the various IGES testing methodology documents. Also resulting from the project were a set of all forms needed for data gathering, five fully completed test cases and an example "SAE Style" test report on each of four CAD systems.

NBS in conjunction with the IGES/PDES Methodology Testing Committee, two CAD Vendors, and staff from the Naval Surface Weapons Center, the Navy's David Taylor Research and Development Center, and Army's Labcom at Ft. Monmouth initiated a test of the SAE procedures using five IGES test cases, a specific set of test instructions, and four separate sites. The first steps were to develop the detailed test procedures and select a group of sample test cases. The test cases chosen for the effort were the line, general note, angular dimension, circular arc, and subfigure. The procedures were derived from the testing methodology document. The test procedures are included in Appendix A. 
The first iteration uncovered a series of problems that had to be quickly dealt with. These included:

- difficulty in following the test procedures,

- errors in test cases,

- difficulty with the construction detalls for preprocessor tests on some systems,

- difficulties in design philosophy of one CAD system that made the postprocessor test cases useless.

The problems encountered on the first iteration led to a much improved second iteration. For this pass a series of entity test cases were created that contained no extra colors, line fonts, levels or text fonts.

Next, a system of forms was designed to help guide the testing teams through the procedures and help the reporting of results. It was felt that the most efficient way to capture the intent of the testing methodology was to embed it in forms rather than text. This led to the development of a new forms packet which is included with the verification procedures in Appendix A.

The results of the second iteration were far superior to the first. Some minor problems with the test cases remained but very useful data was obtained. These results will form the basis for developing the verification methodology in the coming months. Results of "Quickstatrt $j I^{\prime \prime}$ are shown in Appendix $C$. and were presented at the St. Louis meeting.

5.2.3. Methodology Review: In order to demonstrate our methods and bring more members of the IGES community into active participation with the testing effort, a live verification test was performed and a homework exercise was created. The live test featured two CAD vendors, Autodesk and Cadkey, who supplied their systems and an operator for the test. The procedures specified in Appendix A of "Testing Methodology of IGES

Iranslators and IGES Formatted Data Files Version 0.5" were followed with a set of verification test forms contained in the Verification Request Packet. These were filled out during the test, except for the vendor claims, which had been entered prior to the test.

A verification test is a tedious process. Briefly, the test proceeded as follows:

- The test team, vendors, and observers were assembled and a test $\log$ was initiated.

- The hardware and software configurations were verified.

- The Volunteer Entity Test was run.

- The Global Section values were checked against those expected from the vendor claims.

- The test plan was run for preprocessor testing of the line and 


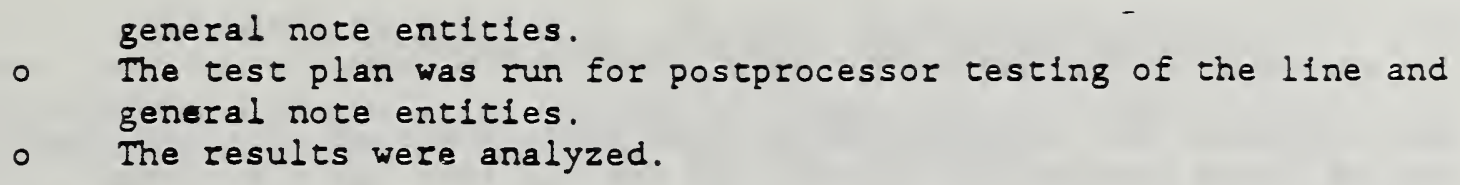

Both systems behaved well and produced a credible showing. The Autocad system displayed more of the functional sub-components of the general note than the Cadkey system. This gave the illusion that it handled the test better. The observers were reminded that verification testing is not a competitive event, and the test results are not a judgement of system quality.

Two Incident Reports were generated on the Autocad system for the general note postprocessor.test. The entities were displaced from their expected location. Analysis of the incident produced three differing views. 1 the test case is in error, 2 - the Autocad postprocessor is in error, and 3 - the general note definition is ambiguous. Further discussion will resolve the issue. Autodesk has stated that, if the problem is in their software, they will fix it immediately.

From this demonstration two important points were illustrated. The first is that verification is a slow, yet vital process requiring care and commitment on the part of the testers. The second is that many of the incidents reported in the early phases of testing will be about the test cases. Discovery of ambiguity in test cases and procedures are welcome. Once discovered, they can become the subject of corrections and recommended practices.

The data gathering by the "Quickstart $j r^{n}$ effort established the information needed for the SAE program. Bullding on this work, a homework exercise was created to get more testing committee members involved in the effort and to gather data from a wider range of CAD systems. The exercise packet contained test cases, blank verification Eorms, and the verification procedures.

5.2.4. Lessons Learned: The development of the implementation approach and the public demonstration highlighted the following points.

- Test cases are much harder to design and perfect than first imagined.

- A complete and comprehensive set of forms is necessary to capture the testing methodology and guide testers through the procedures.

- Verification is a slow process.

- Verification forms are numerous and the results are massive. It will be necessary to have computer assistance for the testing, data gathering, and data analysis process.

- CAD system limitations and design features play a larger role in 
test case design and selection than expected.

Nevertheless, the testing methods have been developed and validated, the set of forms printed and tested, and several live tests performed. The remaining testcase suite development is underway and should be complete under the "Quickstart" scope in time to support the SAE program.

5.3. Role of the Socfety of Automotive Engineers: The IGES testing program will be sponsored by the Society of Automotive Engineers. It is one of several testing programs administered by them. There are four groups which participate in the testing program: the SAE staff, the Performance Review Board, the IGES Verification Panel, and the testing agency(ies).

5.3.1. SAE Staff: The staff of the SAE has administrative responsibility for the testing program. These responsibilities include:

- Provide administrative services and support.

- Arrange logistics of meetings including meeting facilities.

- Maintain detailed financial information on incomes and expenditures of the IGES Verification Program. Provide such information to the Technical Board to assist it in establishing appropriate fee structures.

- Arrange for appropriate legal counsel and report the findings and recommendations of legal counsel to the IGES Verification Panel.

- Arrange for appropriate indemnification insurance for the IGES Verification Panel.

- Assure compliance with all prescribed forms and Procedures involving the IGES Verification Program.

- Hire a capable agency(ies) to perform the testing and provide contract administrative support.

- Maintain appropriate records.

- Establish and maintain procedures to ensure the confidentiality of certain results as appropriate.

5.3.2. Performance Review Board: The SAE Performance Review Board serves as an overseer for the various review Panels sponsored by the SAE. The Board reviews and approves the operating procedures of the review panels as well as their membership. 
5.3.3. IGES Verffication Panel: The IGES Verification Panel shall come under the jurisdiction of and report directly to the SAE Performance Review Board. It shall be composed of people who are technically competent in the area of IGES and CAD data exchange.

Subject to approval by the SAE Performance Review Board, the IGES Verification Panel shall formulate operating procedures, rules and operating guidelines. These guidelines will ensure that the testing program adequately serves all interested parties, including industry and the general public, while adhering to the principles, policies, and objectives of the SAE.

The work of the IGES.Verification Panel is to review the test criteria, testing techniques, and the results of the testing agency to verify that IGES pre and postprocessors satisfy the requirements of data exchange as referenced in the NBS IGES specification. It is the responsibility of the IGES Verification Panel to issue the formal verification results based on the findings of the testing agency(les). The panel may issue a statement setting forth the review and the determination it makes to verify or dispute the conclusion reached by the testing agency(ies). It is not anticipated that the scope of the Verification Panel's work will include verification of all the underlying hardware and supporting software for the translators.

The IGES Verification Panel shall consist of adequate membership to reflect the views of the users, interested agencies, laboratory testing, and other interested and affected parties. Initially, the membership shall be appointed by the SAE Performance Review Board. Subsequent membership will also be approved by this Performance Review Board.

Specific obligations and duties of the IGES Verification Panel are given in Appendix F.

5.3.4. Testing Agencv: The testing agency shall be responsible for verifying the hardware and software configurations, assembling the appropriate test cases, performing the tests, and reporting the results to the IGES Verification Panel.

\subsubsection{Scheduling of Verification Tests: Schedules for testing are to} be arranged by the testing party. However, due to the frequency at which software releases are made and the number of vendors potentially seeking verification, it is suggested that if verification tests cannot be arranged on demand, that verification periods be regularly scheduled on at a least quarterly basis. 
5.3.6. Funding: The charges for this service shall be such that the IGES Verification Program is self-supporting. Fiscal policy for the program shall be established and monitored by the SAE Performance Review Board. 
6. Application Level Testing: Work during FY 87 on application subsets resulted in the creation of a military specification on IGES application subsets covering technical illustrations, engineering drawings and electrical/electronic applications. Testing of translators at the applications level builds upon the earlier verification level but places additional conditions on completeness and range of values. Each application subset specifies entity and form number requirements, entity construction details, and ranges for parametric values within certain entities. Each of these requirements has a corresponding testing procedure. Details of the test procedures for the three applications mentioned are documented in the same military specification. See section 4.0 of MIL-D- 28000 . 
7. Acceptance Level Testing: Acceptance testing differs in three major aspects from application testing. The first is that it is site-specific and involves known parameters: specific systems, specific releases of CAD software, and known applications. The second aspect is that data is transferred across application areas. This leads to the third aspect, which is "100 data transfer is often not required nor possible".

When data is transferred from one application to another, only a certain amount of the avallable information is useful to the new application. The other data may be useful to other applications, but not to the target application. For example, when a fully annotated part model is sent from design to NC production, only the part geometry and manufacturing details are of interest. The fact that the NC generation system does not fully implement the general note entity or support line fonts may be of little consequence. This allows the local engineers and techniclans to narrow their testing focus to the most important aspects of their data flow.

\subsection{Introduction to Acceptance Testing.}

It is the responsibility of the end users, (those people who have the responsibility for moving $C A D$ data between dissimilar systems, and for validating the results of those transfers), to determine the suitability of IGES translators for their applications and operating environments. It is impossible for a single, independent agency to provide the level of testing required to make this determination for all users. Therefore, it is up to the end users to examine their own environments and to devise appropriate tests to ensure that the proposed translators will perform adequately. However, the task is simplified if verification and application level testing has been accomplished previously.

The objective of an acceptance test is to determine whether a specific pair of IGES translators adequately preserve the intended information content while moving the associated data between sending and receiving systems. In this context, the information content of interest in a part model is that wich will be required by applications running on receiving systems downstream from the sending system.

Another way of looking at this situation is that we are trying to answer the question: "Is this way of transferring product data better than the current way of doing it?" In many cases, the baseline for data transfer is the engineering drawing along with additional textual documentation. Therefore, we are interested in comparing the total costs to effect the data transfers. In both the baseline case and the case being evaluated, the costs should include such factors as the costs to create the information initially, to transfer the information, to repair any damaged information and to recreate any missing information.

Testing of the IGES translator pair is necessary to determine the reliability of the information exchange. The amount of testing done should be directly related to the cost to the enterprise of any erroneous or lost information. In accordance with this idea, the test cases should 
be reviewed and updated periodically to reflect the increased demands on the information exchange, and the entire test suite should be rerun periodically to identify any degradation of the translators as well as to certify new versions of the translators. Because of this need to perform acceptance testing repeatedly, a significant concern to the test designer should be the ease of running and evaluating the test cases. A more detailed discussion of acceptance test procedures and the design of acceptance tests will be found in Appendix $E$.

The IGES Verification Program described elsewhere in this document will provide a solid basis for acceptance testing by assuring that the entity mapping claimed by the implementor of a translator accurately reflects the processing carried out by that translator, and, in the case of preprocessors, that the IGES entities are correctly formed. Once the end user is aware of the capabilities and limitations of the translators, a more controlled and effective data exchange can take place between dissimilar systems.

The results of the verification testing for a translator play an important role in assessing how effective the data exchange will be. These results include the translator's entity map along with the findings of the verification testers concerning the preservation of functionality and the correctness of the entity formulations.

7.2. Use of entity Mapping in Data Exchange: In general, entity mapping can be described as the manner in which the implementor of a translator has defined the correspondence between native entity forms (i.e., the entity form maintained within a system) and the IGES entity forms (i.e., the entity form contained in the IGES specification). For example, a string of curve and line segments on a system may be translated into a Composite Curve entity (Type 102) by a preprocessor. This correspondence of a string in the native form to a Composite Curve in the IGES form is the preprocessor's entity mapping for the native string entity.

Similarly, a postprocessor may translate a Copious Data entity (Type 106) into a 3D line entity on the receiving system under some circumstances. Thus, the correspondence of the Copious Data entity to the line entity is the postprocessor's entity mapping for the IGES Copious Data entity.

The forms for the preprocessor entity map shall include the names of the native entities supported and the names of their corresponding IGES entities along with the letter designation which identifies the degree to which the functionality of the native entity is preserved in the translation. The forms for the postprocessor entity map shall include the names of the IGES entities supported and the names of their corresponding native entities along with the letter designation which identifies the degree to which the functionality of the IGES entity is preserved in the translation with respect to the local site. These letter designations are explained in the section dealing with reporting the results of the verification tests. 
The entity maps can be used as a first step in determining how well data can be exchanged between two systems. Knowing the native entities which are to be used on the sending (or Initiating) system, the end user can follow each entity through the entity map for that system's preprocessor and the corresponding entity map for the recelving system's postprocessor to see what the resulting entity will be. The end user can also get an indication of how good the translation of each entity will be by looking at the corresponding letter designations for both translators.

Depending on the end user's application of the information being exchanged, Imperfections in the mapping and translations may be tolerable. Acceptance tests should be performed to determine the effects of imperfections on the overall information exchange. Based on the results of the acceptance testing, the end user can strive to improve the quality of the information exchange by:

- making use of options provided by the translator,

- exploring alternative entity mappings with the translator implementors,

- documenting errors found in translators during acceptance testing,

- adding to and deleting from the list of native entitles being used, and/or,

- developing intermediate processors to deal with "flavoring" during translation.

Flavoring is a term that is used to describe particular practices built into translators to handle situations which are not covered by the IGES specification, or situations where the native system has a peculiar method of handling some data. For preprocessors this may be the case where the underlying system supports entities or relationships which are not directly supported by IGES. For postprocessors this may be the case where the underlying system does not handle the specific entities or relationships supported by IGES. Since the manner in which these situations are handled are not standardized, other knowledge is needed than that available in the IGES specification. This addftional knowledge is frequently built into the translators.

\subsection{The Design of an Acceptance Test: The seeds for success of an} acceptance test lie in constructing suitable test cases which will adequately reflect the user's need for information exchange. The first step in designing an acceptance test, then, is to identify the information content of the data files to be passed. One way to begin this task is to identify all of the entities which are used by the people who create these files on the sending system. The question is then asked for each entity, "What information does this entity convey in the content of the data file?" In some cases, the information content may be conveyed by a group of entities instead of by a single entity. In a similar manner, the information requirements of the receiving system are identified. Finally, the intersection of these two sets of information 
may be determined. It is this final list of information which provides the basis for both the design of the test cases and the evaluation of the results.

The identification of the information content is an iterative process which may involve negotiations between the senders and receivers of the data files. Some of the negotiations may involve making modifications to the modeling standards and conventions of one or both of the parties to the information exchange.

7.4. The Design of the Acceptance Test Models: For the purposes of this work, a test model is defined as a test case which resides on either the sending or receiving system in that system's native data form. These test cases will vary considerably in complexity, but, in general, will be more complex and more application specific than the test cases used for verification resting.

There are several, general principles which should be followed in creating the acceptance test models:

- Each different entity, or group of entities, which occur in the information model should appear at least once in the collection of test models.

- Several, small, simple test models are preferred over one, large, complex test model. The smaller models will be easier to build, easier to validate, and their results easier to evaluate. In addition, the results of large, complex test models have to be examined much more carefully to ensure that no errors have been caused as a secondary effect of another error in processing the model. Some complex models may be required as a part of the test, but these should be kept to a minimum.

- Include limiting (or boundary) conditions if they are important to the information exchange. Into this category fall models of large objects with small tolerances (e.g., $1597+/-0.00001$ ). As another example, if the use of layers is important in the user environment, include in a model the use of layers which fall at each end of the range of available layers.

- Where possible, test models should be self-checking. Redundant data should be included in the model to simplify its evaluation. For example, a test model with a surface could also contain several curves which define the intersection of the surface with specific planes. (This assumes, of course, that an earlier test model has validated the use of the curves.)

- Create a script describing how to generate each test model. This could be in the form of a command file for these systems which support this feature. This script, along with an annotated display of the test model, should be included in the 
documentation for the test model.

- Each test model should be accompanied by a script describing how to evaluate the results of the test. The script should contain specific evaluation procedures and the quantifiable results where possible. This script should also be included in the documentation for the test model.

A sample sulte of test models (and their corresponding IGES files) for an acceptance test is included in Appendix $E$.

It is important to recognize that the intent of an acceptance test is not to exercise the translators exhaustively for all possible occurrences of an entity, but rather to seek assurance that the subset of occurrences that the user is likely to see can be accommodated. As a result of this understanding, pathological problems (e.g., a zero-length line or a zeroradius arc) need not be considered unless they are to be used to convey specific information.

7.5. The Evaluation of the Results: The results of the acceptance tests should be evaluated in the light of preservation of information content (i.e.. "Has the information content of the test model been preserved?"). This is most easily done by examining the errors which were identified during the test and asking whether the errors diminish the information content of the model for the application on the receiving system. As an example, if the application on the receiving system is N/C programming, the preservation of text parameters in the drawing annotation (e.g., height, width, and intercharacter spacing) may not be important, while the preservation of accuracy in the geometry would be.

A useful measure of the effectiveness of a transfer is given by comparing the amount of time required to translate a test model from the sending system (both pre- and post-processing, $t 1$ ) and the time to repair the test model on the receiving system ( $t 2$ ) with the amount of time required to recreate the entire test model on the receiving system ( $t 3)$ :

$$
\left(1-\frac{t 1+t 2}{t 3}\right) * 1008
$$


8. Software Tools: The development and use of software tools is an important concern for the IGES Testing Project. The existence of a set of software tools that is useful and of reasonable cost is crucial to the success of the project.

Ideally, the tools for IGES testing should be in the public domain or readily available, supported, commercial products. To some extent this has happened. Figure 4 shows a list of IGES-related software products that are known to be available.

To date, there have been a number of attempts to completely specify and describe the requirements for testing tools. These attempts have been useful but not completely successful. This arose from two factors. The first is that the IGES testing methodology has not stabilized sufficiently to prove technical soundness and financial practicality. The next reason is cost. Some of the tools and approaches proposed involved levels of funding greatly exceeding anticipated resources.

8.1. Available Software Tools: Regardless of the structure of the final testing methodology, some tools are known to be needed and are currently available. These are shown in Figure 3. Briefly, the list includes three different Syntax analyzers, three different IGES viewers and plotting packages, an application subset checker, and an IGES transfer forecaster. In addition there are some utilities including an IGES file generator, a file compression utility, and a public domain IGES editor.

An important addition to this list is an IGES file comparator. This tool is derived from a thesis by Rainer Glatz and purports to compare two IGES files for equality. The comparator tool is not well known. The first public discussion of it was presented at the St. Louis IGES meeting. Currently there are no known U.S. installations of the product.

8.2. Validation of Software Tools: The case of the IGES comparator brings an important issue into focus. How are software tools validated for use in IGES testing. Though not formally documented, tool validation is performed through usage by the IGES/PDES Methodology Testing Committee. At a future time this validation will be performed by the SAE Verification Panel in conjunction with the IGES Testing Project and the testing agencies.

Not all tools will require validation. Certainly the IGES editor and file compression do not. Those that will require validation are those that judge aspects of the systems under test. The most obvious tool that requires validation is the syntax checker. All files produced from a vendors preprocessor will be sent through the IDA analyzer or the IGES-QC checker. These software packages must be correct. The IGES comparator will require validation.

Its job will be to compare IGES file input to IGES file output. A software tool error would seriously distort the testing results. 
8.3. Desired Tools Do Not Yet Exist: It is anticlpated that a fully operational testing program will need the following, additional software tools.

- A full screen IGES editor that is sensitive to the construction detalls of IGES files. The current NBS IGES editor is useful but not practical for routine operations.

- A test case selector that extracts IGES test cases based on vendor claims.

- A test case generator that can extract vendor claim information and bufld valid IGES test cases from component parts. The tool should operate automatically with little human intervention.

- A test reporting system capable of guiding the test team through the test plan and logging the results of the test. 
Currenty Available IGES Software Tools

\begin{tabular}{|c|c|c|c|}
\hline Program Type & Name & Source & Type \\
\hline Plotting IGES Files & $\begin{array}{l}\text { BASEVIEW } \\
\text { IGESVIEW } \\
\text { IGES VIEW }\end{array}$ & $\begin{array}{l}\text { Digital Equipment Co. } \\
\text { IGES Data Analysis Co. } \\
\text { Loye and Assoclates }\end{array}$ & $\begin{array}{l}c \\
c \\
c\end{array}$ \\
\hline IGES Syntax Checkers & $\begin{array}{l}\text { Verifier } \\
\text { IGES QC } \\
\text { IGES Check }\end{array}$ & $\begin{array}{l}\text { IGES Data Analysis Co. } \\
\text { Leeds CADETC } \\
\text { Loye and Associates }\end{array}$ & $\begin{array}{l}c \\
c \\
c\end{array}$ \\
\hline $\begin{array}{l}\text { Application Subset } \\
\text { Conformance }\end{array}$ & IGES Subset & Loye and Associates & C \\
\hline $\begin{array}{l}\text { IGES Transfer } \\
\text { Forecaster }\end{array}$ & LUDDITE & Leeds CADETC & c \\
\hline IGES File Compararor & IMDES & Rainer Glacz & c \\
\hline File Compressors & $\begin{array}{l}\text { COMPRESS } \\
\text { Dara Compress }\end{array}$ & $\begin{array}{l}\text { National Bureau of Standards } \\
\text { Signum Microsystems }\end{array}$ & $\begin{array}{l}5 \\
5\end{array}$ \\
\hline IGES Ediこor & $\begin{array}{l}\text { IGES EDITOR } \\
\text { EILIGREE }\end{array}$ & $\begin{array}{l}\text { National Bureau of Standards } \\
\text { Interactive Design Consult }\end{array}$ & $\begin{array}{l}P \\
C\end{array}$ \\
\hline IGES File Generator & LUIGI & Leeds CADETC & C \\
\hline
\end{tabular}

$C=$ Commercial Product

$\mathrm{P}=$ Public Domain Product

Eigure 3. 
Appendix A. Verification Testing of IGES Processors 
Appendix B

Test Cases for Quickstart Jr.

This appendix contains the IGES file listings for the test cases used in the Quickstart jr. testing. The test cases are for:

$\begin{array}{ll}\text { Circular Arc } & 100 \\ \text { Line } & 110 \\ \text { Angular Dimension } & 202 \\ \text { General Note } & 212 \\ \text { Subfigure Definition } & 308\end{array}$




\section{Appendix C \\ Test Results File}

The following material was collected during the verification test of the Autotroll S7000 CAD system. The methodology used was that described by the "Quickstart" and "Quickstart $j r^{\prime}$ implementation schemes. The system under test is owned by the Engineering CAD/CAM group at NBS. The verification forms and instructions are contained in Appendix $A$. Appendix B contains the test cases and their plots.

The following is a listing of the packets of information contained in this appendix.

- The packet delivered to the testing agency containing a Verification Request Form and the vendor claims.

- Information filled in by the resting agency: The Test Results File cover sheet, Test Plan Specification, Verification Test Log, Test Incident Reports, and the Pre and Postprocessor Entity Results Forms.

- Volunteer Entity Test with plots.

- System printouts from the circular arc tests

- System printouts from the line test

- System printouts from the angular dimension test

- System printouts from the general note test

- System printouts from the subfigure definition test

- Prototype of the SAE Summary Test Report 
Appendix D

Appendix D contains the exercise given to members of the IGES/PDES Testing Project. The package is not replicated in its entirety because most of the material is included in other appendices in this report. The specified material can be found as follows:

Appendix A - Verification procedures and forms

Appendix B - Test cases and plots

Appendix C - Examples of the procedures on a real system 
Appendix A

\author{
Verification Testing of IGES Processors
}

Interim Verification Methodology

\title{
A.1. Introduction,
}

The following provides a detalled view of the interim Verification Testing Methodology. Two related ideas should be kept in mind. First, Verification Testing works with one translator at a time and thus does not speak to the success of end-to-end data transfer in a users' environment. System-to-system data transfer capability is the concern of Application Validation and Acceptance Testing described in "Testing Methodology of IGES Translators and IGES Formatted Data Files". Verification Testing is concerned with a translator's completeness and correctness in terms of the IGES Specification and the implementor's claims of such. Second, while functionality, as defined in this document, is important to data transfer, the concept is difficult to define in the context of testing a single translator for compliance to the IGES Specification. That is to say, a vendor may have several valid options for mapping an IGES entity into a native entity in full compliance with the IGES specification. However, users of the system may experience data loss. For example, a circle translating to line segments may be acceptable for a technical documentation system and disastrous for a system that generates NC cutter paths. Consequently, the implementors' functionality claims will only be used to assist in the selection of appropriate test cases for postprocessor verification.

The results from a verification test should provide enough information about IGES translators so that users and vendors can make their own functionality assessment in the context of their applications and user environments. It is only at the level of specific applications and specific user environments that unambiguous functional assessments can be made. Furthermore, the presentation of the testing results in the public domain provides a sound basis for application and acceptance testing analysis. This frees users from the burden of having to design and run their own verification tests.

\section{A.2. Preprocessor Verification Procedure.}

The preprocessor verification is initiated by an implementor (called the presenter) filing a Verification Request Package with the IGES

Verification Panel. The Verification Request Package will contain a cover sheet, (Form 1), a set of entity mapping forms, (Forms 8 and 9), and any necessary system, application, and user documentation. Additionally, the presenter must designate a knowledgeable technical representative to be 


\section{Appendix A}

present at the test site for the testing period. The company technical representative is an essential resource for the testing team to draw.

The Verification Request Package cover sheet contains identifying information about the presenter and the processor to be tested. It also contains a checklist of the information required to support the verification testing. The documents required will vary from system to system but all documents submitted should be listed on the cover sheet.

The Verification Request Package contain both preprocessor and postprocessor Entity Mapping Forms (Form 8 and Form 9). These forms contain an extensive listing of entities and their various attributes (Note that these forms may not be avallable in time for release of version 0.4 - Ed) that the translator purports to implement. The test cases selected will be chosen to confirm the accuracy of these forms and the translators conformance to the IGES Specification.

When completed, the entire package is sent to:

IGES Verification Panel

Society of Automotive Engineers

400 Commonwealth Dr.

Warrendale, Pa. 15096

Attn: Gary Pollak

After reviewing the Verification Request for completeness, the IGES

Verification Panel will schedule the test and select a testing authority. Negotiations between the presenter and the SAE and its agents will determine the fees and location of the test. Based on the contents of the Verification Request Packet and the IGES test case library a representative of the Verification Panel will create a test plan of the tests to be run and the test cases to be used. These are listed on the Verification Test Plan Specification, (Form 2). The testing authority then receives the test plan and performs the following functions:

Testing agency staff, a technical representative from the presenter, and any observers (IGES Verification Panel members, other vendor representatives) meet, review the test plan detailed on Form 2, and coordinate their activities. This group constitutes the Test Team.

A test $\log$ (Forms 3 and $3 a$ continuation sheet) is initiated by the senior technical person from the testing agency. The meeting of the test team in the preceding step is noted in the test $\log$. This $\log$ is to be kept in the format presented in IEEE Std 829-1983. The contents of the $\log$ are discussed later.

A current, certified test case suite, on a suitable storage medium (ascii, 9 track, magnetic tape or $51 / 4$ inch floppy diskette) for the system under test, is obtained from the National Bureau of Standards. 
Appendix A

The test team inspects the hardware/software environment, including the translator under test and documentation, and attests to the fact that it complies with that described in Form 1 from the application package.. This is noted in the Test Log.

A folder is prepared to hold the results of the tests to be performed. This folder is commonly referred to as the 'results file'. The first item in the results file is the cover sheet, Form 7.

The Volunteer Entity Test, described later in this appendix, as prescribed in the Test Plan is followed to construct a simple native model in the CAD system. The IGES flle and a listing of the model is next generated by running the Preprocessor according to the system's operating procedures. A Test Log entry is made to note the start and finish of the test. The IGES listing is placed in the results file and Identified by a reference in the Test Log. While the naming convention for these and other entries are not defined, they must be a unique English name/number combination written on the paper copy and in the test log. Use a Test Incident Report (FORM 4) to document any operator input required for this task and any error messages or anomalies encountered. Extensive operator input or error messages should be documented, if possible, by a printout placed into the Ies Results file and referenced by a Test Log entry or Test Incident Report.

Record in the Test Log the values for Global Section System ID (Field 5), Preprocessor Version (Field 6), and IGES Version (Field 23). Compare these values against those obtained from the IGES files supplied by the presenter if any were sent with the vendor request package. The Volunteer entity test is one of these - Ed.) Note any discrepancies between volunteer test results and the vendor-supplied Eiles on a Test Incident Report. In cases of extreme disagreement, the test agency and the presenter will make a decision whether or not to proceed with the test.

Record in the Test Log the resulting values for Global Section Date and Time of Creation (Field 18) and Maximum Coordinate Value (Field 20). Compare against expected values and $\log$ any discrepancies.

Rerun the Volunteer Entity Test for each Preprocessor mode of operation that will be used during the test. Document the volunteer entities that are generated for each Preprocessor mode.

In a similar manner, run each test specified in the Test Plan. Follow the construction script given in each test case to generate a native part model in the CAD system. If any step in the script cannot be accomplished, note the limitation and proceed. Collect screen plots of each native part model and put them in the results file. Compare the screen plot against the test case plot and note discrepancies in a Test Incident Report. Include all items in the Test Results file and reference each item by a Test Log or Test Incident Report entry. 
Use the verification or inquiry capability of the CAD system to identify the entity content of the native model. Record the native model entity content on the Preprocessor Entity Results Form (Form 5)

Convert the native part model to an IGES file using the system's IGES Preprocessor. Carefully collect and label all printouts of operator input and IGES file output. Collect a computer readable copy of each resulting IGES file for later analysis. Include all items in the Test Results file and reference each item by a Test Log or Test Incident Report entry.

In later analysis work, run all IGES files produced through the IDA and the IGES-QC Analyzers. Include printouts in the Test Results file. Record the count of all errors and warnings. Subtract the volunteer entities from the list of entities in the file to get the Test Set of entities generated by the preprocessor for each test case. Document the Test Set on the Preprocessor Entity Results form. Analyze the Test Set as follows:

- Compare entities obtained against those expected for the test case.

- Analyze Global Section against paragraph 2.2.4.2 of the IGES Version 3.0 specification for the following:

\author{
Product ID from Sender (Field 3) \\ System ID (Field 5) \\ Preprocessor Version (Field 6)
}

- Analyze Entity DE Section against mandatory fields and permissible defaults given by Table 2-3 of the specification and for specific content given in the individual test case.

\title{
A.3. Postprocessor Verification procedure,
}

The postprocessor verification is initiated in the same manner as a preprocessor test. An implementor (called the presenter) fills in and sends a Verification Request Package to the IGES Verification Parel. The Verification Request Package will contain a cover sheet, (Form 1), a set of entity mapping forms, (Forms 8 and 9 ), and any necessary system, application, and user documentation. Additionally, the presenter must designate a knowledgeable technical representative to go to the test site for the resting period. The company technical representative is an essential and necessary resource for the testing team to draw upon.

The Verification Request Package cover sheet contains identifying information about the presenter and the processor to be tested. It also 
contains a checklist for the information required to support the verification testing. The documents required will vary from syster to system but all documents submitted should be listed on the cover sheet.

The Verification Request Package contain both preprocessor and postprocessor Entity Mapping Forms (Form 8 and Form 9). These forms contain an extensive listing of entities and their various attributes (Note that these forms may not be available in time for release of version 0.4 - Ed) that the translator purports to implement. The test cases selected will be chosen to confirm the accuracy of these forms and. the translators conformance to the IGES Specification.

When completed, the entire package is sent to:

IGES Verification Panel

Society of Automotive Engineers

400 Commonwealth Dr.

Warrendale, Pa. 15096

Aten: Gary Pollak

After reviewing the Verification Request for completeness, the IGES Verification Panel will schedule the test and select a testing authority. Negotiations between the presenter and the SAE and its agents will determine the fees and location of the test. Based on the contents of the Verification Request Packet and the IGES test case library a representative of the Verification Panel will create a test plan of the tests to run and the test cases to use. These are listed on the Verification Test Plan Specification, (Form 2). The testing authority then receives the test plan and performs the following functions:

Testing agency staff, a technical representative from the presenter, and any observers (IGES Verification Panel members, other vendor representatives) meet, review the test plan detailed on Form 2, and coordinate their activities. This group constitutes the Test Team.

A test $\log$ (Forms 3 and 3 a continuation sheet) is initiated by the senior technical person from the testing agency. The meeting of the test team in the preceding step is noted in the test $\log$. This $\log$ is to be kept in the format presented in IEEE std 829-1983. The contents of the $\log$ are discussed later.

A current, certified test case sufte, on a suitable storage medium for the system under test, is obtained from the National Bureau of Standards.

The test team inspects the hardware/software environment, including the translator under test and documentation, and attests to the fact that it complies with that described in Form 1 from the application 
package. This is noted in the Test Log.

A folder is prepared to hold the results of the tests to be performed. This folder is commonly referred to as the 'results file'. The first item in the results file is the cover sheet, Form 7.

The test case suite (or as much of it as on-line storage permits) is loaded onto the system and converted to the system's internal coding in accordance with the vendor documentation provided. A hard copy of the command sequence and responses to accomplish this will be saved in the test results file.

The first test case is now processed by the translator in accordance with the documentation provided with the test case. If additional information is required from the vendor rechnical representative to accomplish the translation, the exact additions will be recorded in a Test Incident Report and so noted in the log. Any error messages or other anomalies will also be logged.

The resulting part file will then be "activated" and displayed. Again, any error messages, etc., will result in an incident report and be logged.

At this point, a visual comparison between the screen display and the plot of the test case furnished with the test case documentation $i$ ill be made and differences reported. A plot of the screen display ill be made for inclusion in the rest results file.

Using all the verification capability available in the receiving system, the part Eile is checked to determine the entity mapping and functionalizy claims from form 9 and the results recorded on the Postprocessor Entity Mapping Eorm, Eorm 4. Functionality will be verified in terms of geometry, structure, and annotation per $\mathrm{J}$. Fleming position paper of $7 / 87$ (Again, this is the functionality issue - Ed). Details of what is to be verified will be found in the start section of the test case under consideration. All verifications will be supported with hard copy in the test results file.

The remainder of the testing will consist of repeating the above steps for each test case in the suite. As before, all steps, problems, and error messages are recorded in the test $\log$ and $a 11$ problems and error messages result in the generation of an incident report.

At the completion of testing, the test results file will be forwarded to the test team leader or his designee for analysis, interpretation, and the preparation of the sumary test report.

\section{A.4. Documenting the test}


Appendix A

\section{A.4.1. Test Resules File.}

There will be a file maintained for each test conducted under the SAE Verification Testing Program and it will consist of 1) a cover sheet (Form 7), 2) a copy of the application package cover sheet (Form 1), 3) the test $\log$ (Forms 3 and $3 a$ ), 4) all incident reports (Form 4), in chronological order, each with appropriate hardcopy supporting documentation, and 5) all entity mapping forms (Forms 5 and 6), again, each with appropriate hardcopy supporting documentation.

The results file cover sheet (Form 7) will contain the unique test identification number and the names (signatures) and affiliations of the test ream and observers. The signatures are under a statement to the effect that those signing attest to the fact that the file contains all of and only those materials associated with the particular test identification number.

The application package cover sheet is Form 1. The purpose of having it in the results file is to define the hardware/software environment in which the tests began. Any changes to that environment would be documented in the test $\log$ and incident reports.

The test log will follow IEEE std 829-1983. Form 3 with Form 3a as a continuation sheet, will be used for this purpose. The log will contain the test identifier and a prose description of the test at the top of the first page followed by three columns, 1) date/time, 2) event, and 3) incident report reference. Subsequent pages will have the test identifier and the three columns. The event entries will record the who, what, and whys of all testing actions. Where any event results in an incident report, the incident report number will be recorded in column three. For an example of event entries, see Appendix A of IEEE Std 829-1983.

The Test Incident Report (Form 4) will also follow IEEE Std 829-1983. The report will contain 1) the incident identification number, 2) identification of the translator (with version number) under test, 3 ) identification of the test procedure guiding the test, 4 ) specification of the test case resulting in the incident, 5) reference to the test log, 6) a detailed description of the test incident, and 7) the incident's impact on the tests. The description should include the inputs, expected results, actual results, anomalies, date and time, procedure step number, environment, attempts to repeat, testers and observers. Again, an example of an appropriare incident report may be found in Appendix $A$ of IEEE Std 829-1983. The incident reports should have sufficient detail to be an aid to implementors in locating and fixing translator problems.

The Entity Mapping Results Forms record the results of processing the test cases. Forms 5 (preprocessor) and 6 (postprocessor) have been prepared for this purpose. The forms will record the test identifier, the translator identification, the IGES entity being tested, the test case identifier, the resulting native entity or entities, a statement of the extent to which the result matches vendor claims, and a functionalizy 
statement in terms of geometry, structure, and annotation. In addition, there will be space for remarks, explanations, or comments from members of the test team. Test incident reports generated as a result of the particular test case should also be recorded.

\section{A.4.2. The Summary Test Report.}

The work of the testing agency on a translator verification will be covered by a report which accurately, clearly, and unambiguously presents the test results and all other relevant information. The report will have the test results file as an appendix but will stand alone as a document. The testing agency is responsible for the generation of this document.

The summary report will contain at least the following information:

1) name and address of the testing agency;

2) unique identification of the report (such as a serial number), and of each page of the report;

3) name and address of the presenter/implementor;

4) description and identification of the translator tested;

5) date of receipt of the translator test request and the date(s) of performance of the tests;

6) description and identification of the hardware/software test environment;

7) a statement to the effect that the test results relate oniy to the single translator tested when used in the specified environment; 8) identification of the test methodology and procedure followed;

9) a results section cantaining:
a) the test cases used;
b) the test cases for which expected results were obtained;
c) the test cases for which expected results were not obtained;
d) test cases for which results were inconclusive;
e) the number of "information only" tests run;
f) the number of planned tests not run;
g) the total number of tests run; 
Append1x A

h) any additions to, deviations or exclusions from the test case specifications that took place;

1) disclosure of any non-standard test method or procedure used;

j) a test discrepancy sumary.

10) any disclaimers;

11) a signature and title of person(s) accepting technical responsibility for the test report and date of issue;

12) a statement delineating reproduction rights to the report.

Corrections or additions to a test report after issue by the testing agency, whether because of objections on the part of the implementor, IGES Verification Panel actions, or any other reason, shall be made only by a further document, suitably marked, e.g., "Supplement to Test Report Serial Number ...." and shall meet the relevant requirements of the preceding paragraphs.

Upon completion, the test agency will forward a copy of the test summary report and the appended test results file, via the SAE, to the IGES Verification Panel for review and concurrence. Upon completion of the panel's review and the addition of any supplements that result from that review, the panel will prefix its imprimatur to the document and forward a copy to the presenter for review and comment. This action will begin the 30 day review period in which the vendor can take reply to the test results. After the review period and the addition of any supplements required thereby, the test report will be ready for release. The final report will contain:

1) The imprimatur of the IGES Verification Panel;

2) The Summary Test Report with Supplements to date;

3) The appended Test Results File.

\section{A.5. Volunteer Entity Test.}

\section{A.5.1. Description.}

The objective of the volunteer entity test is to discover extra entities present in the IGES file as generated by an IGES preprocessor. While Volunteer Enticy is a term that may have a very broad meaning, for this test plan we will define Volunteer Entity as; IGES entity information that has been added/created by the translator and placed in the directory 
entry (D) and parameter data (P) section of the IGES file that is not resident on the native data file.

The test begins with a simple set of construction details that are to be executed on the CAD system to be tested. The model is then preprocessed to create an IGES formatted file. A listing of this file will then be analyzed.

Any additional entities contained in the listing that have not been specified by the construction detail are volunteer entities.

\section{A.5.2. Running the Volunteer Entity Test.}

The rest is executed by performing the following actions:

- Create a line between the following coordinates $(1,1,1)$ and ( 3 , $4,5)$. If points are used to construct the line, delete the points from the native data file before processing the IGES file.

- Set line font as solid.

- If system is $2-D$ ignore $Z$ values.

- Generate IGES formatted file.

- Generate a paper copy of the file

- Specify the CAD System and IGES Software products, their revision level/release, and the hardware which generated the IGES file. on the file listing or on a separate cover sheet.

\section{A.6. Implementors' Privileges and Obligations,}

It is important to the credibility of the Verffication Program and the IGES Organization that commercial implementors represent their support of IGES appropriately. After completing the verification process, an implementor has the privilege of so claiming in documentation and advertising. The following wording is suggested for use by implementors to designate their support of the IGES work:

"(Implementor's name) supports the work being done by the IGES Organization. Our IGES conforming translators (insert version identifications) have been verified by (insert name of independent testing agency) in accordance with the procedures established by the IGES Organization Testing Methodology Project. Detailed test results are available on request from the ( name of sponsoring government 


\section{Appendix A}

agency )."

Implementors have an obligation to resubmit their translators for verification upon changes to the software which might materially affect the product's verification status.

If in a subsequent use of a verified translator, a user has reason to believe that the translator is not working as verified, the user should notify the Chairperson of the IGES Verification Panel. Such notification should include sufficient information to recreate the fault. The panel shall forward the notification to the presenter for response, and to the test authority for review. If the presenter does not adequately resolve the problem, the verification for the translator will be revoked. 


\section{IGES Verification Request}

Company Name:

Contact:

Address:

Phone:

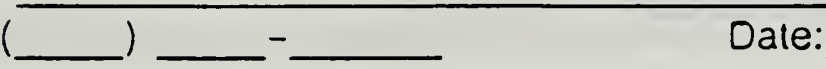

Request for Verification of:

Preprocessor

IGES Specification Version:

Postprocessor

\section{Configuration Information}

CAD Software:

Version/Release ID:

Release Date:

IGES Processor Name:

Version/Release ID:

Release Date:

Computer Mfg:

Model:

CPU:

Memory Size:

Operating System:

Version:

\section{Supporting Information}

- Postprocessor Entity Maps

- Preprocessor Entity Maps

- Processor Documentation

- Tape Access Documentation

System Limit Form

- General Entity Test

- Volunteer Entity Test

Other (itemize)

\begin{tabular}{|ll|}
\hline & \multicolumn{1}{c|}{ For SAE Use Unly } \\
\hline $\begin{array}{l}\text { Vendor Request Number: } \\
\text { Assigned to: }\end{array}$ & \\
\end{tabular}




\section{Verification Test Plan Specification}

Vendor Request Number:

Vendor Name:

Test Log Identification Number:

Test Cases 


\section{Verification Test Log}

Test Log Identification Number:

Test Description:

Date/Time

$\mathrm{mm} / \mathrm{dd} / \mathrm{yy}-\mathrm{hh}: \mathrm{mm}$

Activities and Event Entries
Incident Report

Reference 


\section{Verification Test Log Continuation Sheet}

Test Log Identification Number:

Date/Time

$\mathrm{mm} / \mathrm{dd} / \mathrm{yy}-\mathrm{hn}: \mathrm{mm}$
Ac:ivities and Event Entries
Incident Report

Reference 
Test Incident Report

Incident Identification Number:

Test Log Identification Number:

Description of Incident:

Impact of Incident: 


\section{Pre-processor Entity Results Form}

Test Log Identification Number:

Native entity being Iranslated:

Test Case Name:

Entity or entities in resulting IGES file:

Results agree with vendor entity map? Yes __ No _

Description of functionality retained:

Incident Reports generated:
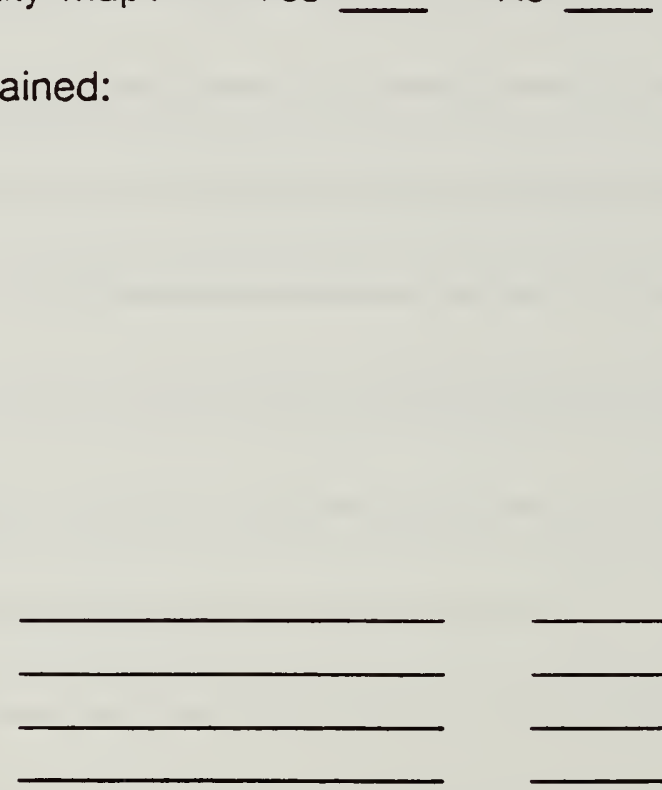

Description of functionality retained:

Incident Reports generated:

Remarks (with originator initials) 


\section{Post-Processor Entity Results Form}

Test Log Identification Number:

IGES entity being translated:

Test Case Name:

Entity or entities in resulting data base:

Results agree with vendor entity map? Yes

No

Description of functionality retained:

Incident Reports generated:
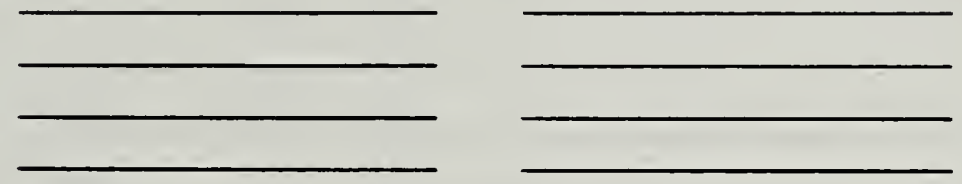

Remarks (with originator initials) 


\section{Test Results File}

Test Identification Number:

Translator Identification:

The Undersigned certify that the materials and records contained in this file are all those and only those associated with the above identified translator test.

Team Leader

Vendor Reresentative

Observer
Affliliation

Affliliation

Affliliation 


\section{IGES Processor Mapping Form Global Section Characteristics}

"ondor Request Number:

Date: stem Name/Nersion:

\begin{tabular}{|c|c|c|c|c|c|c|}
\hline \multicolumn{2}{|l|}{ Field } & \multicolumn{2}{|r|}{ Attribute } & \multicolumn{2}{|c|}{ Supported } & \multirow{2}{*}{$\begin{array}{c}\text { Comments } \\
\text { Mark last column it continuation } \\
\text { Sheet is used }\end{array}$} \\
\hline Name & $\#$ & $\not H$ & Name & Pre & Post & \\
\hline Parameter Delimiter & 1 & & & & & \\
\hline Record Delimiter & 2 & & & & & \\
\hline Product iD & 3 & & & & & \\
\hline GES File Name & 4 & & & & & \\
\hline Vendor System 10 & 5 & & & & & \\
\hline Preprocessor Version & 6 & & & & - & \\
\hline Bits per Integer & 7 & & $\therefore$ & & & \\
\hline Single Precision Mag. & 8 & & & & & \\
\hline Single Precision Signf. & 9 & & & & & \\
\hline Double Precision Mag. & 10 & & & & & \\
\hline Double Precision Signf & 11 & & & & & \\
\hline roduct ID (receiver) & 12 & & & & & \\
\hline Model Soace Scale & 13 & & & & & \\
\hline \multirow[t]{11}{*}{ Units Fiag } & 14 & 1 & $\mathrm{NCH}$ & & & \\
\hline & & 2 & MM & & & \\
\hline & & 3 & & & & $\therefore$ \\
\hline & & 4 & FEET & & & \\
\hline & & 5 & MILES & & & \\
\hline & & 6 & METERS & & & \\
\hline & & 7 & KILOMETERS & & & \\
\hline & & 8 & MILS & & & \\
\hline & & 9 & MICRONS & & & \\
\hline & & 10 & CENTIMETERS & & & \\
\hline & & 11 & MICROINCH & & & \\
\hline \multirow[t]{4}{*}{ Units } & 15 & & $2 \mathrm{HIN}$ & & & $=$ \\
\hline & & & $2 \mathrm{HMM}$ & & & \\
\hline & & & 2HFT & & & \\
\hline & & & $2 \mathrm{HMI}$ & & & \\
\hline
\end{tabular}




\section{IGES Processor Mapping Form Global Section Characteristics}

ndor Request Number:

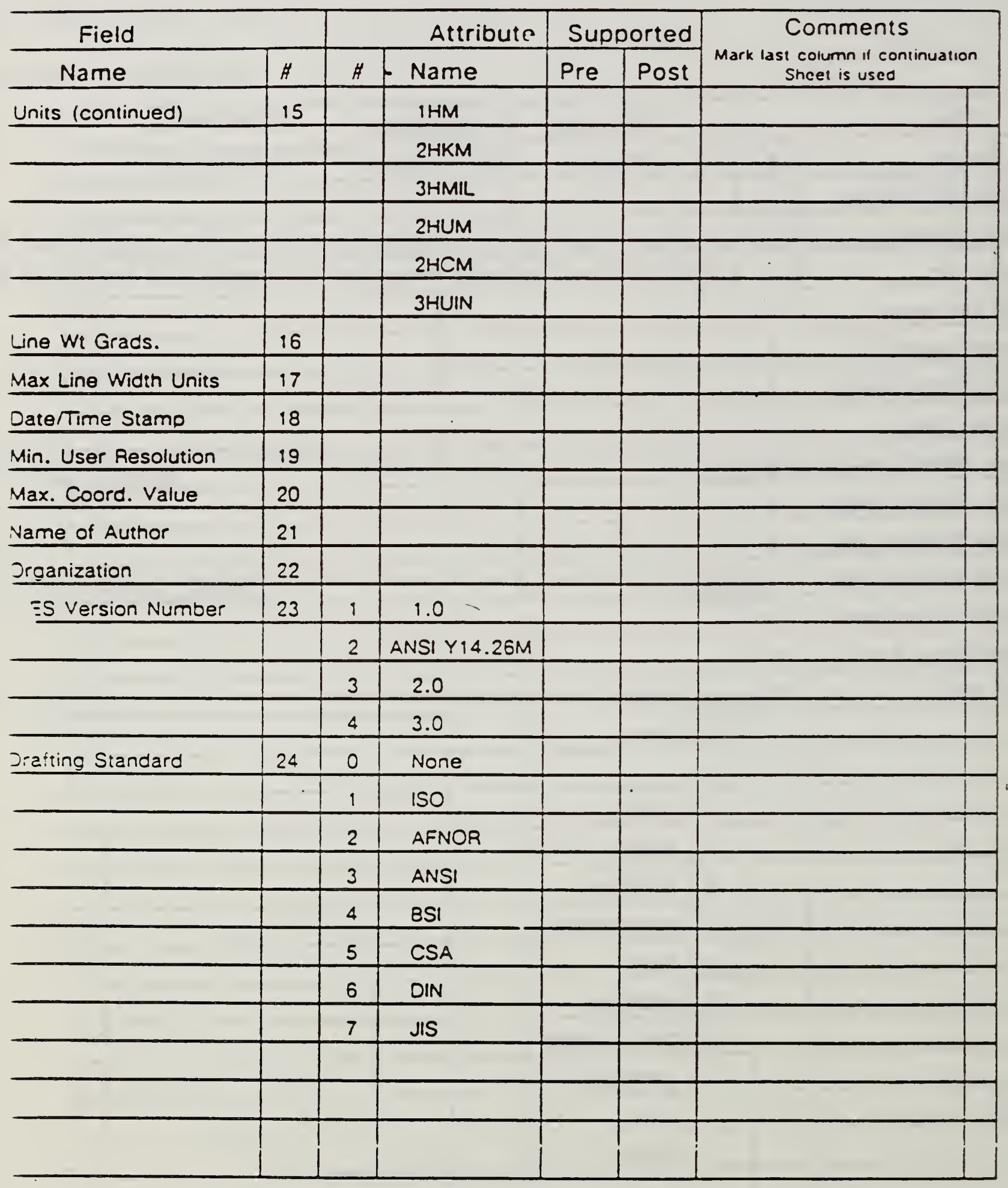




\section{IGES Processor Mapping Form Global Section Characteristics}

'endor Request Number:

Continuation Sheet

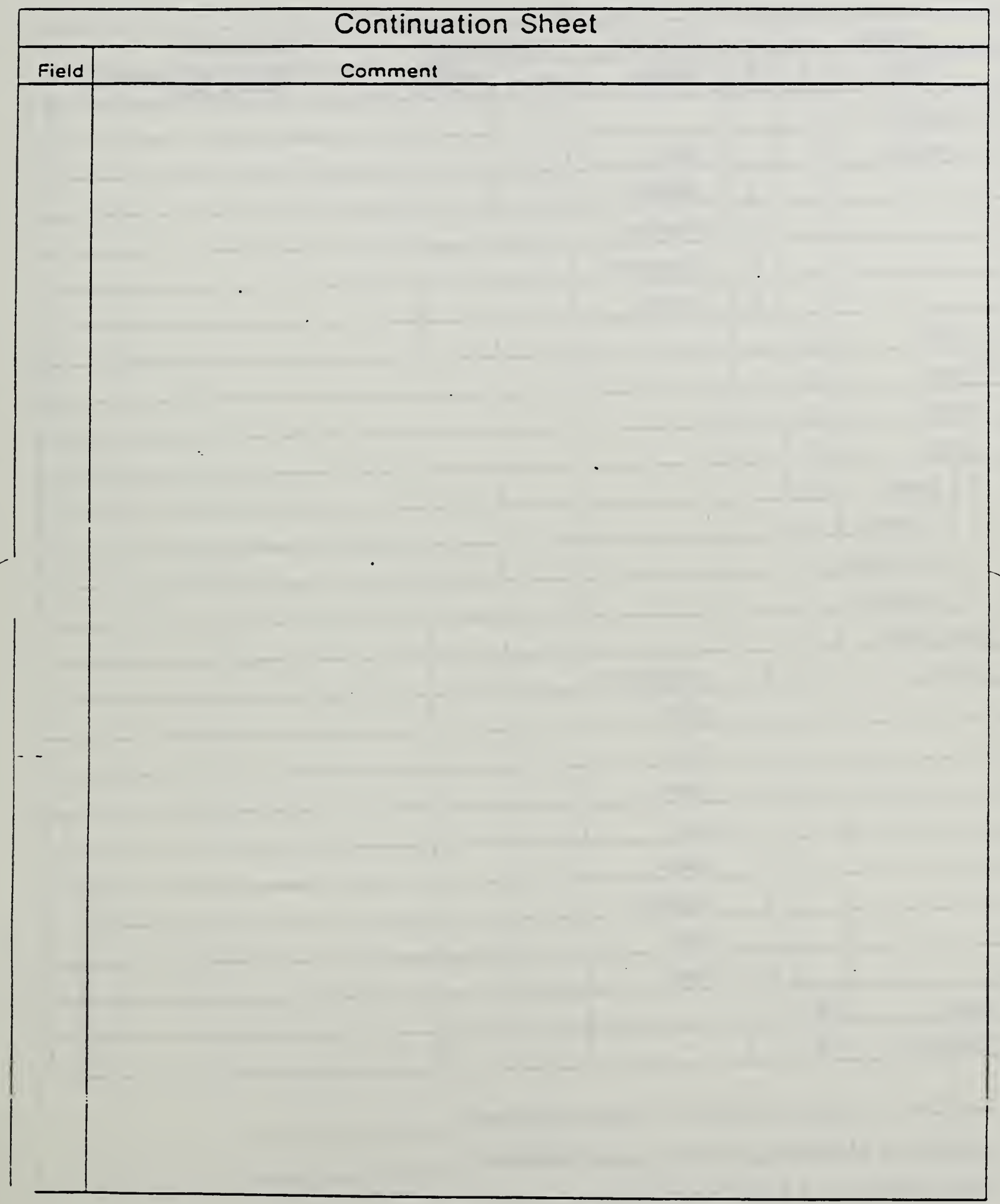

Form $8 A$ Sheet 3 of 3 


\section{Preprocessor Mapping Form Directory Entry Characteristics}

Vendor Request Number:

Date:

\begin{tabular}{|c|c|c|c|c|c|c|}
\hline \multicolumn{2}{|l|}{ Field } & \multicolumn{2}{|r|}{ Attribute } & \multicolumn{2}{|c|}{ Supported } & \multirow{2}{*}{$\begin{array}{c}\text { Comments } \\
\text { Mark last column it continuation } \\
\text { Sheet is used }\end{array}$} \\
\hline Name & $\#$ & 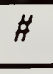 & Name & Pre & Post & \\
\hline Structure & 3 & & & & & \\
\hline \multirow[t]{5}{*}{ Line Font } & 4 & 1 & Solid & & & \\
\hline & & 2 & Dashed & & & \\
\hline & & 3 & Phantom & & & \\
\hline & & 4 & Centerline & & & \\
\hline & & 5 & Dotted & & & \\
\hline Level & 5 & & & & & \\
\hline View & 6 & & & & & \\
\hline Matrix & 7 & & & & & \\
\hline Label & 8 & & & & & \\
\hline S Blank & $9 a$ & & & & & \\
\hline a Subord. & $9 b$ & & & & & \\
\hline $\begin{array}{l}\text { i Use Flag } \\
\text { u U }\end{array}$ & $9 c$ & & & & & \\
\hline s/ hierarchy & 90 & & & & & \\
\hline Line Weight & 12 & & & & & \\
\hline \multirow[t]{9}{*}{ Color } & 13 & 0 & unassigned & & & \\
\hline & & 1 & Black & & & \\
\hline & & 2 & Red & & & \\
\hline & & 3 & Green & & & \\
\hline & & 4 & Blue & & & \\
\hline & & 5 & Yellow & & & \\
\hline & & 6 & Magenta & & & \\
\hline & & 7 & Cyan & & & \\
\hline & & 8 & White & & & \\
\hline Label & 18 & & & & & \\
\hline Subscript & 19 & & & & & \\
\hline
\end{tabular}

ivuniver of iviuliipie Elitiiies Fer Levei Permitied:

Number of Multiple Colors Per Level Permitted:

Total Number of Levels Permitted: 

Directory Entry Characteristics

Vendor Request Number:

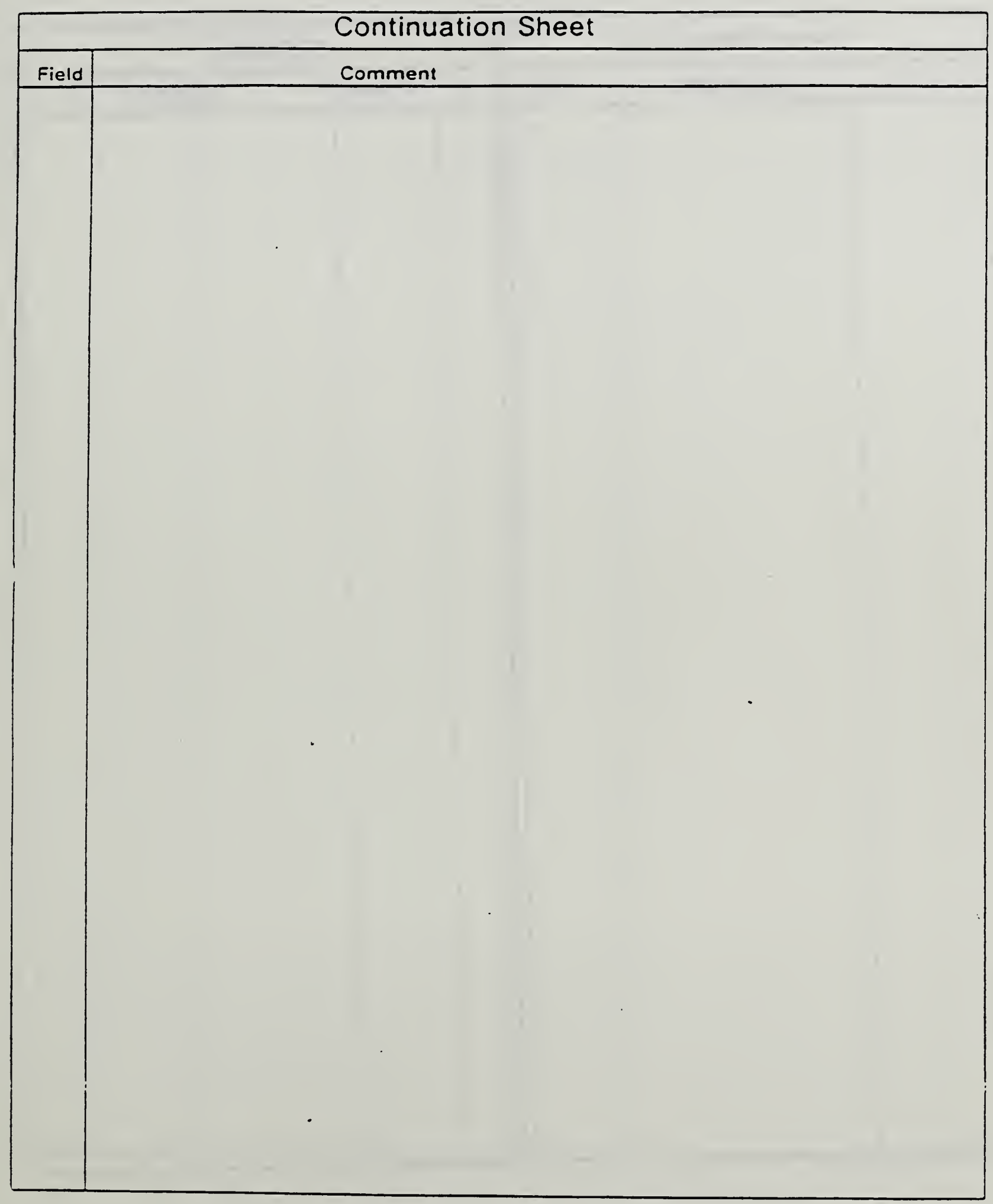




\section{Preprocessor Entity Mapping Form}

Vendor Request Number:

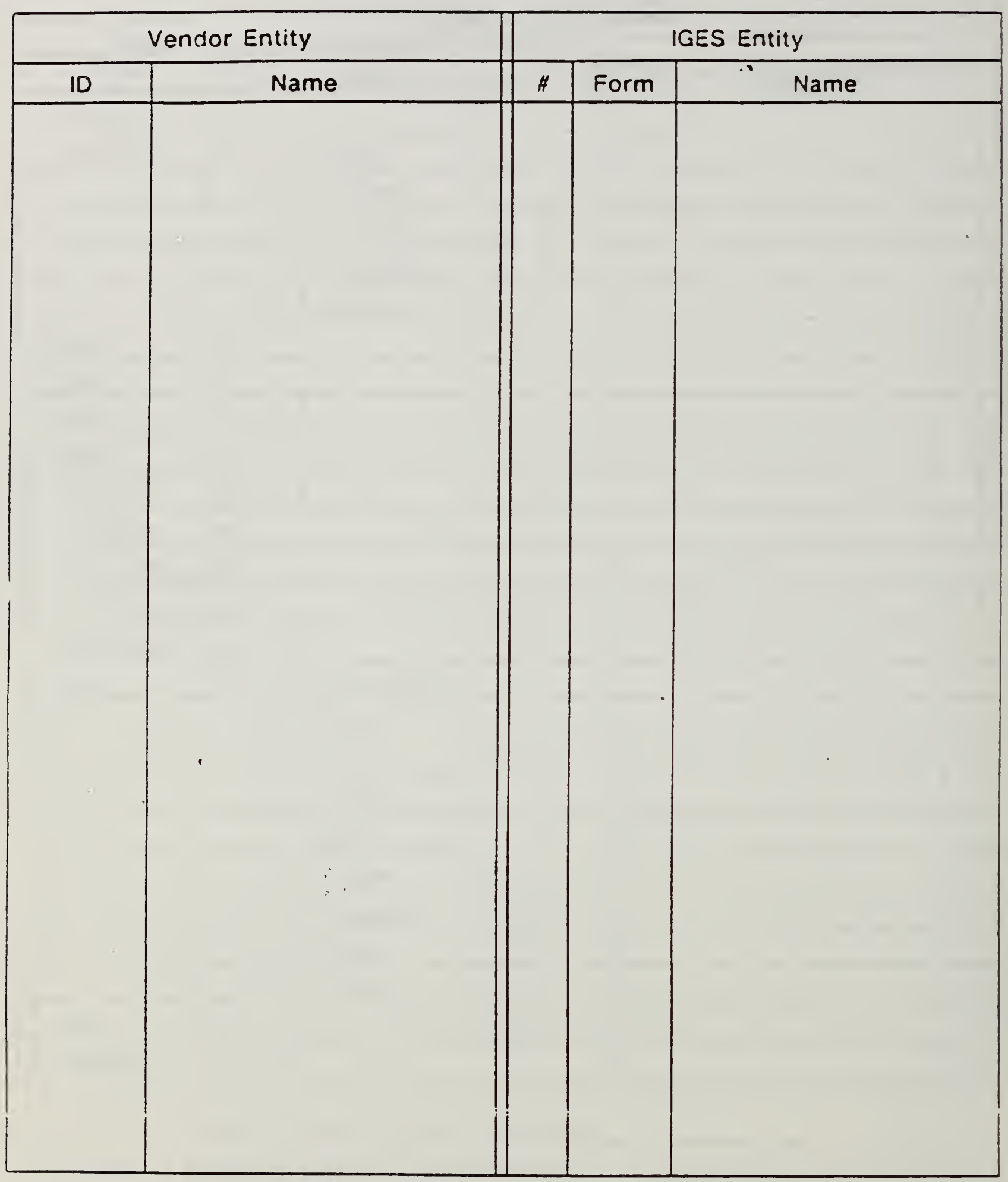


Postprocessor Entity Mapping Form

Vendor Request Number:

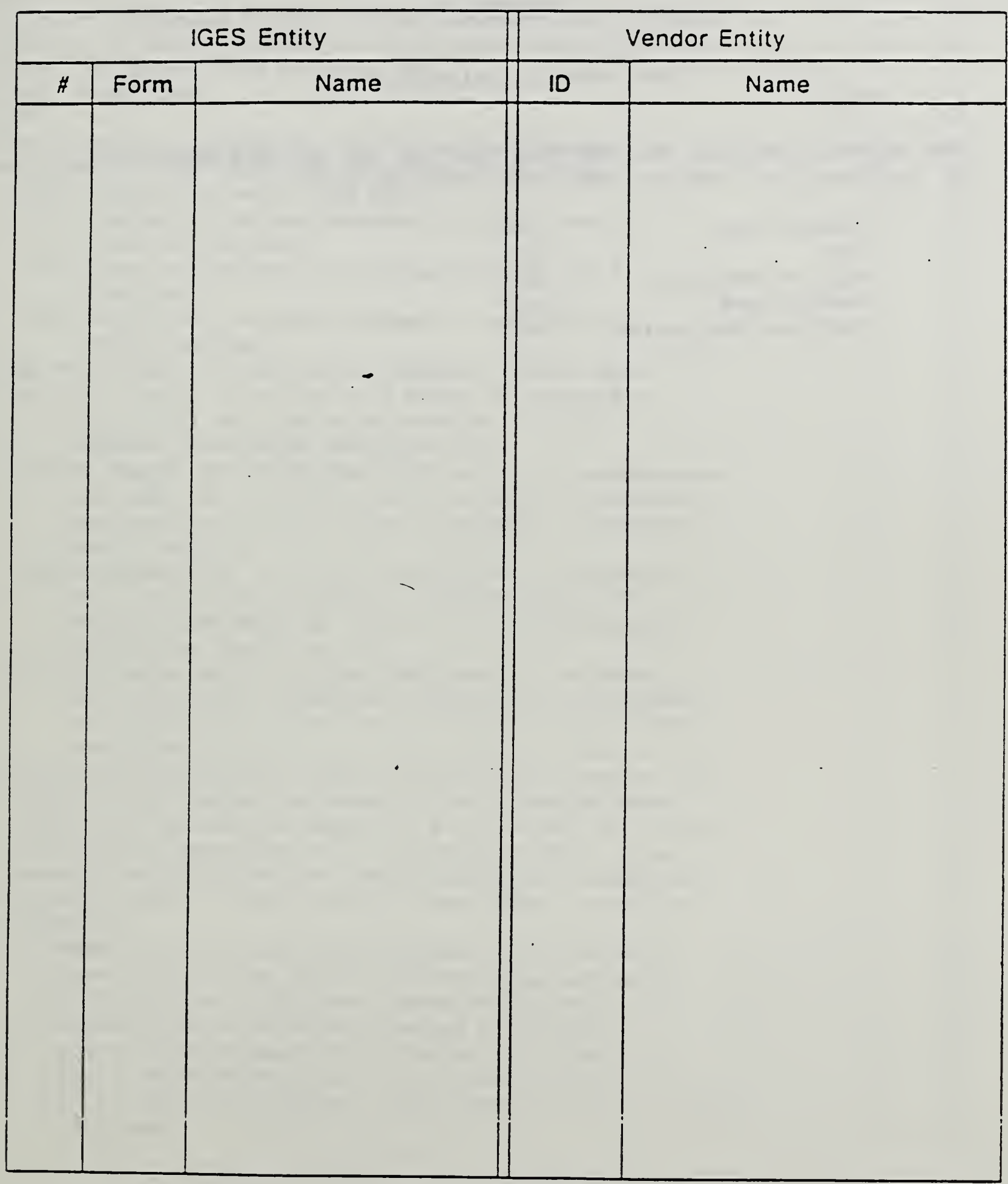




\section{Appendix B.}

Test Cases for Quickstart Jr.

This appendix contains the IGES file listings for the test cases used in the quickstart jr. testing. The test cases are for:

$\begin{array}{ll}\text { Circular Arc } & 100 \\ \text { Line } & 110 \\ \text { Angular Dimension } & 202 \\ \text { General Note } & 212 \\ \text { Subfigure Definition } & 308\end{array}$


F E1000000.A01

A

$V$ IGES 3.0

I Entity Test designed to show correct geometry only without attributes such as level, font, and color. The entity is IGES 100, Form 0--the circular arc.

E Entity Form Type $100 \quad 0$

P Visually verify, comparing with the accompanying plot, that four circular arcs were generated as follows:

A full circle in solid line font

A 270 degree arc through quadrants II, III, and IV in solid line font

A 90 degree arc through in quadrant III in solid line font

A 180 degree arc through quadrants II and III in solid line font

Using the system's verification commands, verify that:

The full circle is in the $Z=10$ plane, is centered at $(15,15,10)$ and starts and ends at $(15,5,10$ or degrees. The radius should be 10 .

The 270 degree arc is in the $\mathrm{Z}=-10$ plane, is centered at $(15,-15,-10)$, starts at $(15,-5,-10$ or 90 degrees $)$, and ends at $(25,-15,-10$ or 0 degrees). Its radius should be 10 .

The 90 degreee arc is in the $\mathrm{Z}=-10 \mathrm{plane}$, is centered at $(-45,15,-10)$, starts at $(-55,15,-10$ or 180 degrees) and ends at $(-45,-5,-10$ or 270 degrees). Its radius should be 10 .

The 180 degree arc is in the $Z=0$ plane, is centered at $(-45,-15,0)$, starts at $(-45,-5,0$ or 90 degrees $)$, and ends at $(-45,-25,0$ or 270 degrees $)$. Its radius should be 10 .

$R$ Post processing this file should produce four circular arcs of radius 10 located as indicated in the $P$ section above. The 360 degree arc may be mapped to a circle on some systems.

C To prepare this test case for a preprocessor test, create a geometric data base on the system hosting the translator according to the following script (Level, font, and color are default):

1) Construct a circular arc of radius 10 in the $\mathrm{z}=10$ plane, centered at $(15,15,10)$, starting and ending at $(15,5,10$ or 90 degrees). Some systems may require this to be constructed as a "circle".

2) Construct a circular arc of radius 10 in the $z=-10$ plane, centered at $(15,-15,-10)$, starting at ( $15,-5,-10$ or 90 degrees), and ending at $(25,-15,-10$ or 0 degrees). 
3) Construct a circular arc of radius 10 in the $z=10 \quad S \quad 50$ plane, centered at $(-45,15,10)$, starting at $(-55,15,10 \quad S \quad 51$ or 180 degree's), and ending at $(-45,5,10$ or $270 \quad s \quad 52$ degrees).

4) Construct a circular arc of radius 10 in the $\mathrm{Z}=0$ plane, centered at $(-45,-15,0)$, starting at $(-45,-5,0$ or 90 degrees), and ending at $(-45,-25,0$ or 270 degrees).

5) Make a plot of the resulting graphics model and compare it with the plot accompanying the test case

$N$ WARNING: This file has been accepted as a candidate test file by the Test Case Development Committee but it has not been approved as a member of the Test Case Library.

D Not available

H 02-Oct-1987 DOR created this file

L These data were prepared in conjunction with work sponsored by an agency of the United States Government. Nelther the United States Government nor any agency thereof, nor any of their employees, makes any warranty, express or implied or assumes any legal liability or responsibility for the accuracy, completeness, or usefulness of any information, apparatus, product, or process disclosed, or represents that its use would not infringe privately owned rights. Reference herein to any specific commercial product, process, or service by trade name, trademark, manufacturer, or otherwise, does not necessarily constitute or imply its endorsement, recommendation, or favoring by the United States Government or any agency thereof.

, 8HE1000000, , 12HHANDMADE $1.0,3 \mathrm{H} 1.0,32,38,6,38,15,8 \mathrm{HE} 1000000,1.0,1$,

$4 \mathrm{HINCH}, 1,0.001,13 \mathrm{H} 021987.074640,0.0001,100.0000, \ldots, 4,0$;

$\begin{array}{lllll}100 & 1 & & 1 & 0 \\ 100 & 0 & 0 & 1 & 0 \\ 100 & 2 & & 1 & 0 \\ 100 & 0 & 0 & 1 & 0 \\ 100 & 3 & & 1 & 0 \\ 100 & 0 & 0 & 1 & 0 \\ 100 & 4 & & 1 & 0 \\ 100 & 0 & 0 & 1 & 0\end{array}$

$0 \quad 0000000000$

$100,10.0000,15.0000,15.0000,15.0000,5.0000,15.0000,5.0000$;

$100,-10.0000,15.0000,-15.0000,15.0000,-5.0000,25.0000,-15.0000$;

$100,10.0000,-45.0000,15.0000,-55.0000,15.0000,-45.0000,5.0000$; OO0000000D

CIRCARC 3D

OD CIRCARC $\quad 4 D$ $100,0.0000,-45.0000,-15.0000,-45.0000,-5.0000,-45.0000,-25.0000$; $78 \mathrm{G}$ 2D $8 \mathrm{P}$ 
I The intent is to check the LOCATION, ORIENTATION, LENGTH and END POINTS to be within the limits specified in field 19 of the Global Section. The model cube is $X=3.75, Y=4.875, Z=0.0$.

E ENTITY FOEY 1100

$P$ Verify the following:

* The correct TEST FILE has been loaded,

* The correct IGES VERSION is being used,

* That a line exists from $(1.5,1.0,0.0)$ to $(3.75,1.0,0.0)$,

* That a lirie exists from $(1.5,1.0,0.0)$ to $(1.5,4.875,0.0)$. COUNTS

$R$ The results should be a line 2.25 long and parallel to the $X$ axis at $S$ an offset distance of $Y=1.0$. A second line should be 3.875 long and $S$ parallel to the $Y$ axis at an offset distance of $X=1.5$.

C Construct a LINE from $(1.5,1.0,0.0)$ to $(3.75,1.0,0.0)$ and a LINE from $(1.5,1.0,0.0)$ to $(1.5,4.875,0.0)$.

D Not available

H 28-Sept-1987 JLC wrote this test case.

N WARNING: This file has been accepted as a candidate test file $S \quad 22$ by the TEST CASE DEVELOPMENT COMMITTEE but it has not been $\quad$ S 23 approved as a member of the TEST CASE LIBRARY.

L This data was prepared in conjunction with work sponsored by an agency of the United States Government. Neither the United States Government nor any agency thereof, nor any of their employees, makes any warranty, express or implied or assumes any legal liability or responsibility for the accuracy, completeness, or usefulness of any information, apparatus, product, or process disclosed, or represents that its use would not infringe privately owned rights. Reference herein to any specific commercial product, process, or service by trade name, trademark, manufacturer, or otherwise, does not necessarily constitute or imply its endorsement, recommendation, or favoring by the United States Government or any agency thereof.

1H, ,1H; ,9HLINE TEST,12HE1100000.A01,12HHANDMADE $1.0,3 \mathrm{H} 1.0,32,38,6$, $38,15,1.0,1,4 \mathrm{HINCH}, 1,0.030,13 \mathrm{H} 870928.161357,1.0 \mathrm{E}-04,5.5 \mathrm{E}+02$, $8 \mathrm{HJ}$ CRUSEY, 3HNBS, 4,0 ;

$\begin{array}{lllllll}110 & 1 & & 1 & 1 & 0 & 0 \\ 110 & 0 & 0 & 1 & 0 & & \\ 110 & 2 & & 1 & 1 & 0 & 0 \\ 110 & 0 & 0 & 1 & 0 & & \end{array}$

$110,1.5,1.0,0.0,3.75,1.0,0.0,0,0$

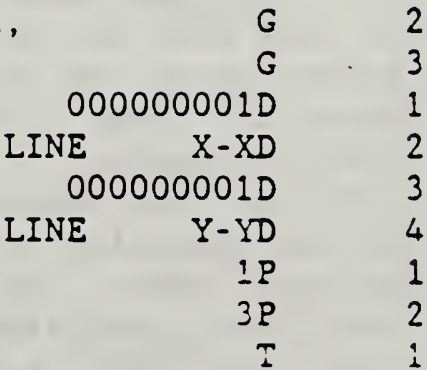

$110,1.5,1.0,0.0,1.5,4.875,0.0,0,0$;

S
$3 n$

4? 
F E2020000.A01

A

$\checkmark$ IGES 3.0

I TEST CASE FOR ANGULAR DIMENSION, IGES ENTITY 202 WITH NO FRILLS

E ENT FORM SUBTYPE

$\begin{array}{ccc}202 & 0 & 0 \\ 212 & 0 & 0 \\ 214 & 2 & 0 \\ 106 & 40 & \\ 110 & 0 & \end{array}$

P Visually verify, comparing the display with the accompanying plot, that two lines were generated as follows:

a horizontal line in the $\mathrm{Z}=0$ plane and extending from $(5.68326,3.207)$ to $(10.9673,3.207)$ and a non-horizontal line from $(5.68326,3.207)$ to $(8.52258,7.6743)$.

Visually verify that three angular dimensions were generated as follows: the text string, "57.56", in default font, should be located at $(4.214377,5.800756,0),(8.749586,5.201729,0)$, and $(11.7294,6.44752,0)$; the arrow heads should all be inside the lines (or witness lines) and should be .15 long by .05 wide. For the first leaders, DE7 and DE9, the arrow heads should should be at $(9.60104,9.37112)$ and $(12.9871,3.207)$ with the tails at $(12.0971,6.70102)$ and $(12.2762,6.35002)$. For the second pair of leaders, DE19 and DE21, the arrow heads should be at $(9.77381,3.207)$ and $(7.87744,6.65927)$ with the tails at $(9.30722,5.10423)$ and $(9.10058,5.45523)$. For the third leader "pair", DE27 and DE29, the arrow heads should be at $(8.53908,3.207)$ and $(7.21513,5.6172)$ with the tails at $(5.23229,6.02699)$ and $(8.1863,4.58195)$. The horizontal witness line should leave a .093 gap to $(11.0609,3.207)$ and extend to $(13.1138,3.207)$. The other witness line extends from $(8.57278,7.75329)$ to $(9.66903,94781)$. All coordinate are inches.

$R$ The resulting data base/display should contain two lines, coincident at.their left ends, with the angle between them dimensioned in three different positions, first, above the lines, second, between the lines, and third within the angle formed by the lines but beyond their end points. The angular dimension is 57.56 degrees.

C To prepare this test case for a preprocessor test, create a geometric data base on the system hosting the translator to be tested according to the following script:

1) Create two lines with end points as designated in the $P$ section above.

2) Using the host systems dimensioning commands, place an angular dimension on the lines with the text located as indicated above. Use default attributes for the dimensions (text font, text size, etc.) The radii of the leaders are $2.85582,4.09055$, and 7.30379 .

3) Make a plot of the resulting graphics model and compare it with the plot accompanying the test case.

$N$ WARIING: This file has been accepted as a candidate test file by the Test Case Development Committee but it has not been approved as a member of the Test Case Library. 
H 03-Oct-1987 DOR created this file

L These data were prepared in conjunction with work sponsored by an agency of the United States Government. Neither the United States Government nor any agency therof, nor any of their employees, makes any warranty, express or implied, or assumes any legal liability or responsibility for the accuracy, completeness, or usefulness of any information, apparatus, product, or process disclosed, or represents that its use would not infringe privately owned rights. Reference herein to any specific commercial product, process, or service by trade name, trademark, manufacturer, or otherwise, does not imply its endorsement, recommendation, or favoring by the United States Government or any agency thereof.

, 12HE2020000.A01, 25HWO. IGES.TESTCASE.E202.A01,

45HCOMPUTERVISION CADDS4X REV 5.0 GRAPHIC SYSTEM,16HIGES VERSION 3.0 , $16,8,24,8,56,12 \mathrm{HE} 2020000$. A01, 1.0,1,4HINCH, 32767, 32.767,

$13 \mathrm{H} 8710$ 2. $75054,0.000001$, , 3HDOR, 4HNSWC , 4, ;

$\begin{array}{rrl}110 & 1 & 1 \\ 110 & 0 & 0 \\ 110 & 2 & 1 \\ 110 & 0 & 0 \\ 212 & 3 & 1 \\ 212 & 0 & 0 \\ 214 & 5 & 1 \\ 214 & 0 & 0 \\ 214 & 6 & 1 \\ 214 & 0 & 0 \\ 106 & 7 & 1 \\ 106 & 0 & 0 \\ 106 & 8 & 1 \\ 106 & 0 & 0 \\ 202 & 9 & 1 \\ 202 & 0 & 0 \\ 212 & 10 & 1 \\ 212 & 0 & 0 \\ 214 & 12 & 1 \\ 214 & 0 & 0 \\ 214 & 13 & 1 \\ 214 & 0 & 0 \\ 202 & 14 & 1 \\ 202 & 0 & 0 \\ 212 & 15 & 1 \\ 212 & 0 & 0 \\ 214 & 17 & 1 \\ 214 & 0 & 0 \\ 214 & 18 & 1 \\ 214 & 0 & 0 \\ 202 & 19 & 1 \\ 202 & 0 & 0 \\ 168326 & 207 & 8 \\ 14\end{array}$

$\begin{array}{ll}1 & 0 \\ 1 & 0 \\ 1 & 0 \\ 1 & 0 \\ 0 & 0 \\ 2 & 0 \\ 1 & 0 \\ 1 & 2 \\ 1 & 0 \\ 1 & 2 \\ 1 & 0 \\ 1 & 40 \\ 1 & 0 \\ 1 & 40 \\ 1 & 0 \\ 1 & 0 \\ 0 & 0 \\ 2 & 0 \\ 1 & 0 \\ 1 & 2 \\ 1 & 0 \\ 1 & 2 \\ 1 & 0 \\ 1 & 0 \\ 0 & 0 \\ 2 & 0 \\ 1 & 0 \\ 1 & 2 \\ 1 & 0 \\ 1 & 2 \\ 1 & 0 \\ 1 & 0 \\ 1 & 0 \\ 1 & 0 \\ 1 & 0\end{array}$

$\begin{array}{llll}0 & 0 & 0 & 0\end{array}$

0

$0 \quad 0$

0

00

0

0

0

2

0

2

0

40

0

0

$$
0
$$


$214,1,0.15,0.05,0.0,12.9871,3.207,12.2762,6.35002$

$106,1,3,0.0,8.52257,7.83229,8.57278,7.75329,9.66903,9.4781$;

$\begin{array}{rr}9 P & 6 \\ 11 P & 7\end{array}$

$106,1,3,0.0,10.9673,3.207,11.0609,3.207,13.1138,3.207$;

$202,5,11,13,5.68326,3.207,7.30379,7,9$;

$13 P \quad 8$

$15 \mathrm{P} \quad 9$

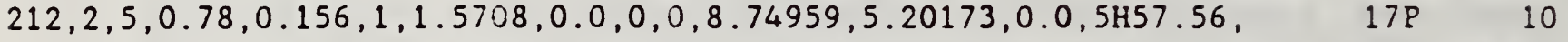

$1,0.1404,0.156,1002,1.5708,0.0,0,0,9.52959,5.20173,0.0,1 \mathrm{H} \$ ; \quad 17 \mathrm{P} \quad 11$

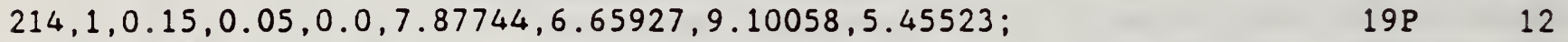

$214,1,0.15,0.05,0.0,9.77381,3.207,9.30722,5.10423 ; \quad 21 P \quad 13$

$202,17,0,0,5.68326,3.207,4.09055,19,21 ; \quad 23 P \quad 14$

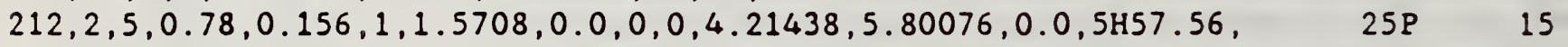

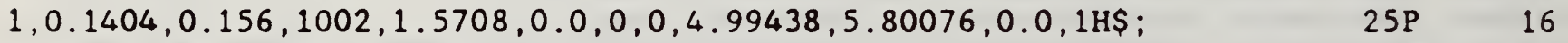

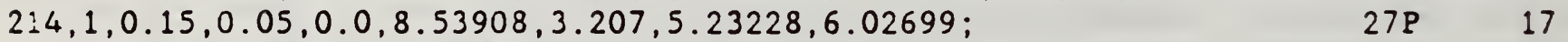

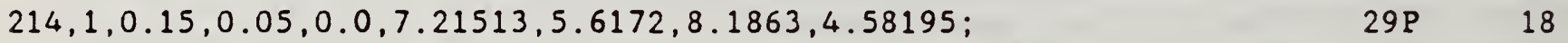

$202,25,0,0,5.68326,3.207,2.85582,27,29 ; \quad 31 P \quad 19$

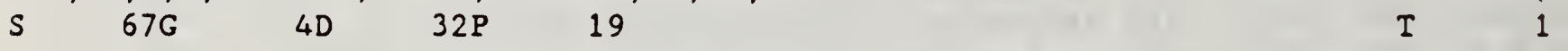


I Test the General Note (Type 212, Form 0) for all functionality 5 with a single Font Code FC=1. Functions exercised include: S 6

Text Height Vertical Text Slant Angle Mirroring $\quad$ S 7

Text Width Horiz Text Rotation Multi Line $\quad S \quad 8$

The working cube for this test extends from $\quad$ S 9

$X=-180$ to $X=280, Y=-180$ to $Y=320, Z=0 . \quad S \quad 10$

E Entity Form Type CountS 2120 28S

$P$ Verify the following:

* All character strings read as, 5 MM TEXT, 10 MM TEXT or 20 MM TEXI S except for the MULI-LINE text.

* A 5 MM TEXT string located at $(20.0,20.0,0.0), 0$ slant and $S \quad 16$ string length $50 \mathrm{~mm}$.

* A 10 M TEXI string located at $(20.0,40.0,0.0) 0$ slant and $S \quad 18$ string length $100 \mathrm{~mm}$. $\quad S \quad 19$

* A 20 MM TEXT string located at $(20.0,60.0,0.0), 0$ slant angle and $S \quad 20$ string length $200 \mathrm{~mm}$. $\quad S \quad 21$

A 7 character rosette of 5 MM TEXI rotating each string 45 degrees $S \quad 22$ from 0 thru 360 degrees for $\quad s \quad 23$

VERTICAL text with rosette center at $(-100.0,200.0,0.0)$, S 24

HORIZONTAL text with rosette center at $(-100.0,-80.0,0.0)$. S 25

* A COMPRESSED $20 \mathrm{MM}$ TEXI string with 0 slant angle S 26

located at $(20.0,280.0,0.0)$ and string length $=50 \mathrm{~mm}, \quad s \quad 27$

located at $(20.0,250.0,0.0)$ and string LENGTH $=100 \mathrm{~mm}, \quad$ S 28

located at $(20.0,220.0,0.0)$ and string LENGTH $=150 \mathrm{~mm}$. S 29

* A SLANTED $20 \mathrm{M}$ TEXI string with string length $=200 \mathrm{~mm}$ and $\mathrm{S} \quad 30$

45 degree SLANT angle located at $(20.0,170.0,0.0), \quad s \quad 31$

30 degree SLANT angle located at $(20.0,140.0,0.0), \quad$ S 32

15 degree SLANT angle located at $(20.0,110.0,0.0)$. S 33

* A MIRRORED 10 MM TEXI steigg located at $(20.0,40.0,0.0)$ and is .. $S$. 34 mirrored about the $Y$ axis at $(-20.0,40.0,0.0)$ with each string $S \quad 35$ length $=100 \mathrm{~mm}$.

* A MIRRORED 20 TEXT string located at $(20.0,-60.0,0.0)$ and is $S \quad 37$ mirrored about the strings baseline, each string length $=200 \mathrm{~mm}$. S $\quad 38$

* A 10 MUII-LINE text string located at $(20.0,-120.0,0.0)$, S 39 each line starting at $X=20.0$ and maximum string length $=100 \mathrm{~mm}$. S 40

$R$ The results should be :

Font 1 characters.

Two rosettes of 8 text strings showing horiz \& vertical characters. S

Two groups of $320 \mathrm{~mm}$ text strings showing text width \& slant angle.s

One $10 \mathrm{M}$ text string showing vertical mirroring,

One $20 \mathrm{M}$ text string showing horizontal mirroring,

A simple Multi-line text string example.

C All TEXT input requested for this test is shown between " "DO NOT S 48 enter the QUOTE symbols with the Text. Some Text request a leading $S \quad 49$ BLANK .

Prepare to generate text strings as follows:

Set text height $5 \mathrm{~mm}$, aspect ratio 1.0, slant 0 , horizontal text

Generate a text string reading " 5 MM TEXI" at X $=-100, Y=-80$

Replicate 7 times at 45 degree increments about normal at given $X Y S$ 
Generate a text string reading " 5 MM IEXI" at $X=20, Y=20$ Set text height $5 \mathrm{~mm}$, aspect ratio 1.0 , slant 0 , vertical text Generate a text string reading " 5 MM IEXI" at X $=-100, Y=200$

Replicate 7 times at 45 degree increments about normal at given $X Y$ Set text height $10 \mathrm{~mm}$, aspect railo 1.0, slant 0 , horizontal text Generate a text string reading " 10 MY TEXI" at $X=20, Y=40$ Generate a text string reading " 10 MM IEXI" at $X=-20, Y=40$

Mirror this string about a vertical line through the given $X Y$ Set rext height $20 \mathrm{~mm}$, aspect ratio 1.0 , slant 0 , horizontal text Generate a text string reading "20 MM TEXI" at $X=20, Y=60$ Generate a text string reading "20 MM IEXT" at $X=20, Y=-60$

Mirror this string about a horizontal line through the given $X Y$ Set text height $20 \mathrm{~mm}$, aspect ratio 1.0 , slant 15 , horizontal text Generate a text string reading "20 MM IEXI" at $X=20, Y=110$ Set text height $20 \mathrm{~mm}$, aspect ratio 1.0 , slant 30 , horizontal text Generate a text string reading "20 MM TEXT" at $X=20, Y=140$ Set text height $20 \mathrm{~mm}$, aspect ratio 1.0 , slant 45 , horizontal text Generate a text string reading "20 MM IEXI" at $X=20, Y=170$ Set text height $20 \mathrm{~mm}$, aspect ratio .75 , slant 0 , horizontal text Generate a text string reading " 20 MM IEXI" at $X=20, Y=220$ Set text helght $20 \mathrm{~mm}$, aspect ratio .50, slant 0 , horlzontal text Generate a text string reading "20 MM IEXI" at $X=20, Y=250$ Set text height $20 \mathrm{~mm}$, aspect ratio .25 , slant 0 , horizontal text Generate a text string reading "20 MM TEXI" at $X=20, Y=280$ Set text height $10 \mathrm{~mm}$, aspect ratio 1.0 , slant 0 , horizontal text Generate a text string at $X=20, Y=-120$ reading: "THIS IS A TEST" "OF MULTIPLE" "LINE TEXT"

N WARNING: This file has been accepted as a candidate test file by the Test Case Development Committee but it has not been approved as a member of the Test Case Library.

D Not available

H 30-SEPT-1987 JLC Wrote this TEST CASE as requested.

I This dara was prepared in-conjunction with work sponeared by an agency of the United States Goverment. Neither the United States Government nor any agency thereof, nor any of their employees, makes any warranty, express or implied or assumes any legal liability or responsibility for the accuracy, completeness, or usefulness of any information, apparatus, product, or process disclosed, or represents that its use would not infringe privately owned rights. Reference herein to any specific commercial product, process, or service by trade name, trademark, manufacturer, or otherwise, does not necessarily constitute or imply its endorsement, recommendation, or favoring by the United States Government or any agency thereof.

1H, ,1H; ,17HGENERAL NOTE TEST, 12HE2120000.A01,14HTEST HAND MADE, 3H1.0, $32,38,6,38,15, .1 .0,2,2 \mathrm{HMM}, 1,0.045,13 \mathrm{H} 870930.110545,0.0010,300$. $8 \mathrm{HJ}$ CRUSEY, $3 \mathrm{HNBS}, 4$, ;

$\begin{array}{lll}212 & 1 & 0 \\ 212 & 0 & 0 \\ 212 & 2 & 0 \\ 212 & 0 & 0\end{array}$

$\begin{array}{ll}0 & 1 \\ 0 & 1 \\ 0 & 1 \\ 0 & 1\end{array}$

$\begin{array}{ll}1 & 0 \\ 1 & 0 \\ 1 & 0 \\ 1 & 0\end{array}$
0

$\begin{array}{lrr}0 & 000000101 D \\ & \text { GENNOTE } & 1 D \\ 0 & \text { O00000101D } \\ \text { GENNOTE } & \text { 2D }\end{array}$




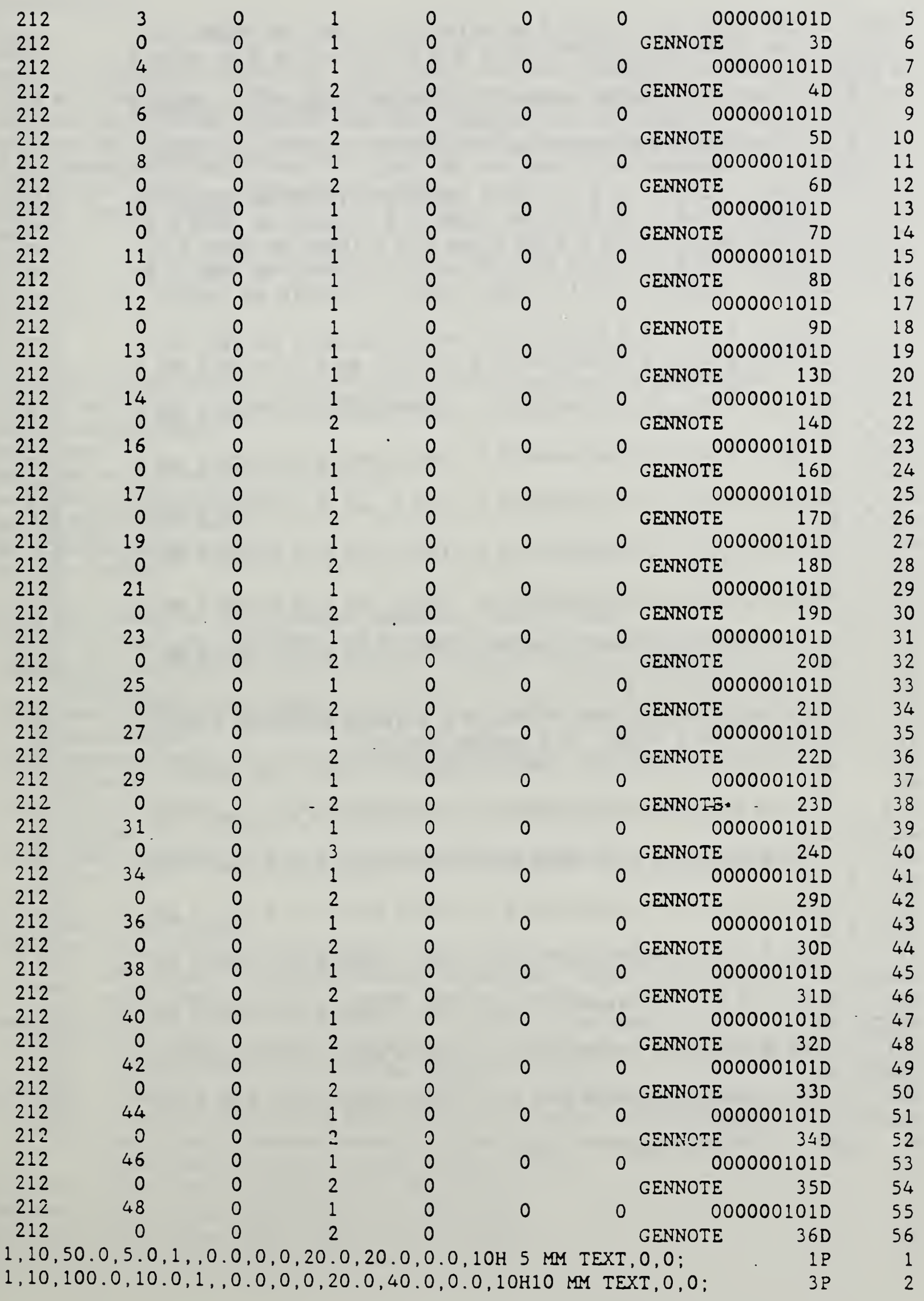


$212,1,10,200.0,20.0,1,0.0,0,0,20.0,60.0,0.0,10 \mathrm{H} 20$ MM TEXT,0,0;

$212,1,10,200.0,20.0,1,1.308996939,0.0,0,0,20.0,110.0,0.0,10 \mathrm{H} 20 \mathrm{M}$ M TEXT, 0,0;

$212,1,10,200.0,20.0,1,1.047197551,0.0,0,0,20.0,140.0,0.0,10 \mathrm{H} 20 \mathrm{M}$ M TEXT, 0,0;

$212,1,10,200.0,20.0,1,0.785931634,0.0,0,0,20.0,170.0,0.0,10 \mathrm{H} 20 \mathrm{M}$ M TEXT, 0,0;

$212,1,10,150.0,20.0,1,0.0,0,0,20.0,220.0,0.0,10 \mathrm{H} 20$ TEXT, 0,0; $212,1,10,100.0,20.0,1,0.0,0,0,20.0,250.0,0.0,10 \mathrm{H} 20$ TEXT, 0,0 ; $212,1,10,50.0,20.0,1,0.0,0,0,20.0,280.0,0.0,10 \mathrm{H} 20$ MM TEXT, 0,0 ; $212,1,10,200.0,20.0,1,0.0,2,0,20.0,-60.0,0.0,10 \mathrm{H} 20$ MM TEXT, 0,0; $212,1,10,100.0,10.0,1,0.0,1,0,-20.0,+40.0,0.0,10 \mathrm{H} 10$ MM TEXT,0, 0 ;

$2: 2,1,10,50.0,5.0,1,0.0,0,0,-100.0,-80.0,0.0,10 \mathrm{H} 5$ M TEXT,0,0; $212,1,10,50.0,5.0,1,0.785398163,0,0,-100.0,-80.0,0.0,10 \mathrm{H} 5 \mathrm{MM} \mathrm{T}$ EXT, 0,0:

$212,1,10,50.0,5.0,1,1.570796328,0,0,-100.0,-80.0,0.0,10 \mathrm{H} 5 \mathrm{MM}$ EXI, 0,0;

$212,1,10,50.0,5.0,1,2.356194490,0,0,-100.0,-80.0,0.0,10 \mathrm{H} 5 \mathrm{MM} \mathrm{T}$ EXT, 0,0;

$212,1,10,50.0,5.0,1,3.141592654,0,0,-100.0,-80.0,0.0,10 \mathrm{H} 5 \mathrm{MM}$ EXT, 0, 0;

$212,1,10,50.0,5.0,1,3.926990817,0,0,-100.0,-80.0,0.0,10 \mathrm{H} 5 \mathrm{MM}$ I EXI, 0,0;

$212,1,10,50.0,5.0,1,4.712388980,0,0,-100.0,-80.0,0.0,10 \mathrm{H} 5 \mathrm{MM}$ EXI, 0, 0;

$212,1,10,50.0,5.0,1,5.499787144,0,0,-100.0,-80.0,0.0,10 \mathrm{H} 5 \mathrm{MM} T$ EXT, 0, 0;

$212,3,14,120.0,10.0,1,0,0,0,0,20.0,-120.0,0.0,14$ HTHIS IS A TEST $, 11,110.0,10.0,1,0.0,0,0,20.0,-135.0,0.0,11$ HOF MUITPLE, 9,90.0. $10.0,1,0.0,0,0,20.0,-150.0,0.0,9$ HLINE TEXT, 0,0 ;

$212,1,10,50.0,5.0,1,0.0,0,1,-100.0,+200.0,0.0,10 \mathrm{H} 5 \mathrm{MM}$ TEXT,0, 0 ;

$212,1,10,50.0,5.0,1,0.785398163,0,1,-100.0,+200.0,0.0,10 \mathrm{H} 5 \mathrm{MM}$ TEXT, 0, 0;

$212,1,10,50.0,5.0,1,1.570796328,0,1,-100.0,+200.0,0.0,10 \mathrm{H} 5 \mathrm{MM}$ TEXI, 0,0;

$212,1,10,50.0,5.0,1,2.356194490,0,1,-100.0,+200.0,0.0,10 \mathrm{H} 5 \mathrm{MM}$ TEXT, 0,0 ;

$212,1,10,50.0,5.0,1,3.141592654,0,1,-100.0,+200.0,0.0,10 \mathrm{H} 5 \mathrm{MM}$ TEXT, 0,0;

$212,1,10,50.0,5.0,1,3.926990817,0,1,-100.0,+200.0,0.0,10 \mathrm{H} 5 \mathrm{MM}$ TEXT , 0,0;

$212,1,10,50.0,5.0,1,4.712388980,0,1,-100.0,+200.0,0.0,10 \mathrm{H} 5 \mathrm{M}$ TEXT, 0,0;

$212,1,10,50.0,5.0,1,5.499787144,0,1,-100.0,+200.0,0.0,10 \mathrm{H} 5 \mathrm{MM}$ TEXT, 0,0 ;

$S \quad 101 G$ 
I Test the subfigure definition (Type 308 ) and the subfigure instance (Type 408) entities. The resulting graphics model should have the $S$ the same positioning, orientation and elements as indicated by the $S$ plot and the elements listed in the PD section. All the elements S of the subfigure should act as a part of the whole for rotation, $S$ translation, moving, coping and scaling.

E Entity Form Type 100

$P$ Visually verify against the plot that a smiling face is generated

consisting of the following entities:

Three circular arcs

Four lines

Also used to create this file were:

One subfigure definition

One subfigure instance

One transformation matrix

One view entity

$R$ Using the system's verification commands, verify that:

there is only one occurance of the subfigure, with no translation $S$

that every element in the subfigure rotates when the subfigure is $S$ rotated

that every element in the subfigure translates when the subfigure is translated

that every element in the subfigure moves when the subfigure is moved

that every element in the subfigure copies when the subfigure is $S$ copied

that every element in the subfigure changes size when the subfigure $S$ scaled

C To recreate the figure:

Generate a full circle with center $=(10,10,0)$ and radius $=5$ $(z=0$ plane, counterclockwise direction, center point $(10,10) \mathrm{S}$ start point $(15,10)$, term. point $(15,10))$

Generate a full circle with center $=(-10,10,0)$ and radius $=5 \quad \mathrm{~S}$ $(z=0$ plane, counterclockwise direction, center point $(-10,10) \mathrm{S}$ start point $(-5,10)$, term. point $(-5,10))$

Generate a circular arc with center $=(0,0,0)$ and radius $=10$ with a start angle of 180 and a terminate angle of 360 degrees ( $z=0$ plane, counterclockwise direction, center point $(0,0)$ start point $(-10,0)$, term. point $(10,0)$ )

Generate a line from $(20,20,0)$ to $(20,-20,0)$

Generate a line from $(20,-20,0)$ to $(-20,-20,0)$

Generate a line from $(-20,-20,0)$ to $(-20,20,0)$

Generate a line from $(-20,20,0)$ to $(20,20,0)$ 
D Not Available

H 15-Sept. -1987 created

N Not Available

L This data was prepared in conjunction with work sponsored by an agencys of the United States Government. Neither the United States Governments nor any agency thereof, nor any of their employees, make any warranty, $S$ express or implied or assumes any legal liability or responsibility $S$ for the accuracy, completeness, or usefulness of any information, $S$ apparatus, product, or process disclosed, or represents that its use $S$ would not infringe privately owned rights. Reference herein to any $S$ specific commercial product, process, or service by trade name, $S$ trademark, manufacturer, or otherwise, does not necessarily constitutes or imply its endorsement, recommendation, or favoring by the United $S$ States Government or any agency thereof. , , 1H1, 12HE3080000.A01, 4HNONE,

16HIGES VERSION $3.0,16,8,24,8,56,1 \mathrm{H} 2,1.0,1,4 \mathrm{HINCH}, 32767,32.767,13 \mathrm{H} 87915 \mathrm{G}$ . 92738,0.000001, ,7HUNKNOWN, 17HTEST CASE LIBRARY,4,3;

\begin{tabular}{|c|c|c|c|}
\hline 110 & 1 & 1 & \\
\hline 110 & 0 & 0 & \\
\hline 110 & 2 & 1 & \\
\hline 110 & 0 & 0 & \\
\hline 110 & 3 & 1 & \\
\hline 110 & 0 & 0 & \\
\hline 110 & 4 & 1 & \\
\hline 110 & 0 & 0 & \\
\hline 100 & 5 & 1 & \\
\hline 100 & 0 & 0 & \\
\hline 100 & 6 & 1 & \\
\hline 100 & 0 & 0 & \\
\hline 100 & 7 & 1 & \\
\hline 100 & 0 & 0 & \\
\hline 308 & 8 & 1 & \\
\hline 308 & 0 & 0 & . \\
\hline 124 & 9 & 1 & \\
\hline 124 & 0 & 0 & - \\
\hline 410 & 10 & 1 & \\
\hline 410 & 0 & 0 & \\
\hline 408 & 11 & 1 & \\
\hline 408 & 0 & 0 & \\
\hline
\end{tabular}

$\begin{array}{ll}1 & 0 \\ 1 & 0 \\ 1 & 0 \\ 1 & 0 \\ 1 & 0 \\ 1 & 0 \\ 1 & 0 \\ 1 & 0 \\ 1 & 0 \\ 1 & 0 \\ 1 & 0 \\ 1 & 0 \\ 1 & 0 \\ 1 & 0 \\ 0 & 0 \\ 1 & 0 \\ 0 & 0 \\ 1 & 0 \\ 0 & 0 \\ 1 & 0 \\ 1 & 0 \\ 1 & 0 \\ 0 & \end{array}$

SE
0
0
0
0
0
0
0
0
0
0
0
0
0
0
0
0
0
0
0
0
0
0
0

$110,20.0,20.0,0.0,20.0,-20.0,0.0$ $0 \quad 0 \quad 100010$

$110,20.0,-20.0,0.0,-20.0,-20.0,0.0$;

$110,-20.0,-20.0,0.0,-20.0,20.0,0.0$;

$110,-20.0,20.0,0.0,20.0,20.0,0.0$;

$100,0.0,10.0,10.0,15.0,10.0,15.0,10.0$

$100,0.0,-10.0,10.0,-5.0,10.0,-5.0,10.0$;

$100,0.0,0.0,0.0,-10.0,0.0,10.0,0.0$;

$308,0,12 \mathrm{HE} 3080000$.FIG $7,1,3,5,7,9,11,13$;

$124,1.0,0.0,0.0,0.0,0.0,1.0,0.0,0.0,0.0,0.0,1.0,0.0$ :

$0 \quad 0 \quad 0 \quad 10001 D$

$410,2,1.0,0,0,0,0,0,0$;

$408,15,0.0,0.0,0.0,1.0$;

$68 \mathrm{G}$

3D

$22 P$ 




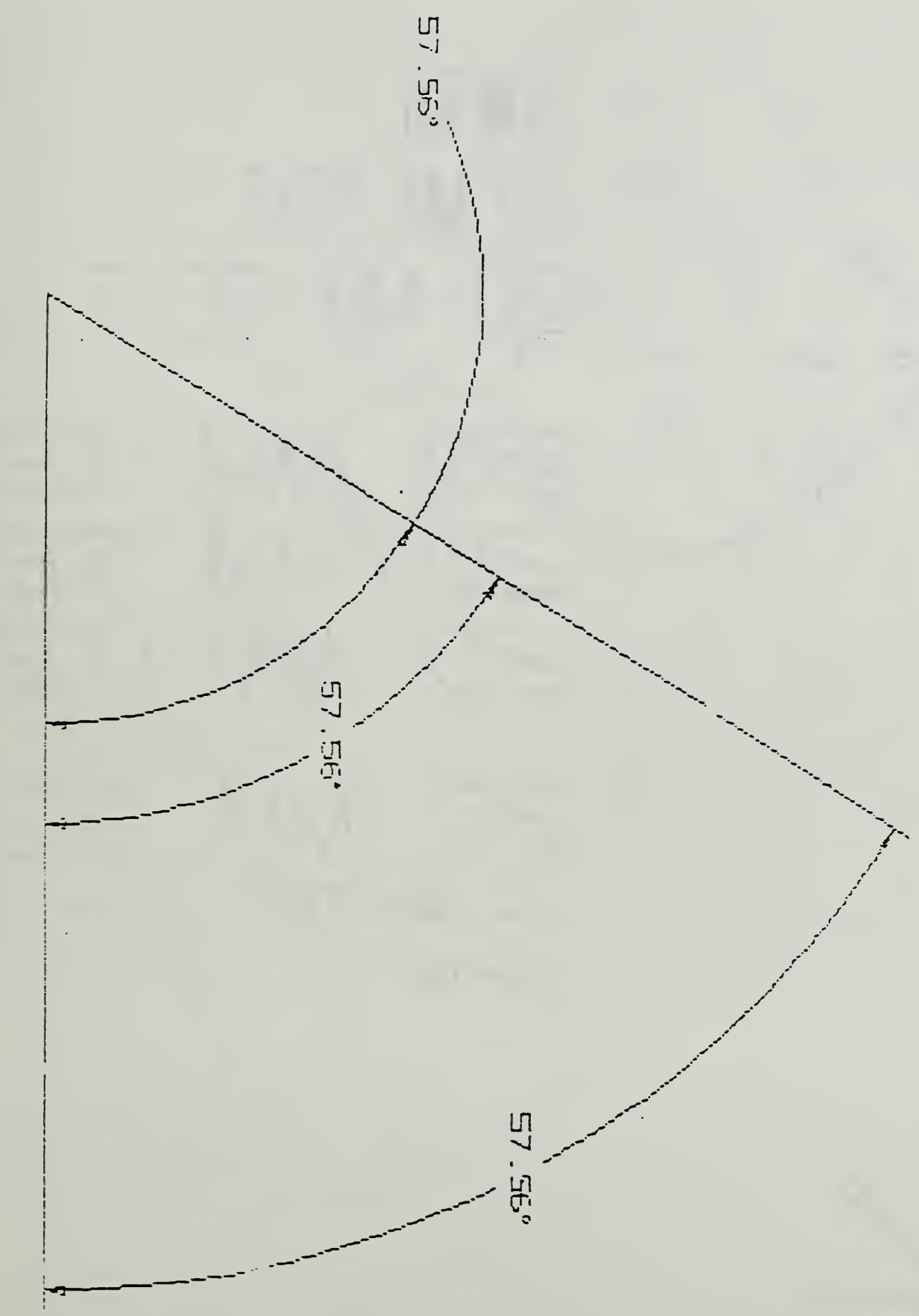




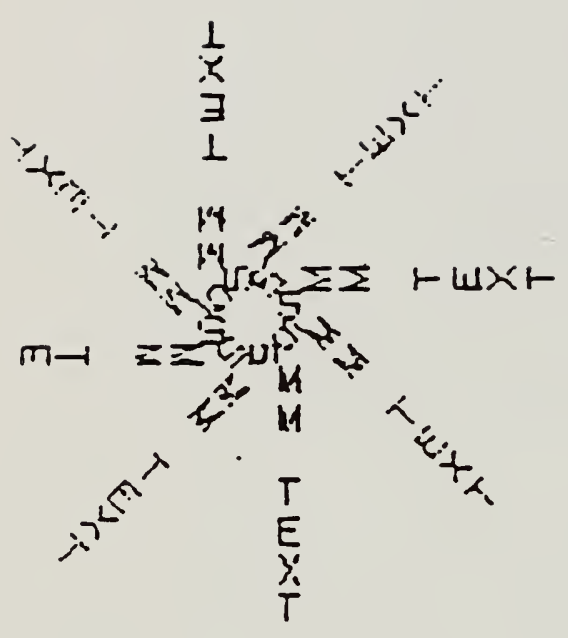

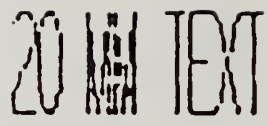

20 M TEXT
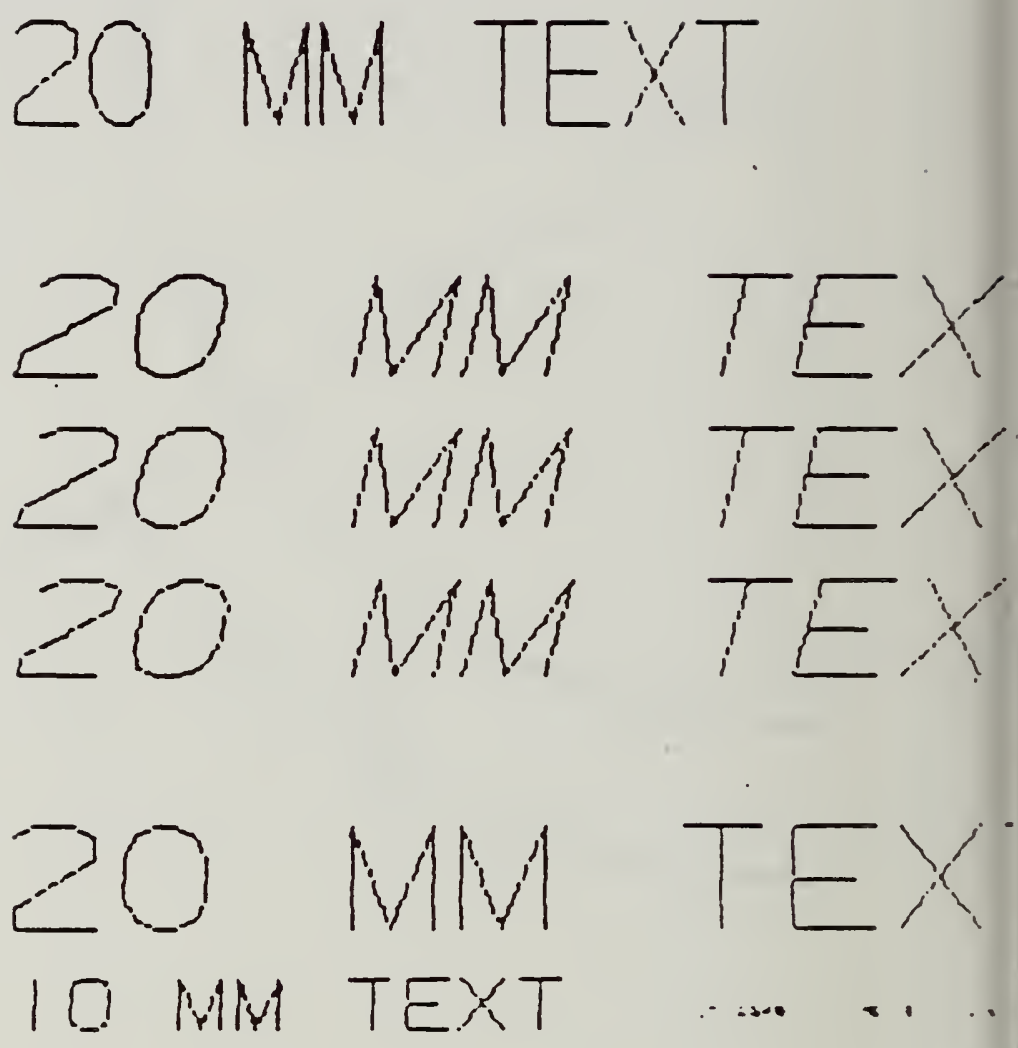

5 MNM TEXT
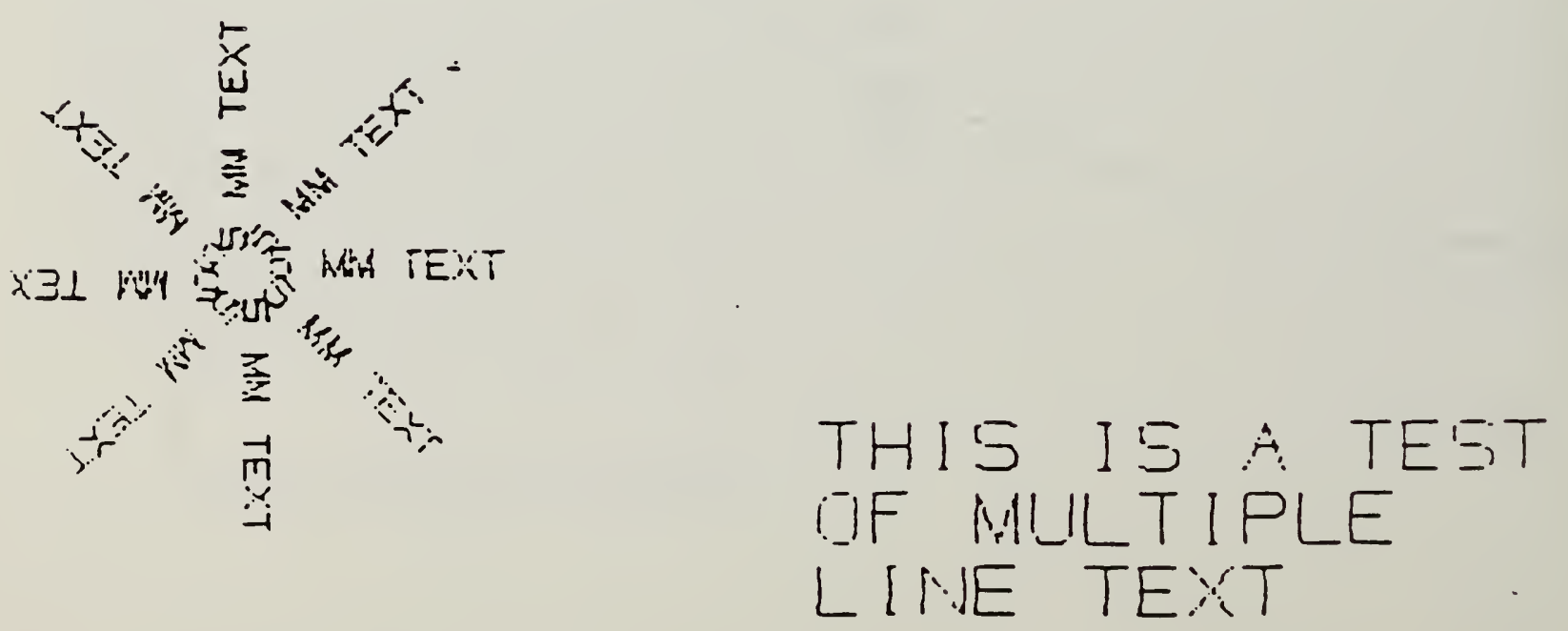


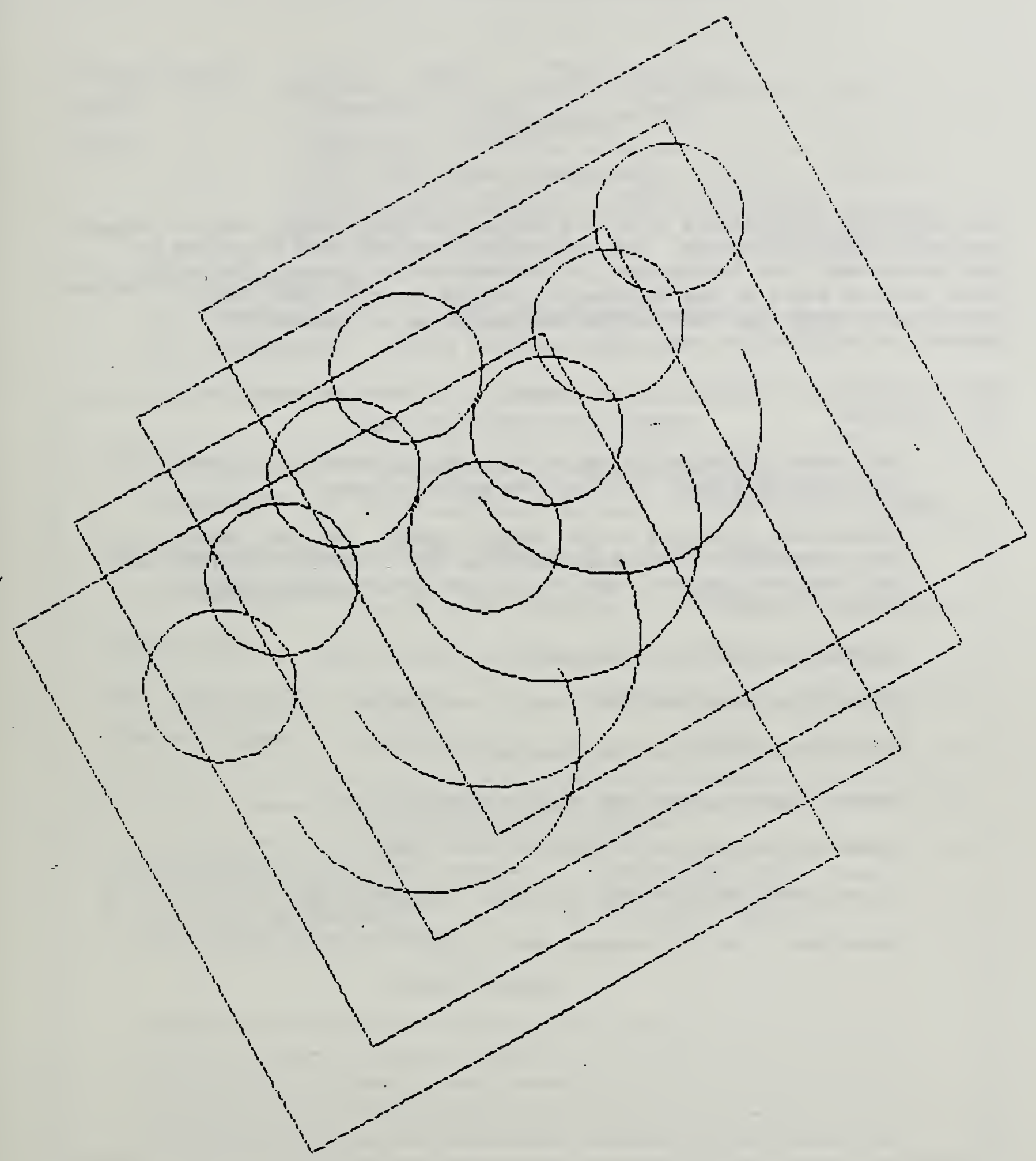




\section{Appendix C \\ Test Results File}

The following material was collected during the verification test of the Autotroll S7000 CAD system. The methodology used was that described by the "quickstart" and "quickstart $j 5$ " implementation schemes. The system under test is owned by the Engineering CAD/CAM group at NBS. The verification forms and instructions are contained in Appendix $A$. Appendix B contains the test cases and their plots.

The following is a listing of the packets of information contained in this appendix.

- The packet delivered to the testing agency containing a Verification Request Form and the vendor claims.

- Information filled in by the testing agency: The Test Results File cover sheet, Test Plan Specification, Veriflcation Test Log, Test Incident Reports, and the Pre and Postprocessor Entity Results Forms.

- Volunteer Entity Test with plots.

- System printouts from the circular arc tests

- System printouts from the line test

- System printouts from the angular dimension test

- System printouts from the general note test

- System printouts from the subfigure definition test

- Prototype of the SAE Summary Test Report 
Company Name:

Contact:

Address:

AUTO-TReL TECHNolory SAMRLE TEST AT NBS

Tound $B \angle D S$

RH BII3

Gaitureszueg th $2 x e 99$

Phone:

(301) $975-3566$

Dale: 5 oCT 1887

Request for Verification of:

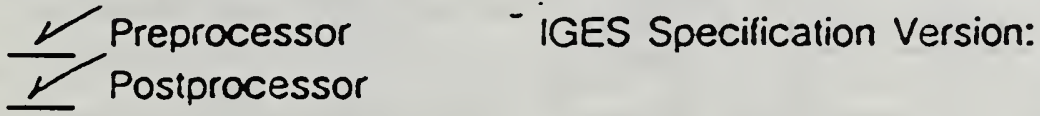

\section{Configuration Information}

CAD Software:

RuTO-TReL TERIR 7000

Version/Release ID:

10.06 REL. 11.0

Release Date: $3 / 2 / 87$

IGES Processor Name: STK PRE E SZK POST

Version/Release 1D: 6.0 PEVee0e $q$ Release Date: $3 / 19 / 87$

Computer Mig: APollo Model: DN550

CPU: Hoterela 68020

Operating System:

AEGIS

Memory Size: 2 HEGABYTES version: $9 \cdot 2 \cdot 3$

\section{Supporting Information}

$\not$ Postprocessor Entity Maps

$\not{Z}$ Preprocessor Entity Maps

$\not$ Processor Documentation

- Tape Access Documentation

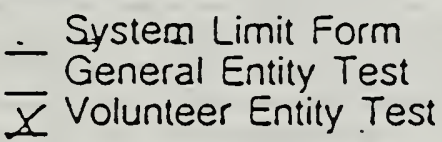

Other (itemize)

\begin{tabular}{|ll|}
\hline \multicolumn{2}{|c|}{ For SÂE Use Only } \\
\hline $\begin{array}{l}\text { Vendor Request Number: } \\
\text { Assigned 10: }\end{array}$ & Date: 5 ect 1987 \\
\hline
\end{tabular}




\section{IGES Processor Mapping Form Global Section Characteristics}

'endor Request Number: $R 875002$

Date: 2 OCT 1987 /stem NameNersion:

\begin{tabular}{|c|c|c|c|c|c|c|}
\hline & & & & & & $D=D E F A U \angle T^{-}$ \\
\hline \multicolumn{2}{|l|}{ Field } & \multicolumn{2}{|r|}{ Attribute } & \multicolumn{2}{|c|}{ Supported } & \multirow{2}{*}{$\begin{array}{c}\text { Comments } \\
\text { Mark last colum if continuation } \\
\text { Sheet is used }\end{array}$} \\
\hline Name & $\#$ & $\#$ & Name & Pre & Post & \\
\hline Parameter Delimiter & 1 & & & $D$ & 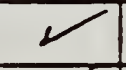 & DEFAULTCD/PRE \\
\hline Record Delimiter & 2 & & & $D$ & $r$ & $\because$ \\
\hline Product 10 & 3 & & & 5 & $\checkmark$ & 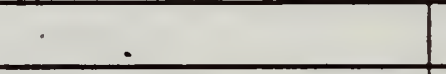 \\
\hline IGES File Name & 4 & & & $\checkmark$ & 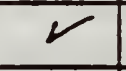 & \\
\hline Vendor System 10 & 5 & & & $\checkmark$ & $\checkmark$ & \\
\hline Preprocessor Version & 6 & & & $\checkmark$ & $\sim$ & \\
\hline Bits per Integer & 7 & & & $\checkmark$ & $\nu$ & \\
\hline Single Precision Mag. & 8 & & & $\checkmark$ & $\nu$ & \\
\hline Single Precision Signt. & 9 & & & $\checkmark$ & 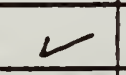 & \\
\hline Double Precision Mag. & 10 & & & 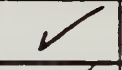 & $\longleftarrow$ & \\
\hline Double Precision Signt & 11 & & & 7 & $V$ & \\
\hline Product 10 (receiver) & 12 & & . & 5 & $\checkmark$ & \\
\hline Model Space Scale & 13 & & & $\checkmark$ & $\square$ & \\
\hline \multirow[t]{11}{*}{ Units Flag } & 14 & 1 & INCH & 7 & 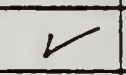 & \\
\hline & & 2 & MM & $\checkmark$ & $\checkmark$ & \\
\hline & & 3 & & $=\square$ & 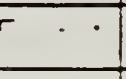 & \\
\hline & & 4 & FEET & & & \\
\hline & & 5 & MILES & & & \\
\hline & & 6 & METERS & & & \\
\hline & & 7 & KILOMETERS & & & \\
\hline & & 8 & MILS & & & \\
\hline & & 9 & MICRONS & & & \\
\hline & & 10 & CENTIMETERS & & & \\
\hline & & 11 & MICROINCH & & & \\
\hline \multirow[t]{4}{*}{ Innits } & $: 5$ & & $2 H I N$ & 5 & 7 & \\
\hline & - & & $2 \mathrm{HMM}$ & 7 & $\checkmark$ & $\cdots \cdots$ \\
\hline & & & $2 \mathrm{HFT}$ & & & \\
\hline & & & $2 \mathrm{HMI}$ & & & \\
\hline
\end{tabular}




\section{IGES Processor Mapping Form Global Section Characteristics}

"endor Request Number: 2875002

\begin{tabular}{|c|c|c|c|c|c|c|c|}
\hline \multicolumn{2}{|l|}{ Field } & \multicolumn{2}{|r|}{ Attribute } & \multicolumn{2}{|c|}{ Supported } & \multirow{2}{*}{\multicolumn{2}{|c|}{$\begin{array}{l}\text { Comments } \\
\text { Mark last cokmm if contimuation } \\
\text { Sheet is usec }\end{array}$}} \\
\hline Name & $\not H$ & $\not H$ & Name & Pre & Post & & \\
\hline Units (continued) & 15 & & $1 \mathrm{HM}$ & & & & \\
\hline & & & $2 H K M$ & & & & \\
\hline & & & 3HMIL & & & & \\
\hline & & & $2 H U M$ & & & & \\
\hline & & & $2 \mathrm{HCM}$ & & & & \\
\hline$\cdot$ & & & 3HUIN & & & $\cdot$ & \\
\hline Line Wi Grads. & 16 & & & $D$ & L & USES TO SET & $x$ \\
\hline Max Line Width Units & 17 & & & $D$ & レ & PEU NUMTER -. & $x$ \\
\hline Date/Time Stamp & 18 & & - & $\nu$ & 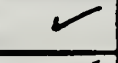 & & \\
\hline Min. User Resolution & 19 & & & $\checkmark$ & $\checkmark$ & & \\
\hline Max. Coord. Value & 20 & & & $\nu$ & $\nu$ & & \\
\hline Name of Author & 21 & & & $D$ & 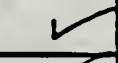 & & \\
\hline Organization. : & 22 & & & 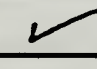 & r & & \\
\hline ZES Version Number & 23 & 1 & 1.0 & & & & \\
\hline & & 2 & ANSI Y14.26M & & & & \\
\hline & & 3 & 2.0 & & $\sim$ & & \\
\hline & & 4 & 3.0 & & & & \\
\hline Drafting Standard & 24 & 0 & None & & $\sim$ & & \\
\hline & & 1 & ISO & & & & \\
\hline & & 2 & AFNOR & & & & \\
\hline & & 3 & ANSI & & & & \\
\hline & & 4 & BSI & & & & \\
\hline & & 5 & CSA & & & & \\
\hline & & 6 & DIN & & & & \\
\hline & & 7 & JIS & & & & \\
\hline & & & & & & & \\
\hline & & & & & & & \\
\hline & & & & & & & \\
\hline
\end{tabular}


IGES Processor Mapping Form Globa! Section Characteristics

'endor Request Number: $P 8750 \mathrm{C}$

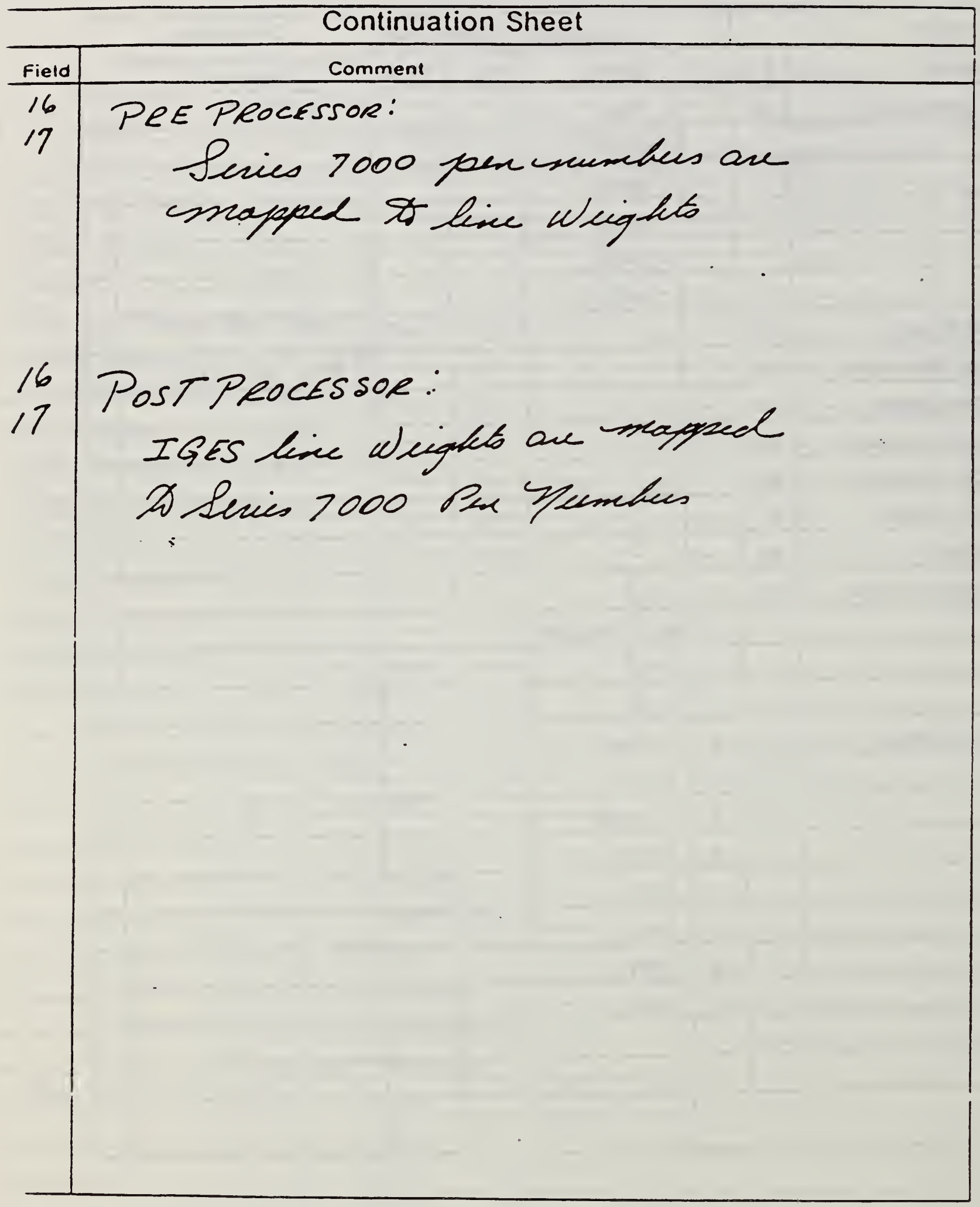




\section{Preprocessor Mapping Form Directory Entry Characteristics}

Vendor Request Number:

R875002

Date: 7 oct 1987

\begin{tabular}{|c|c|c|c|c|c|c|c|}
\hline \multicolumn{2}{|l|}{ Field } & \multicolumn{2}{|r|}{ Attribute } & \multicolumn{2}{|c|}{ Supported } & \multirow{2}{*}{$\begin{array}{c}\text { Comments } \\
\text { Atark :as: column i: cen:iniation, } \\
\text { Sheet is used }\end{array}$} & \\
\hline ivaine & \# & मे & Name & Pre & Post & & \\
\hline Structure & 3 & & & $D$ & $D$ & DEFAULIED & \\
\hline \multirow[t]{5}{*}{ Line Font } & 4 & 1 & Solid & $\longleftarrow$ & 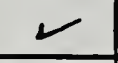 & & \\
\hline & & 2 & Dashed & $\longleftarrow$ & $\sim$ & & \\
\hline & & 3 & Phantom & $\longleftarrow$ & $\sim$ & & \\
\hline & & 4 & Centerline & レ & $\longleftarrow$ & & \\
\hline & & 5 & Dotted & & & & \\
\hline Level & 5 & & & $\longleftarrow$ & 2 & & $x$ \\
\hline View & 6 & & - & $\sqrt{2}$ & 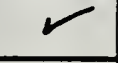 & TYPE 50, FOLN 4 & $x$ \\
\hline Matrix & 7 & & & 2 & 2 & & $x$ \\
\hline Label & 8 & & & & & & \\
\hline S Blank & $9 a$ & & & $\nu$ & 2 & 00,01 & \\
\hline a Subord. & $9 t$ & & & r & - & 00,01 & \\
\hline u Use Filag & $9 c$ & & & $x$ & $\sim$ & $00 \quad 01$ & \\
\hline s) Hierarchy & $9 d$ & & & L & $\leftarrow$ & 01 & \\
\hline Line Weight & 12 & & & & & & $x$ \\
\hline Color & 13 & 0 & unassigned & $\nu$ & $\sim$ & & \\
\hline & & 1 & Black & & - & & \\
\hline & & 2 & Red & & $\checkmark$ & $\ldots$ & \\
\hline & & 3 & Green & & - & & \\
\hline & & 4 & Blue & & 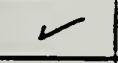 & & \\
\hline & & 5 & Yellow & & 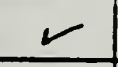 & & \\
\hline & & 6 & Magenta & & $\sim$ & & \\
\hline & & 7 & Cyan & & 2 & & \\
\hline & & 8 & White & & 2 & & \\
\hline Label & 18 & & & & & & \\
\hline Subscript & 19 & & & $D$ & $D$ & DEFAULTRO & \\
\hline
\end{tabular}

iNumber of Multipie Ënuties Per Level Permitted:

Number of Multiple Colors Per Level Permitted:

Total Number of Levels Permitted: 
Preprocessor Mapping Form

Directory Entry Characteristics

Vendor Request Number: $R 875002$

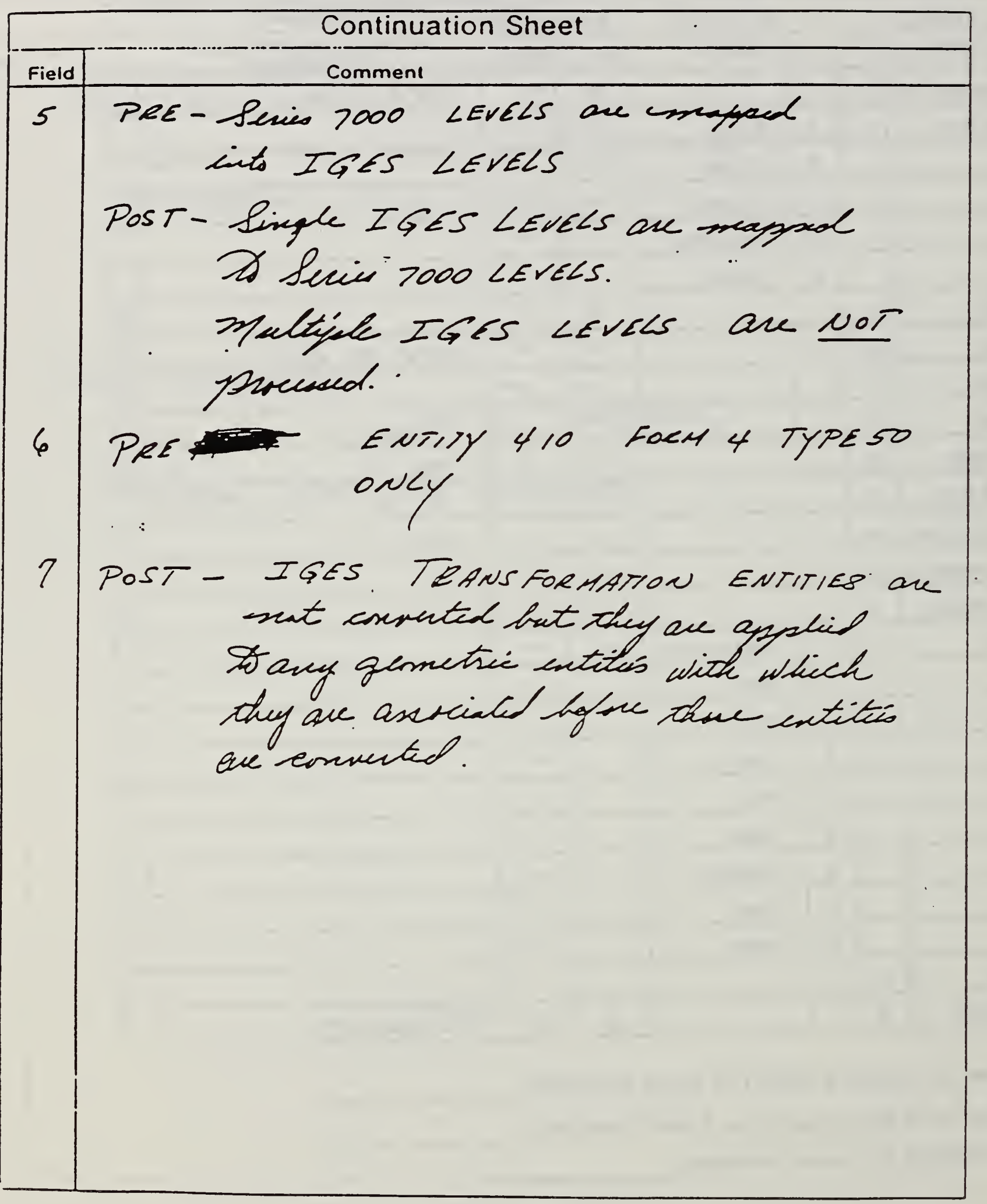




$$
\overline{11}
$$




\section{Preprocessor Entity Mapping Form}

Sheel or 5

Vendor Requesi Number: $R 875002$

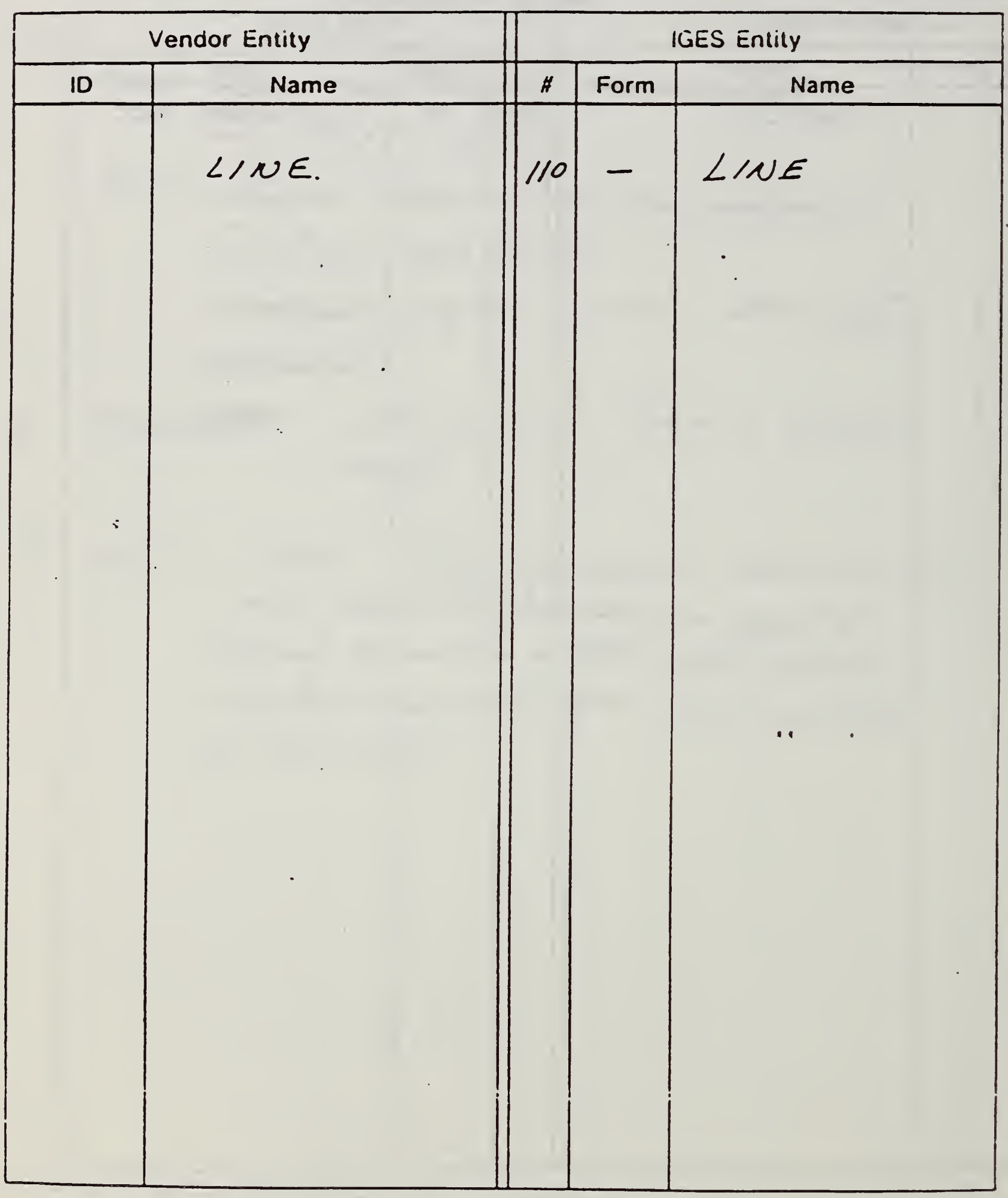


Sheet 3 or 5

Preprocessor Entity Mapping Form

Vendor Request Number: $\ 875002$

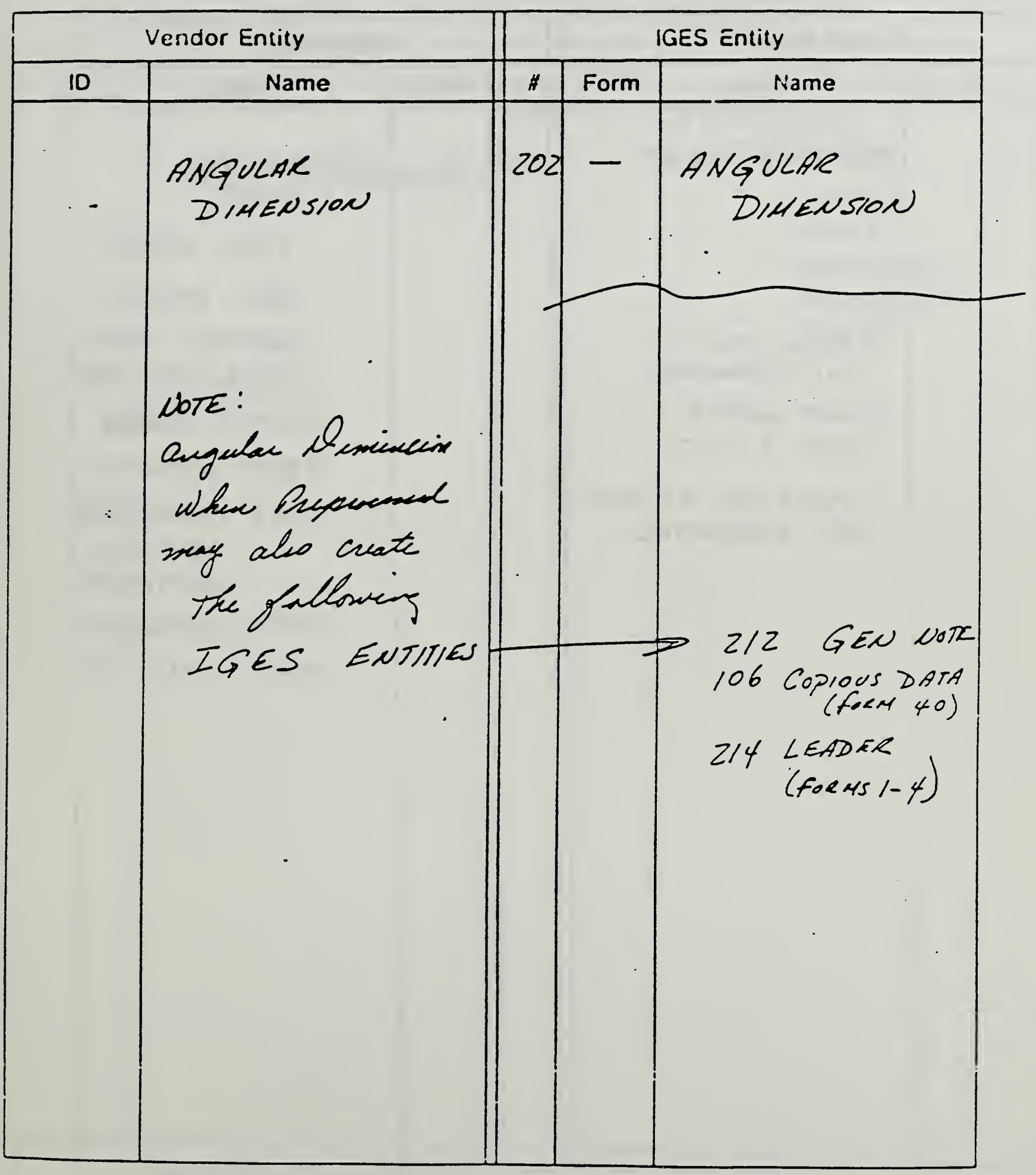

Form $8 C$ 


\section{Preprocessor Entity Mapping Form}

vendor Request Number: $T 875002$

\begin{tabular}{|c|c|c|c|c|}
\hline \multicolumn{2}{|r|}{ Vendor Entity } & \multicolumn{3}{|c|}{ IGES Entity } \\
\hline 10 & Name & 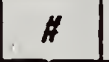 & Form & Name \\
\hline$\therefore$ & $\begin{array}{l}\text { GENEKAL NOTE } \\
\text { VERTICAL TEXT } \\
\text { NOT SUPPORTED. } \\
\text { SLANT ANGLE } \\
\text { FIXED AT IS- } \\
\text { HIRRORIUG OF TEXT } \\
\text { NOT SUPPORIED. }\end{array}$ & $2 / 2$ & 0 & $\begin{array}{l}\text { GENERAL } \\
\text { NOTE } \\
\text { TEXT HEIGHT } \\
\text { TEXT WIDTH. } \\
\text { VERTICAL TEXT } \\
\text { HORIZOXTAL TENT } \\
\text { SLANT ANGLE } \\
\text { TEXT ROTATION } \\
\text { TEXT HIKRORINO } \\
\text { VELTICAL } \\
\text { HORIZONTAO } \\
\text { TEXT COMPRESNOA } \\
\text { HULTI-LINE TEXT } \\
\text {.. }\end{array}$ \\
\hline
\end{tabular}


Sheet 5 or 5

Preprocessor Entity Mapping Form

Vendor Request Number: $R 875002$

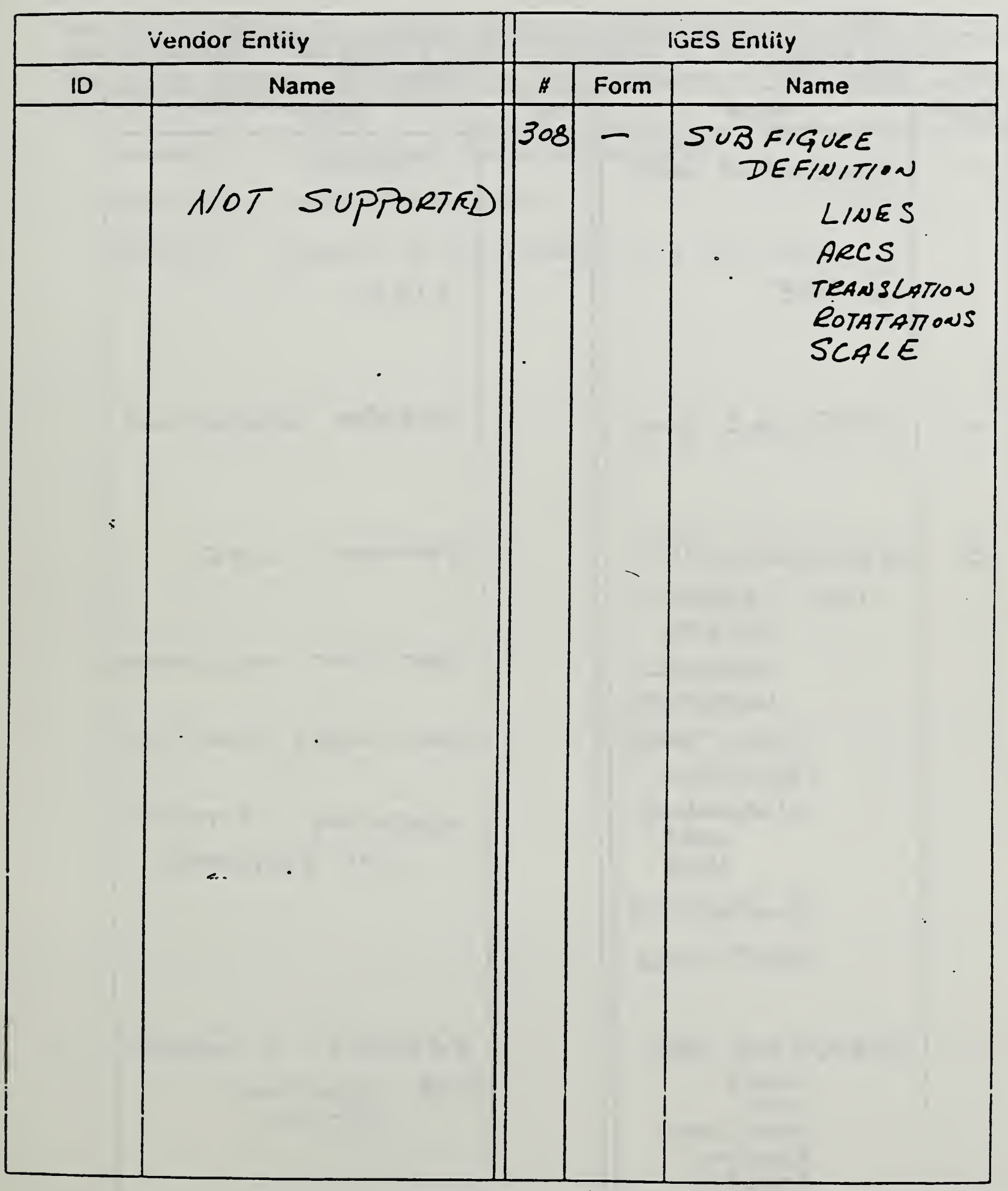

Form $8 C$ 


\section{Postprocessor Entity Mapping Form}

Vendor Request Number:

$R 875002$

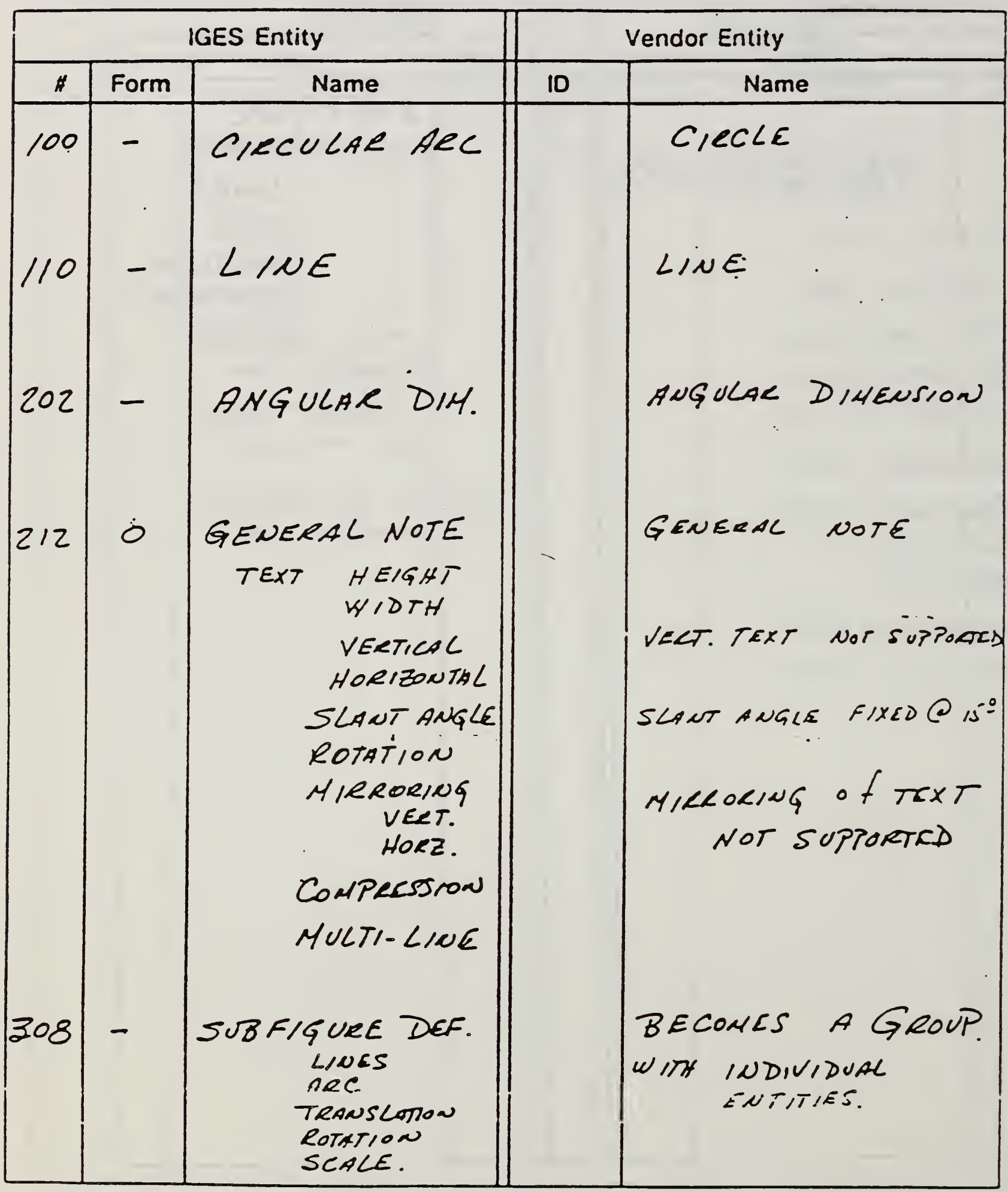




\title{
Appendix D
}

Appendix $D$ contains the exercise given to members of the IGES/PDES Testing Project. The package is not replicated in its entirety because most of the material is included in other appendices in this report. The specified material can be found as follows:

\author{
Appendix A - Verification procedures and forms \\ Appendix B - Test cases and plots \\ Appendix C - Examples of the procedures on a real system
}


IGES Testing Project

October 7, 1987

\title{
An informative Exercise in Verification Testing \\ and \\ Test Case Design
}

To: All interested parties

From: Methodology Testing Committee and the NBS

The following packet of information contains directions for building an IGES test case and running an IGES Verification Test. This exercise is necessary for anyone who wants to. understand IGES testing and IGES test case development beyond a general level. The tasks of writing a test case and defining a Verification Test are immutably bound together. and accordingly, presented together.

You will need a copy of the IGES Testing Methodology Document Version 0.5 and the materials contained in this packet. These include:

\author{
Instructions for the exercise, \\ Set of Verification Testing Forms \\ One Example \\ Listing of test cases. \\ Plot of test cases \\ Extractions from IEEE std 829-1983
}

After completing the exercise, the results need to be sent in for compilation, analysis, and distribution. Testing comments and results should be sent to NBS. Test case comments and results should be sent to Julia Terry.

IGES Testing

National Bureau of Standards

Sound A-101

Gaithersburg, Md. 20899
Julia Terry

Martin Marietta Energy Systems

Bldg 9103 MS 4

PO Box: Y

Oak Ridge, Tenn. 37831

Good Luck.

Thomas Wright, NBS 


\section{IGES Testing Project}

October 7, 1987

\section{Instruction for Verification Test and Test Case Design}

Verification Test: In order to run the Verification Test it is necessary to get a copy of Testing Methodology of IGES Translators and IGES Formatted Data Files, Version 0.5. Particular attention needs to be paid to chapter 5 on verification testing, chapter 9 on the IGES Verification Panel, and appendix $A$ on performing a verification test. The other materials contained in this packet will need to be reviewed as well.

As you go through this exercise, you will wear the hat of each group mentioned. Be a CAD vendor when filling out the preprocessor and postprocessor mapping forms; be the SAE when receiving the forms and results; be the testing agency when running the test; and so forth. If you have an IGES verifier available to you or have access to one, use it to analyze IGES files. There is a company that will analyze your files for a fee that can be used. If all else fails, skip this step and proceed.

There are five test cases available for this test. These will be available through the IGES bulletin board and on floppy disk at the St. Louis IGES meeting.

Keep track of your questions and comments and send them in with your results. Comments without results can also be sent, but please indicate how much of the procedures you went through. These comments are an important part of this alpha test cycle.

As part of the Testers Forum in St. Louis, we will try to run a demonstration Verification Test with one or more vendors of P.C. products. It is possible that modifications to these instructions will occur at that time.

Cautions: 1 - Do not try to assess the functionality of the entity maps. This represents an important issue that will be addressed in St. Louis. An approach has been developed that will use a more comprehensive claim form to get specific details about each entity. Unfortunately these forms will not be available to be placed in this packet. In their place will be the old forms from version 0.3 of the testing document. An attempt will be made to have these forms available in St. Louis.

Test Case Development: To develop a test case, first read Appendix D, Guide to Developing IGES Test Cases. Pay particular attention to the documented jest cases in this packet_-Using one of these cases as a model, redesign it for the same entity and test it on a CAD system. Remember that enough information must be provided about the test case to clearly determine its intent. This is important for preprocessor scripts that may define illegal operations on some systems. For example, some systems with circle entities can not accept 360 degree arcs as input. When finished, send the completed test case to Julia Terry for comment.

The second part of the exercise involves modifying or extending the collection of candidate test cases. When comments are returned, the IGES Test Case Committee will assign a test case to be modified or a test case to be developed. Complete the assignment and return it to Julia Terry.

Cautions: There is a proposal to change the definition of the ' $C$ ' area of the Start Section from Comments to Construction Scripts. Comments will be moved to the Note area. Also there needs to be emphasis placed on the intent of the test case for the ' $I$ ' area of the Start Section. 



GUIDELINES FOR IGES APPLICATION SUBSETS

Prepared for the

DOD CALS Program office

Bradford M. Smith

Thomas P. Wright

29 March 1987 

TABLE OF CONTENTS

PREFACE

FOREWORD

Acknowledgements

1.0 SCOPE AND PURPOSE

2.0 BACKGROUND

2.1 Importance to CALS

2.2 Digital Product Data

2.3 Life Cycle Use

2.4 Product Data as a Resource

3.0 APPLICATIONS SUBSETS

3.1 Definition and Importance

3.2 Present Use of Application Subsets

3.3 IGES Subsets of Interest to DOD

3.4 General Subset Requirements Information Mapping

Entity Content

Restrictive set

3.5 Specific Technical content

3.6 Prioritization of Development

3.7 Example Application Entity Subsets

Technical Publications

Engineering Drawing

Electrical PC Boards

4.0 TESTING METHODOLOGY FOR APPLICATION SUBSETS

4.1 Testing Methodology Concepts

4.2 Use of Entity Mapping in Data Exchange

4.3 Requirements for a National Verification Program

4.4 The Verification Process

4.5 Current Efforts and Status

5.0 TECHNICAL ISSUES

5.1 Control over Operator Data Entry

5.2 Requirements on IGES Translator Design

5.3 Flavoring and Deflavoring Requirements

5.4 Software Tools for Acceptance Testing

5.5 Testing of Datasets for Conformance

6.0 POLICY CONSIDERATIONS

6.1 Policy on Purchase of Datasets

6.2 Acceptance Testing of Datasets

6.3 Verification of Source Preparation systems

7.0 ACTION REQUIRED TO IMPLEMENT

8.0 REFERENCES Glossary Bibliography

9.0 APPENDICES 


\section{PREFACE}

The enclosed material represents ideas and concepts that are under active discussion by members of IGES Technical Committees. Your comments and ideas are solicited on these topics and should be addressed to the author.

It should be noted that this document has been submitted for detailed review by the IGES organization and, as a result, may undergo major changes during technical review. In its present form, the document represents opinions of the authors only and should not be taken as representing any wider consensus such as from an IGES committee. 


\section{FOREWORD}

This document addresses the specification, purchase and acceptance testing of product data in digital form. It has been prepared by the National Bureau of Standards under a contract from the Computer Aided Logistics Program in the Department of Defense. The document reports on the IGES application subset concept, identifies several urgently needed subsets, itemizes the required technical content of any subset, and gives several examples of draft application subset documents.

It is intended that this report be reviewed widely by the Department of Defense, by its industrial contractors, by committees of the IGES organization and by interested professional associations. While the document has been prepared for DOD use, the information is generic and usefull for by all parties involved with the transfer of digital product data files.

Suggestions for additions and corrections to this document should be sent to Mr. Bradford Smith, Al0l Sound Building, National Bureau of Standards, Gaithersburg, MD 20899

\section{Acknowledgements}

This document draws heavily from thousands of man-hours of experience gained by members of the IGES Organization who have volunteered their time and energies to solve the problems of digital product data exchange.

Particularly important has been the work of the Testing Methodology Committees under Jim Fleming of Cummins Engine Company, the Electrical Committee under Larry o'conneli of Sandia National Laboratories, the Technical Publications Committee under Kelly Chi of McDonnell Douglas MDAIS and the Drafting Committee under Bob Colsher of IGES Data Analysis Company. In addition, Ron Downer's work on application subsets at Hughes Aircraft EDSG has added much to this document.

Special thanks also go to Phil Kennicott from General Electric Company, to J C Kelly from Sandia National Laboratories and to Mark Palmer from the National Bureau of Standards. 



\subsection{SCOPE AND PURPOSE}

This document has been prepared for the Department of Defense program on Computer Aided Logistics. The report addresses mechanisms for incorporating the exchange of digital product data into the normal procurement and business operations of the DOD. Requirements are given for the specification, purchase and acceptance testing of product data in digital form. The document calls for the use of application subsets of the Initial Graphics Exchange specification (IGES).

The report defines the general content and use of an IGES application subset and presents the rationale for technical choices made. Present use in government and industry is documented, and several urgently needed subsets are specifically identified. The report itemizes the required technical content of any subset, enumerates several application subsets for future development, and presents draft application subsets for Technical Illustrations, 2-D Engineering Drawings and Electrical Printed wiring Boards.

Finally, this document addresses the implementation of the application subset concept. A draft policy statement is given in Appendix $A$ as a model for adoption. The policy addresses digital data exchange for internal transfer within an organizational element, external transfer to contractors, acquisition of new parts/systems, data transfer from design to product support, and archival storage of parts/assembly product data.

Appendix B contains an updated DOD Standard addressing the use of digital product data. It generalizes the earlier Air Force work on MII-STD 1840 which was primarily concerned with exchange of technical documentation in digital form. The standard calls for the use of SGML, IGES, CGM and CCITT for technical documentation and IGES, CGM and CCITT for 2-D engineering drawings. other product data is specified to use the existing IGES standard and the evolving standards PDES, EDIF and VHDL. Where IGES or SGML is specified, a reference is made to a separate DOD specification.

Appendix $C$ contains the recommended draft DOD specification for IGES Application subsets. The document identifies the general content for any subset and specifically gives the requirements for three initial subsets; Technical Illustrations, 2-D Engineering Drawings and Electronic Printed Wiring Boards. More application subsets are expected to be added in the future. 


\section{0 BACKGROUND}

\subsection{Importance to CALS}

The objective of the CALS program in digital product data is the effective exchange of data throughout the life cycle of weapons systems development and deployment through the use of computer readable datasets describing the systems, their individual piece parts and their product support data. A central issue here is the technology of digital representation of product data in its many forms of illustrations, drawings, 3-D wire frame models, surfaced models, solids models and complete product models.

The NBS CALS Program in product data exchange addresses the exchange, archiving and future use by DOD of digital product data. Major thrusts are:

development of a comprehensive program of testing and evaluation

identification and solution of problems encountered in intersystem data exchange

research into the unique requirements for long-term archiving

development of software tools to assist users in making routine production use of digital product data

continued development of new applications capability

validation of new applications areas

developmental work for complete product model data.

Throughout the DOD and its partners in industry, an increasingly larger number of computer aided design systems are being used in all phases of design, analysis, manufacture and test of weapons products. Over a hundred vendors offer these CAD systems. And it is natural that different DOD activities or different companies would choose different vendor systems to meet their varying needs. Hence, there is a requirement in the normal course of business to be able to exchange the digital part models that are developed on one system to be used on another system.

Estimated at $\$ 4.3$ billion in gross sales for 1986 , the CAD industry is expanding quickly, and the capabilities of CAD systems are similarly changing. But the need for part model exshange among these systems has not diminished. Rather, with over 10,000 new CAD systems being sold each month, portability of data is even more important to the DOD and its contractors each dzy. The exchange of digital product models is expected to become as commonplace in the 1990's as the exchange of paperbased engineering drawings is today. 
It is essential for CALs to be able to fully utilize these automation resources both at contractor and subcontractor facilities as well as inhouse for design review, second sourcing, overhaul planning and spare part production. Digital product data exchange plays a key role in each of these areas.

\subsection{Digital Product Data}

Two terms will be used; product definition data and product data. Product Definition Data (PDD) denotes the totality of data elements to completely define the product. Product definition data includes the geometry, topology, relationships, tolerances, attributes and features necessary to completely define a component part or an assembly of parts for the purposes of design, analysis, manufacture, test, inspection. Very little, if any, process data is included, with the exception being reference to a process standard (MILSTD) or reference to a procedure which results in a product condition that is not easily specified, e.g., heat treating for 1 hour at 320 degrees. The product definition is expected to be sufficiently complete as to enable the generation of all downstream process data.

Product Data is more broadly defined than Product Definition Data. Product data includes all of the product definition data plus a larger class of data elements necessary to fully support the product for all applications over its expected life cycle.

\subsection{Life Cycle Use}

Indicative of this larger class of product data are engineering analysis models or results and illustrations of the product to be used in documentation regarding operation, maintenance and engineering change control. Product data spans the entire range of disiplines from conceptual design and engineering analysis to manufacturing planning, production, test, inspection and deployment. Data packages are expected to go through repeated exchanges between primes, subs, government project managers, test labs, and consultants.

\subsection{Product Data as a Resource}

The CALS Program requires the ability to deal with digital product data for four generic applications:

Internal transfer of product data among DOD components

The acquisition of new manufactured parts/systems

Data transfer fom Design systems to Product support systems Archival storage of parts/assembly information 
Numerous internal transfers of product models are found in R\&D, prototype design, overhaul and retrofit planning, and each is a candidate for digital exchange in the immediate future.

Digital product data is becoming an important consideration in DOD's contractual relationship for purchase of manufactured parts, assemblies or whole systems. Considerable work is evolving in the area of electronic publication and digital exchange of technical documentation. MIL-STD 1840 is being coordinated for DOD-wide approval and makes use of a subset of IGES for the exchange of the illustrations in a document. This is thought to be quite appropriate since many of these illustrations are derived directly from the 3-D CAD product model.

DOD has significant investments in data archives necessary to support its deployed forces. Presently this data consists of millions of drawings stored in data repositories, but many agencies are beginning to address the problem of long-term archiving of digital product data.

The economic significance of digital product data is easily seen from these examples. Efficiency, accuracy and leadtime improvements are all substantially enhanced through the use of CAD and CAM technology made possible by the sharing of product data. The CALS Program addresses this importance and is expected to produce deliverables of use by all of US industry. 


\subsection{APPLICATIONS SUBSETS}

Even with the great variety of CAD systems in the marketplace today, no one system has the depth and breadth of capability to be able to satisfy the needs of all users. Hence, an organization tends to purchase a variety of CAD systems, each one thought to be best suited for its intended application. Data must be transferred among these business entities at major milestones of a project - design to engineering, manufacturing to inspection, prime to subcontractor or vendor to customer. When IGES is used for the exchange, a range of entities are needed. to convey the application's information content. This list of entities, a subset of the IGES entity list, becomes of priority importance to the successful exchange of the application.

\subsection{Definition and Importance}

The range of applications for digital product data is extremely large. Missile nose cone geometries, tank tread designs, footware sole pattern molds, machining geometries, technical illustrations and architectural floor plans each have their own requirements for data content and organization. Some applications like drawings make use of simple modeling techniques like wireframe geometry while more sophisticated applications like tank vulnerability analyses require a solids modeling approach.

Each of these applications areas has different requirements for the data needed to describe the product model. The first step in specifying how an applications area can exchange its product description as a digital dataset is to carefully define the information content to be transmitted. The second step is to specify how this information is mapped unambiguously into each IGES entity. The resulting list of IGES entities and their meaning in the context of the application forms what is termed the application subset.

An application subset of IGES can then be defined as a set of specific IGES entity types which are used to completely and unambiguously represent the information requirements of the product for the named application purpose.

\subsection{Present Use of Applications Subsets}

Application subsets are a natural way of organizing the informational needs for product data transfer and are being used already by several companies and government projects. Among these are CAD system procurement specifications from the Naval Sea systems Command and from Hughes Aircraft, the Boeing TOP Technical and office Protocols specification for product data exchange, and the draft Military standard 1840 for Automated Interchange of Technical Information. 
The impending Navy procurement of CAD workstations recognizes that there are five major application areas to be addressed mechanical design, aeronautical design, architectural engineering, electrical/electronic design and technical publications. It is felt that no one vendor system can effectively meet the Navy specifications in all areas. Hence, the Navy strategy is to allow multiple vendor awards and require IGES for internal transfer of product data among the dissimilar CAD systems. Because it is unrealistic to require each vendor to support all IGES entity types, application subsets of IGES will be specified. Conformance to version 3.0 is required. Conformance to future versions of IGES are called for within six months of publication.

The Hughes Aircraft Company makes use of multiple CAD systems in all phases of their mechanical design, electrical design, engineering and manufacturing processes. To be able to make use of the best tool for each job, they have stressed the need for digital data exchange through IGES entity subsets as mandatory requirements of their CAD system procurements. Version 3.0 of IGES is specified. Application subsets have been defined for solids modeling, mechanical design/drafting and printed circuit boards. Future work will develop subsets for finite element modeling, manufacturing process planning and NC tool paths.

The TOP specifications are being developed by an industry consortium administered by the Boeing company to address the exchange of typical data in the engineering, manufacturing and general office environments over telecommunications networks. One problem, of course, is the identification of standard formats for product data description. TOP views product data exchange as critical to the successful implementation of an integrated business strategy. In the TOP 3.0 Specifications, product data is to be exchanged via a defined subset of IGES 3.0 entity types with explicit constraints on file format, structure and content.

Two additional subsets are given in the appendices of IGES Version 3.0 and Version 4.0 documents. These are the Process Plant Flowsheets and the 3-D Piping System application subsets. The piping material has been influenced by the work of the Navy Seawolf Project (SSN2I) and has been approved by the IGES Architectural Engineering Committee.

Table 1 compares the IGES Entity Type content of the above subsets. The application subsets listed across the top have been assigned acronyms as:

$\begin{array}{ll}\text { MLSTD } & \text { MIL-STD } 1840 \text { of } 11 \text { Sept } 1986 \\ \text { T PUB } & \text { IGES Tech Pubs Application Guide - Draft Feb } 87 \\ \text { HA/EL } & \text { Hughes Aircraft Electrical Subset - V } 1.5 \\ \text { ELCAG } & \text { IGES Electrical Application Guide - Draft June } 86 \\ \text { SOLID } & \text { Hughes Aircraft Solid Modeling Subset - V } 1.5 \\ \text { DES/D } & \text { Hughes Mechanical Design/Drafting Subset - V } 1.5 \\ \text { TOP } & \text { Technical \& Office Procedures - Draft Feb } 87 \\ \text { FLOW } & \text { Flowsheet \& Instrumentation Diagrams - IGES } 3.0 \text { App C } \\ \text { PIPE } & \text { 3-D Piping Systems - IGES Version 4.0 Appendix }\end{array}$


TABLE 1 - IGES ENTITY CONTENT FOR SUBSETS

F

O

T R

100

102

104

104

104

104

106

106

106

106

106

106

106

106

106

106

108

108

108

110

112

114

116

118

118

120

122

124

125

125

125

125

126

132

202

206

210

212

214

214

214

214

214

214
125

ENTITY NAME

Circular Arc

Composite Curve

Conic Arc - General

Conic Arc - Ellipse

Conic Arc - Hyperbola

Conic Arc - Parabola

Coordinate Pairs

Coordinate Triples

11 Linear Planar Curve

12 Linear Curve

13 Linear Curve/Vector

20 Centerline Thru Points

21 Centerline Thru Centers

31 Section Lines

40 Witness Line

63 Simple Closed Area

Unbounded Plane

1 Bounded Plane

-1 Planar Hole

Line

Parametric Spline Curve Parametric Spline Surf Point

- Ruled Surface - Eq Arc

1 Ruled Surface - Eq Param Surface of Revolution

Tabulated Cylinder

Transformation Matrix

Flash - Ref Entity

1 Flash - Circular

2 Flash - Rectangle

3 Flash - Donut

4 Flash - Canoe

Rat B-Spline Curve

Connect Point

Angular Dimension

Diameter Dimension

General Label

General Note

1 Leader Arrow - Wedge

2 Leader Arrow - Triangle

3 Leader Arrow - Fill Tri

4 Leader Arrow - None

5 Leader Arrow - Circle

6 Leader Arrow - Filled C

$\mathrm{X}=$ Supported on Input \& output $\begin{array}{lllllllll}\text { M } & \text { T } & \text { H } & \text { E } & \text { S } & \text { D } & & & \\ \text { L } & & \text { A } & \text { L } & \text { O } & \text { E } & & \text { F } & \text { P } \\ \text { S } & \text { P } & \text { I } & \text { C } & \text { L } & \text { S } & \text { T } & \text { L } & \text { I } \\ \text { T } & \text { U } & \text { E } & \text { A } & \text { I } & \text { I } & \text { O } & \text { O } & \text { P } \\ \text { D } & \text { B } & \text { L } & \text { G } & \text { D } & \text { D } & \text { P } & \text { W } & \text { E }\end{array}$

$\begin{array}{lllllllll}X & X & X & X & X & x & x & x & x\end{array}$

$\begin{array}{lllllll}x & x & x & x & x & x & -\end{array}$

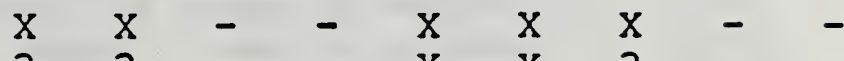

?

$?-?-\mathrm{X}-\mathrm{X}$

$-\quad-R-\frac{R}{R}$

$\begin{array}{llllll}- & - & R & - & - & R \\ X & X & X & X & - & R\end{array}$

$-\quad-x \quad X-R$

- $-\mathrm{X} X-\mathrm{X}$

$-\quad-\quad-\quad-x--$

$-\quad-\quad-\quad-X-1$

$-\quad-\quad-\quad-$

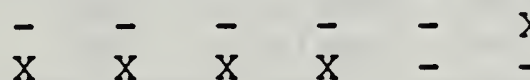

$-\quad-\quad-\quad-R$

- $-X X X$

$\begin{array}{lllllllll} & - & X & X & X & R\end{array}$

$\begin{array}{llllll}X & X & X & X & X & X\end{array}$

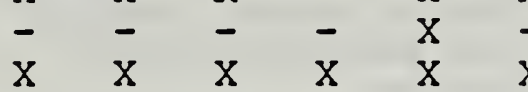

$----x--x-5$

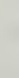

$\begin{array}{llll}- & \bar{x} & \bar{x} & \bar{x}\end{array}$

$-\quad-x$

$-\quad-\quad x$

$-\quad-x$

$\bar{x} \bar{x}-\bar{x}$

$\mathrm{x} x-\bar{x}$

$-\quad-\quad x$

$-\quad-x$

$-\quad-x$

$-\quad-x$

$\mathrm{x} \quad \mathrm{x}$

$x-x-x$

$-\quad-x--x$

$--x--x$

$-\quad-\quad-\quad--$

$-\quad-\bar{x}-\bar{x}$

$\mathrm{R}=$ Supported on Input only 
TABLE 1 - IGES ENTITY CONTENT FOR SUBSETS (Continued)

I

$\begin{array}{lrl}214 & 7 & \text { Leader Arrow - Rectangle } \\ 214 & 8 & \text { Leader Arrow - Filled R } \\ 214 & 9 & \text { Leader Arrow - Slash } \\ 214 & 10 & \text { Leader Arrow - Integral } \\ 214 & 11 & \text { Leader Arrow - Open Tri } \\ 216 & & \text { Linear Dimension } \\ 218 & & \text { Ordinate Dimension } \\ 220 & & \text { Point Dimension } \\ 222 & & \text { Radius Dimension } \\ 228 & & \text { General Symol } \\ 230 & & \text { Sectioned Area } \\ 302 & & \text { Associativity Def } \\ 308 & & \text { Subfigure Definition } \\ 312 & 0 & \text { Text Template - Abs } \\ 312 & 1 & \text { Text Template - Rel } \\ 320 & & \text { Network Subfigure Def } \\ 402 & 1 & \text { Group W BP Instance } \\ 402 & 3 & \text { Views Visible Inst } \\ 402 & 4 & \text { Views Vis, Color, LW } \\ 402 & 7 & \text { Group wo BP Instance } \\ 402 & 9 & \text { Single Parent Inst } \\ 402 & 18 & \text { Flow Associativity } \\ 404 & & \text { Drawing - R } \\ 406 & 2 & \text { Property - Region Res } \\ 406 & 4 & \text { Property - Region Fill } \\ 406 & 5 & \text { Property - Line Widen } \\ 406 & 6 & \text { Property - Drill Hole } \\ 406 & 7 & \text { Property - Ref Desig } \\ 406 & 8 & \text { Property - Pin No. } \\ 406 & 9 & \text { Property - Part No. } \\ 406 & 11 & \text { Property - Tabular Dat } \\ 406 & 12 & \text { Property - Ext Ref FL } \\ 406 & 13 & \text { Property - Nominal Size } \\ 406 & 14 & \text { Property - Line Spec } \\ 406 & 15 & \text { Property - Name } \\ 408 & & \text { Subfigure Instance } \\ 410 & & \text { View } \\ 412 & & \text { Rect Array Sub Inst } \\ 414 & & \text { Circ Array Sub Inst } \\ 416 & 0 & \text { External Reference } \\ 416 & 1 & \text { External Reference } \\ 416 & 2 & \text { External Reference } \\ 420 & & \text { Network Subfigure Inst } \\ & & \end{array}$

$\begin{array}{lllllllll}M & \text { T } & \text { H } & \text { E } & \text { S } & \text { D } & & & \\ \text { L } & & \text { A } & \text { L } & \text { O } & \text { E } & & \text { F } & \text { P } \\ \text { S } & \text { P } & \text { I } & \text { C } & \text { L } & \text { S } & \text { T } & \text { L } & \text { I } \\ \text { T } & \text { U } & \text { E } & \text { A } & \text { I } & \text { I } & \text { O } & \text { O } & \text { P } \\ \text { D } & \text { B } & \text { I } & \text { G } & \text { D } & \text { D } & \text { P } & \text { W } & \text { E }\end{array}$

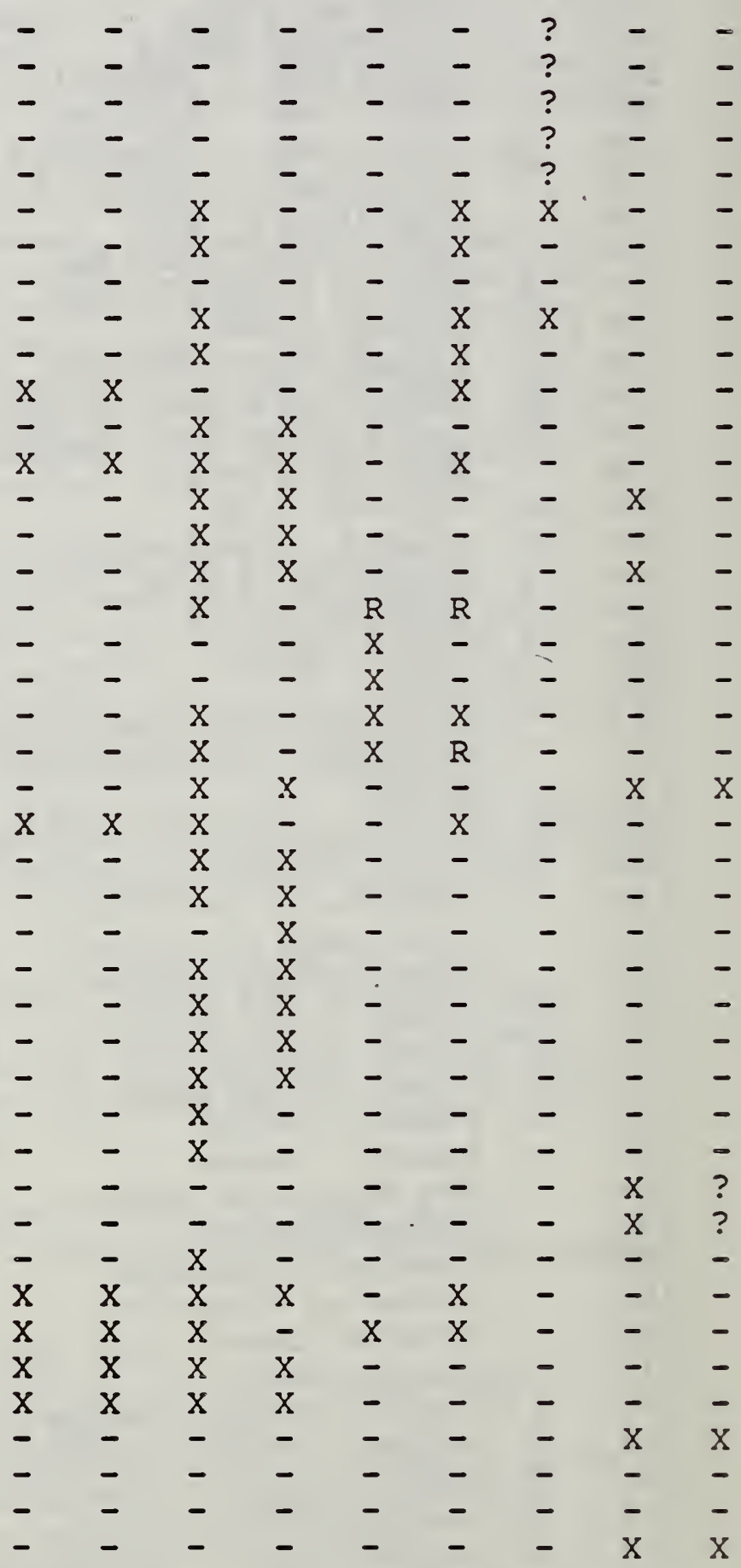

$\mathrm{X}=$ Supported on Input \& Output

$R=$ Supported on Input only 
As can be seen from Table 1 , several inconsistancies remain to be resolved among the different application subsets:

1. MIL-STD $1840^{\circ}$ has chosen to allow only default identity Transformation Matrices while the IGES Tech Pubs subset allows arbitrary Transformation Matrices to move entities from Definition space to Model space position.

2. MIL-STD 1840 and the IGES Tech Pubs subset use a simplified form of Drawing and View entities to make the illustration file acceptable to most CAD systems. The Hughes solid subset is missing the Drawing entity.

3. The IGES Electrical Application subset and the TOP Mechanical Subset contain neither the View nor the Drawing entities. This makes it impossible to construct a part model on some CAD systems.

4. The TOP specification calls for an application subset to be implemented in accordance with a list of IGES Recommended Practices which further specify the processing algorithms to be used. These include:

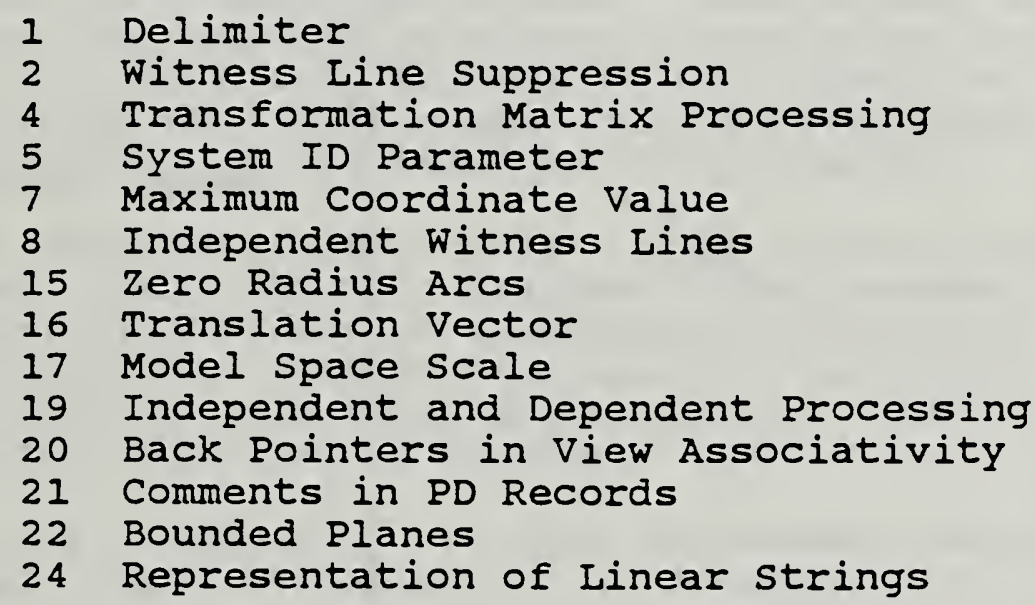

5. The TOP Specification calls for implementation of $R P 12$ on Flag Notes without requiring the Flag Note entity.

6. The TOP Specification is not specific as to which Leader Arrow Form Numbers are required.

7. MIL-STD 1840 and the IGES Tech Pubs subset both call for adherance to IGES Version 3.0 yet ask for Line Font 5 (Dotted) in Global Field 4. This capability exists only in IGES Version 4.0

8. The Hughes Aircraft Specification for Electrical and for Mechanical Design/Drafting requires three new Leader Arrows (2pts, 3pts and 4 pts) not in IGES. 
9. The Hughes Aircraft Specification for Electrical and for Mechanical Design/Drafting requires General Note Fonts 1. 1001, and 1002 to be fully supported with Font 0 only processed when reading in an IGES file. No other subse... requires these fonts to be fully supported, although two others restrict the value of the $P D$ Index to these fonts.

10. MIL-STD 1840 and the IGES Tech Pubs Subset both call for a DE Field 4, Line Font Pattern, value restriction of 0 for Entity type 414, Circular Array subfigure Instance. But neither subset places a similar restriction on Entity type 412 , Rectangular Array Subfigure Instance.

11. Only the Hughes Aircraft Specifications place requirements on the Global Section parameters. Notable among these are:

Field
1
2
3
4
5
6
7
8
9
10
11
12
13
14
15
16
17
18
19
20
21
22
23
24
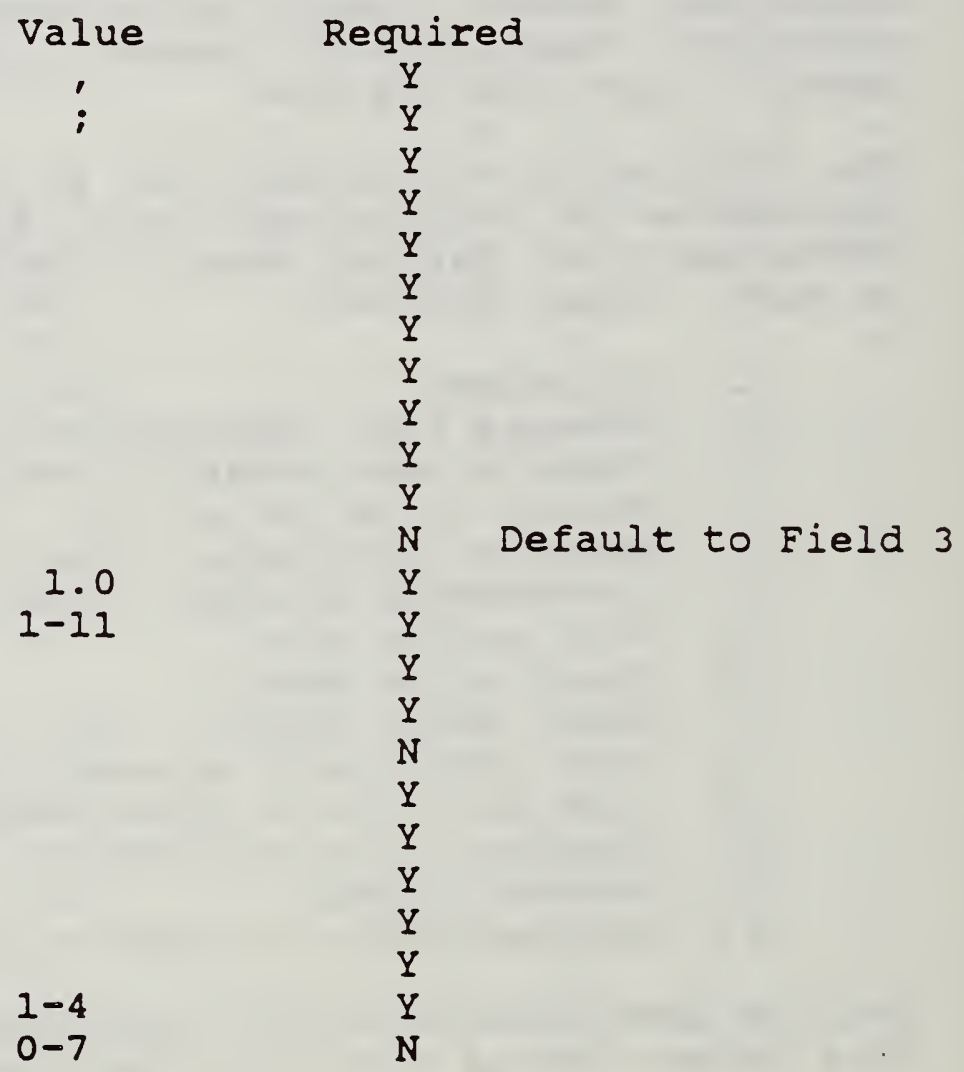


\subsection{IGES Subsets of Interest to DOD}

The list of application areas of interest to the Department of Defense is expected to be quite long and to grow with experience as digital product data exchanges become commonplace. But a controllable population is expected. Historically, the IGES organization has worried about the proliferation of entity types as new application areas express their requirements. Fortunately, this has not been found as major a problem as anticipated, and the same is expected with application subsets.

Presented here are several subset definitions known to have a following in the DOD. Undoubtably, there are others. And no special effort has been made to eliminate an overlap of requirements. They are by no means specific only to DOD needs and will benefit from industry collaboration as well.

Technical Publication Illustrations - The exchange of figures for a technical document requires 2-D geometry plus annotation. Emphasis is on visual clarity for human interpretation.

Engineering Drawing - The 2-D Engineering Drawing is presently the backbone of product definition. Information is presented to conform with certain standards of style and content as set forth by ANSI Y14.5, MIL-SPEC's and MIL-STD's. Exchange emphasis is on completeness, visual equivalency and functionality of the received drawing model.

Electrical Printed Wiring Boards - This subset handles both the physical description of printed wiring assemblies as well as the logical information describing connectivity and schematic representation. Design, engineering, manufacturing, testing and inspection processes are supported. Cabling and connectors can also be modeled.

Process Plant Flowsheets - Process flowsheets identify the process streams, their direction and instrumentation lines flowing through a plant. They identify the equipment names and the positions on the equipment where the lines connect. properties can be attached to the lines or to the equipment.

Mechanical Design/Drawing - Frequent exchanges are made of 3-D mechanical part models along with a drawing derived from the model. Part geometry is given as a 3-D model in either wireframe and/or surfaced form. The drawing must be able to meet ANSI Y14.5 or MIL-SPEC requirements. Data requirements include those of 3-D mechanical models, those of 2-D Engineering Drawings and other entities which define how the views on the drawing are derived from the part model.

Architectural Engineering and Construction - Many AEC applications exist and are rich in non-geometric data content. Progress is being made in Tabular Data, Connectivity and External File Reference to assist these future application subsets. 
3-D Piping and Tubing - Found in buildings, refineries, ships and trucks, piping and tubing systems direct fluids to various pieces of equipment. The information content of these systems includes equipment nomenclature, connect nozzles, connecting pipes and the pipe line attributes.

Mechanical Solid Modeling - Solid modeling is predominently used for conceptual design of mechanical devices and assemblies. The solid model allows the user to check for clearance problems, compute mass properties and generate shaded images of the product. Data generated in the solid model application is often passed to other solid model based applications. This application subset addresses the solid-to-solid information exchange.

NC Data Generation - The mechanical part model and the manufacturing process plan form the input for numerical control machining data preparation. outputs include the required fixtures, the cutting tools and the toolpath control data for the selected machine. The input requirements for the part model are addressed by this IGES NC Data Generation subset. They include 3-D wireframe geometry, 3-D surface geometry and first order continuity along part geometry.

Finite Element Modeling - Exchange between a product design system and a product structural analysis system requires capability to describe the 3-D finite element mesh, the engineering parameters of each finite element and the nodal analysis results.

This list of applications is far from complete and will grow with experience and time. No priority order is inferred by this list although Technical publication Illustrations is becomming quite mature with the coordination of MIL-STD 1840 for DOD-wide use. The Electrical PC Board subset represents years of work by the IGES Electrical Committee and is ready for prototype trial. Process Plant Flowsheet has been reviewed as an appendix to IGES Version 3.0, and 3-D Piping is a recent product of the IGES AEC Committee to appear in IGES 4.0 The Hughes Aircraft procurement specification is the source for the remaining subsets and has been reviewed by knowledgable staff and vendor implementors.

Remaining to be done is to poll the DOD community for additional ideas on IGES application subsets and their priority needs. This can best be done through the NSIA CAIS committees, the DOD Manufacturing Technology Advisory Group, inhouse program managers from all service components concerned with each application, CALS service contacts and members of the IGES organization who are in the DOD or affected companies. 


\subsection{General Requirements}

It is important that the specification of any application subset be complete, precise and unambiguous. Incomplete translator implementations or differing interpretations of entity meaning will degrade the quality or will limit the quantity of information which can be exchanged between sender and receiver. The application subset specification must be complete in that it be designed to stand alone as a document referencable in a legal contract for deliverables. It must be precise so that the accuracy and functionality of the received data is sufficient to support the intended use of the data. And the specification must of course be unambiguous so that application information which was mapped into IGES entities can be fully recovered without any loss at the receiving site.

An application subset is thought to be a mechanism which will substantially improve the completeness of data exchange in the specified area of use over what can now be transferred. For this end-to-end data exchange to happen:

The information to be transferred must be identified.

The information must be uniquely mapped into IGES entities.

The entities must be exchanged accurately and completely.

The receiving system must be capable of processing each entity in the subset.

The receiving system must be capable of representing each information construct.

The most demanding of these steps is that of identifying the information content of a prescribed application area. Formal modeling techniques such as IDEFIX, NIAM and EXPRESS which are being used in the IGES organization are certainly of help for this.

Next the information must be mapped into a series of IGES entity types. It is important that this mapping be unique, for if a dashed line is represented in any of three different ways as IGES now allows, a receiving CAD system must be very intelligent to recognize they are identical.

This leads to a restrictive entity subset for each application area. No entities can be used which are not enumerated in the application subset. While it is recognized that this places burdens on the software developer and on the CAD operator, no other way guarantees the needed completeness of data exchange. See section 5.0 of this report.

A last requirement of an application subset is to properly limit the range of entity type numbers and their parameter values. The entity descriptions which result are called the application subset. 


\subsection{Technical Content of an Application Subset}

An application subset must be sufficiently precise and comprehensive in its definition to serve as a portion of a contract between the two parties of the data exchange. At a miminum, the documentation requirements for an application subset include the following:

SCOPE - A general introduction of the application and the discipline being served. Statements of purpose of the subset and a specific description of the industry and range of applications to be served will be given.

INFORMATION REQUIREMENTS and DATA FUNCTIONALITY - A detailed list of what must be transferred through the use of the subset. This could include 3-D geometry, associativity elements denoting fluid flows, view transforms, fonts, and so forth. This section must be filled out with considerable care because it will serve as the basis for deciding which entities will be included in the IGES subset.

IGES ENTITY SUBSET SPECIFICATION - The description of the entities to be used for the subset. An optional section describing why these specific entities and not others were used, can go here. Limits on parameter range.

MAPPING Of INFORMATION CONTENT to IGES SUBSET ENTITIES This is the specification of how the application functions and related information is to be mapped into an IGES subset. As an example "All steam lines will be represented by copious data entities of Form 3 denoting $x, y$, and $z$ coordinates". The Implementors of IGES translators will use this section as a guide for designing their products.

DATA ACCURACY REQUIREMENTS - A description of data accuracy requirements not covered by the data functionality section. Such items as the minimum number significant digits would be included here

USER CONVENTIONS and DATA ORGANIZATION - A listing of the required usages not normally covered by the IGES specification. An example would be: "Electrical details are presented in level 4. plumbing in level 5"

TESTING REQUIREMENTS - A detailing of the test cases used and their purpose. The concept and its implementations must be tested. Each functional component should be covered by one or more test cases. This section describes them and the results.

EXAMPLES of APPLICATION SUBSET USE - An instructional set of examples showing typical use of the subset. 


\subsection{TESTING METHODOLOGY FOR APPLICATION SUBSETS}

The development of IGES validation testing methods is one of the major projects of the IGES Organization. This section summarizes the current efforts in testing methodology, summarizes the concepts developed for the program, and provides a more detailed look at how application subsets can be tested. Version 0.3 of the Testing Methodology working paper is included as an appendix. This document is now being coordinated by NBS and will be substantially revised and expanded by March 1987.

\subsection{Testing Methodology Concepts}

IGES Testing is concerned with developing and maintaining test procedures which deal with verification testing, validation of processors for specific application subsets, and application specific, user performed acceptance testing.

Verification testing is aimed at ensuring that the implementor's claims for entity mapping and functionality of translation are accurate. Validation testing is aimed at ensuring that application subsets of IGES are treated in a manner consistent with the application. And acceptance testing is aimed at ensuring that particular IGES processors will work adequately in a user's environment. The immediate goal of the Testing Methodology Committee is to establish a verification program for translators.

objectives of this testing are to verify the correctness of the implementor's claims for individual entity processing, to measure the precision of data translation and to assess the degree to which the functionality of the entities have been maintained. Functionality of the results of a translation is defined as the degree to which received entities can be manipulated as if they had been generated on the receiving system.

There are several major reasons why testing IGES processors is necessary. Both implementors and users of the processors are interested in testing. Implementors need a set of widely accepted test procedures and data in order to ensure that their products conform to and adequately support entity subsets for a specific application area of the IGES standard (i.e., verification and validation testing). Users and implementors need a set of widely accepted test procedures to determine if the processors in question will adequately support the user's data exchange requirements (i.e., acceptance testing). In addition, users frequently desire advice on how to construct test data sets which will accurately reflect these data exchange requirements. Finally, since much data exchange, worth millions of dollars, will be accomplished using IGES translators, users are requiring more assurance that the data is not being modified or lost during the exchange process. 
The objective of IGES testing is to expose flaws in the IGES products (i.e., to show where products do not work as they should). In his book, "The Art of Software Testing" (MYER79), Glenford Myers cites the following basic principles:

- Testing is the process of executing a program with the intent of finding errors.

- A good test case is one that has a high probability of detecting an as yet undiscovered error.

- A successfui test case is one that detects an as yet undiscovered error.

In the context of generalized IGES translator testing, the test cases developed will be aimed at exposing flaws in important

features of the translators. A broad range of test cases will be validated and thoroughly documented.

This section has been condensed from the working papers of the testing methodology committees with modifications to incorporate recent progress and to specificaliy address the needs of application subsets. The intent is to provide a background in testing concepts for the reader. More detailed information can be found in the working document (TEST86).

\subsection{Use of Entity Mapping in Data. Exchange}

Entity mapping can be described as the manner in which the implementor of a translator has defined the correspondence between native entity forms (i.e., the entity form maintained within a system) and the IGES entity forms (i.e., the entity form contained in the IGES specification). For example, a string of curve and line segments on a system may be translated into a composite Curve entity (Type 102) by a preprocessor. This correspondence of a string in the native form to a Composite curve in the IGES form is the preprocessor's entity mapping for the native string entity. similarly, a postprocessor may translate a Copious Data entity (Type 106) into a 3-D ine entity on the receiving system under some circumstances. Thus, the correspondence of the Copious Data entity to the line entity is the postprocessor's entity mapping for the IGES Copious Data entity.

The entity maps can be used as a first step in predicting the expected completeness of data exchange between two systems. Knowing the native entities which are to be used on the sending (or initiating) system, the end user can follow each entity through the entity maps for both the preprocessor and the postprocessor to see what the resulting entity will be on the receiving system. 


\subsection{Requirements for a National Verification Program}

It is proposed that the thrust of the verification of a processor be the substantiation by an independent agency of an implementor's claims for th:e entity mapping and other processing carried out by a translator. The method proposed here is to collect this information from an implementor for each processor to be verified, and then to perform sufficient testing so as to verify that the claims made are correct and that the entity mapping is correctly described.

The IGES verification program will be sponsored by the society of Automotive Engineers (SAE). It is one of several verification programs administered by them. There are four groups which participate in the verification program: the SAE staff, the Technical Board, the IGES Verification Panel, and the testing agency (s)

The SAE Technical Board serves as an overseer for the various review panels sponsored by the SAE. The Board reviews and approves the operating procedures of the review panels as well as their membership. The Technical Board is also responsible for ensuring that, in the event of dispute, the appeals procedure as outlined in the SAE Technical Board Rules and Regulations apply and are carried out.

The IGES Verification Panel will come under the jurisdiction of and report directly to the SAE Technical Board. It will be composed of people who are technically competent in the area of IGES and CAD data exchange.

Subject to approval by the SAE Technical Board, the IGES Verification Panel will formulate operating procedures, rules and operating guidelines ensure that the verification program adequately serves all interested parties, including industry and the general public while adhering to the principles, policies, and objectives of the SAE.

The work of the IGES Verification Panel is to review pertinent test criteria, testing techniques and test results to verify that IGES pre- and postprocessors satisfy the requirements of data exchange as referenced in the NBS IGES specification. The Panel may issue a statement to the interested party setting forth the review and determination it makes to verify or dispute the conclusion reached by the testing agency(s). It is not anticipated that the scope of the Verification Panel's work will include verification of all the underlying hardware and supporting software for the translators.

The IGES Verification Panel will consist of adequate membership to reflect the views of the users, interested agencies, laboratory testing, and other interested and affected parties. Initially the membership will be appointed by the SAE Technical Board. Subsequent membership will also be approved by this Technical Board. 


\subsection{The Verification Process}

Initially the SAE Testing Program is directed at providing a verification that a vendor claim of IGES entity processing is correct. This has the effect of testing on an entity level only and leaves a user to verify, first, that the required entities are present for a prescribed application subset and, second, that the information is being mapped correctly into and out of those entities. In later stages of the SAE Program, subset testing may be possible.

The verification process is initiated by an implementor completing a Verification Request Package and submitting it to the with the IGES Verification Panel of the SAE. The verification package contains all the needed information including the implementors entity maps and native forms. This information is necessary to enable the verification testers to determine which test cases need to be executed.

The IGES Verification Panel will schedule the test and assign a tester. Using the information on the request form, the tester will identify the test cases needed from the test library and execute a test plan and record the results. These results will be returned to the IGES.Verification Panel for a decision on whether the processing of the translator has been verified.

The IGES Verification Panel will notify the Presenter of its findings prior to any public release of the verification material. The Presenter will than have an opportunity to respond to any problems encountered or to appeal the decision of the Panel. When a translator has been successfully verified, the verification Package (the request, test results, and summary report) will be forwarded to a sponsoring government agency for distribution. This agency will distribute copies of the summary Report and the Verification Package on request.

\subsection{Current Efforts and Status}

Prior to the fall, 1986 IGES meeting in Huntsville, the decision was made to split the Testing Methodology Committee into six separate committees. This action was deemed necessary because of the massive effort needed, the slow progress in reaching our final goal, and the difficulty in conducting technical meetings with fifty to sixty people in attendance. The functions of the six committees can be summarized as follows:

- Verification Testing Methodology Committee which is responsible for establishing verification policy and procedures for translator testing. This is the general translator testing where vendor claims are verified against test libraries. 
- Application Validation Methodology Committee which is responsible for developing the concepts of application subset testing and the procedures for validating translators for specific applications.

- Acceptance Testing Methodology Committee which is responsible for developing the mechanisms where users can verify that systems will work correctly in their user environment.

- Methodology Testing committee which is responsible for verifying that all of the developed procedures are valid. They will also inspect the test cases and audit the IGES verification program.

- Test Case Development Committee which is responsible for devising the guidelines for developing and documenting test cases, developing the test cases, and distributing the test cases.

- User Information Committee which is responsible for developing documentation, gathering and distributing information, and developing tutorials.

Application subset testing requires a known testing environment before its special problems can be addressed. This decision may adversely impact MIL-STD-1840 development. A possible interim method will be discussed in a following section.

The Society of Automotive Engineers is actively pursuing the initiation of an IGES Verification Program by the summer of 1987. They have designated members for the Technical Board and are putting together a list of candidates for the IGES Verification Panel. Universities have also been contacted as possible sites for the translator testing. NBS is looking for a way to provide some seed money for this program. The major problem for the SAE is the lack of a completely defined testing program with ample test cases.

NBS is sponsoring two meetings in February 1987 to help accelerate the testing program. The first meeting is geared to developing the criteria for test cases, test case documentation, and the generation of prototype test cases. These cases will be used the following week for a meeting that is designed to revise the testing documentation and to do a trial run of the verification test on a CAD system at NBS. The results of these two meetings will provide the basis for the testing methodology committee agenda at the April IGES meeting.

Through the User Information Committee, NBS has been contacting major CAD vendors seeking vendor entity maps, permission to use the maps to develop IGES testing methods, and permission to release the maps to the public as part of the reporting and education process. The vendor response has been very positive with seven vendors having given their verbal permission to use their mapping data. As of yet NBS has not received written approval from these vendors. 


\subsection{TECHNICAL ISSUES}

The restrictive nature of the application subset concept calls for some mechanism to limit the entity content of the IGES file to only those entities specified in the subset. Further restrictions exist for some parameter value ranges in some specified entities. Enforcing this requirement can be done in several ways:

1. Require that a CAD operator generate a native CAD Model with no entities that will be mapped to IGES entities outside of the subset.

2. Configure the vendor IGES output translator to enforce the desired subset by converting native entities into conforming IGES entities.

3. Develop separate software routines to convert an IGES file resulting from a "best try" on some CAD system into a conforming subset IGES file.

No other methods are known for assuring that the needs of a prescribed IGES subset are met. Each of these methods places serious restrictions on a class of users, and these drawbacks are sure to cause much debate. It is not essential that one method be chosen over all others. Rather, it would be entirely appropriate to use a combination of the three. The Pros and cons of each alternative are explored in the sections to follow.

\subsection{Control over the operator Selection of Entities}

A CAD system offers a large range of functionality to its user community, and conventions for its use vary from shop to shop. An operator can with equal ease prepare a drawing to Y14.5 specifications or intentionally violate accepted drafting principles. The question is one of enforcing a policy, and the CAD systems of today generally cannot enforce a company or a national policy on how a part model is created.

Similar problems exist when a part model is being created to satisfy a policy on application subsets. If the operator makes use of CAD menu functions which create entities outside of the prescribed subset, the IGES file created by a general purpose translation process will be noncompliant. In the absence of any other technique, compliance to a subset absolutely requires that an operator not be allowed to use certain CAD system capabilities. This requirement can only be relaxed if one of the other two methods can aid in the conversion of entities to those in the subset. 


\subsection{Requirements on IGES Translator Design}

IGES translator designs have focused on faithfully representing the native CAD model in the IGES entity set so that it could be made available to a "foreign" process. If both the input and the output translators are done well, an IGES file generated by a CAD system can be read back into the same system to create a part model indistinguishable from the first.

As our attention turns to generating correct application subsets, it should be understood how a CAD system translator could be of assistance. An IGES output translator could be configured to do any or all of the following:

Flag any noncompliant entities.

Throw away any native entity not mapping directly to a conforming IGES entity.

Approximate native entities with the closest conforming IGES entity.

Approximate native entities by a set of conforming IGES entities.

While these would be valuable functions for any user wishing to prepare an IGES file conforming to an application subset, they place a tremendous burden on the developer of IGES translator software. Consider the problem of developing and maintaining separate IGES translators for each of umteen application subsets.

\subsection{Flavoring and Deflavoring Requirements}

Flavoring is a term that is used to describe particular practices built into a translator in situations where, for preprocessors, the underlying system supports entities or relationships which are not directly supported by IGES, and, for postprocessors, the underlying system does not handle specific entities or relationships supported by IGES. Since the manner in which these situations are handled is not standardized, other knowledge than what is available in the IGES document is needed. This additional knowledge is frequently built into the translators and results in files that have a noticable style of IGES entity construction.

Flavoring can also be taken to mean that an IGES file contains legal IGES entity types outside the range of a particular application subset, i.e. a Linear Dimension entity in the Tech Pubs subset. one method of correcting the problem is to write a flavor converter which reads a tainted IGES file and writes a correct one. In the example given, the offending Linear Dimension is approximated in appearance by Iine entities and a General Note. 
Construction of flavor converters is not trivial, but it is not by any means an enormous project. And it places a user in a position of control. Standardized input and output routines can be used to ease the work. Additional functions other than entity manipulation can be performed such as quality control over all datasets shipped to a customer. Certainly it is a valuable tool to have at one's disposal should a CAD system not provide all the functionality needed for a particular job.

\subsection{Software Tools for Acceptance Testing}

Since the DOD will soon be purchasing and accepting IGES files, they will need a software package that can verify that the entities in the dataset conform to both the application subset and to the IGES specification. This can either be accomplished by creating new software or through modification of one of the commercial IGES syntax checkers.

To demonstrate both options, the CALS Product Data Exchange project at NBS has developed a PC-based program and has made changes to the IDA Analyzer. Using a test file library, several datasets were tested with the modified IDA analyzer for conformance to the technical publishing subset. The analyzer correctly identified the undefined entities and ran to completion. This result indicates that separate software modules do not have to be used to check different conformance aspects of application datasets. The IGES QC analyzer from the University of Leeds has not been used to test subset conformance. However, representatives from the University indicate that the changes to do so would be simple.

But while this represents a good start, the tools require considerable refinement in concert with the evolving application subsets. In the future a better array of tools need to be developed to properly test the processors producing the datasets and the datasets themselves. The software needed for the processor validation will be expensive to develop. Cost estimates to date significantly exceed the funds available to the IGES office. Software for the functionally testing will take longer to develop because the process is not well defined. The impact of the lack of these software tools will be that testing will be less rigorous and be much more labor intensive. 


\subsection{Testing of Datasets for Conformance}

Because IGES entity subsets are being created and developed to address specific application areas, the concepts of dataset acceptance issues will also have to be developed in parallel. Agencies such as the DOD and large corporations typically build conformance safeguards into their contracts so that they know they are purchasing correct data and products. IGES in its attempt to serve as broad a user segment as possible incurs special conformance problems in being all things to all users. For example, not only is geometry being communicated but also presentation information, associativity information, annotations, and transformations.

Acceptance testing represents the attempt on the part of receiving agencies to guarantee that all of the information in the sending system is correctly interpreted in the target system. To this end, acceptance can be broken down into three areas; they are functionality, logical, and physical. Functionality is the highest level and the most difficult to test. It refers to the semantics or the information content of the model in the native database of the sending system. Logical testing refers to the entity mapping and system limits of a vendors system - does the vendor correctly handle all of the entities in the subset correctly and does the system generate entities not included in the subset. Physical checking refers to the structure of the data file and its syntax. Files must be constructed properly with all entities, forms, pointers and associated information correctly positioned. Alphanumeric rules must be rigorously followed, data type conventions followed, units used consistently, and precision rules followed. This type of test is conceptually simple but very complex because of the allowable freedom in the IGES specification.

Functional checking to an application subset specification is a complicated process that is currently ill-defined and impossible to test exhaustively. The evaluation system for such functional testing has also no clear consensus at this time. Such subjects as visual equivalence, pictorial accuracy, data functionality, application functionality and information functionality will need further discussion and evaluation.

At this time the testing method for IGES transfer of any kind is the visual comparison of a drawing from both the sending and the receiving systems. This will not verify that the functionality associated with entities remain intact. For example collections of lines may represent a cooling system. This shortcoming is serious because the need to transfer functionality unambigiously is the primary reason for the existence of application subsets.

It has been proposed to use a neutral database to compare IGES files built from standard reference models with those generated for reference scripts on a vendors CAD system. This tool would then have application to both translator verification testing and application validation testing. Though potentially useful, such a verification tool is expensive and not currently funded. 
Actually much of the functionality checking is for application subsets is done in the formulation of the application subset and conventions for its use.

Most problems with IGES files are rooted in the inherent ambiguities of the specification and imprecise vendor translations of IGES entities. With subsets, constraints on allowable constructs reduce semantic difficulties reducing the potential for error. There is no longer redundant constructs and as a consequence the translators will be smaller and easier to maintain.

Physical conformance testing is an exhaustive process where IGES files are checked for strict adherence to the IGES specification. Such programs are large, tedious, and absolutely essential. These syntax checkers must check all of the entities, their forms, attributes, associations, structures, construction details and organization. Fortunately, there are two commercial products that can do these tests. They are the 'IGES Analyzer' from IGES Data Analysis Corporation and 'IGES QC' from the University of Leeds in the UK. Both checkers are available at a reasonable cost to run on Vax based systems. The IDA analyzer also runs on UNIX based systems. Both systems have been exercised with sample IGES test files and found to be satisfactory. These checkers have the additional benefit that they can check subset conformance with their syntax check.

Conformance of entities to the application subset is the easiest test. A conformance checker must be able to read an IGES file and and extract the data from it. Next the program must inspect the entities in the file and verify that they are members of a target subset. Such a conformance program has been written at NBS in the Basic language. This program is in the public domain and when documentation is complete can be copied freely. The program is expected to be the first building block in what will be a series of IGES utility programs. It is important to bear in mind that, although checking subset conformance to the subset specification is necessary, it is by no means a sufficient test. IGES files are more likely to be in error syntactically or functionally. 
Table 2 Summary of Testing Levels

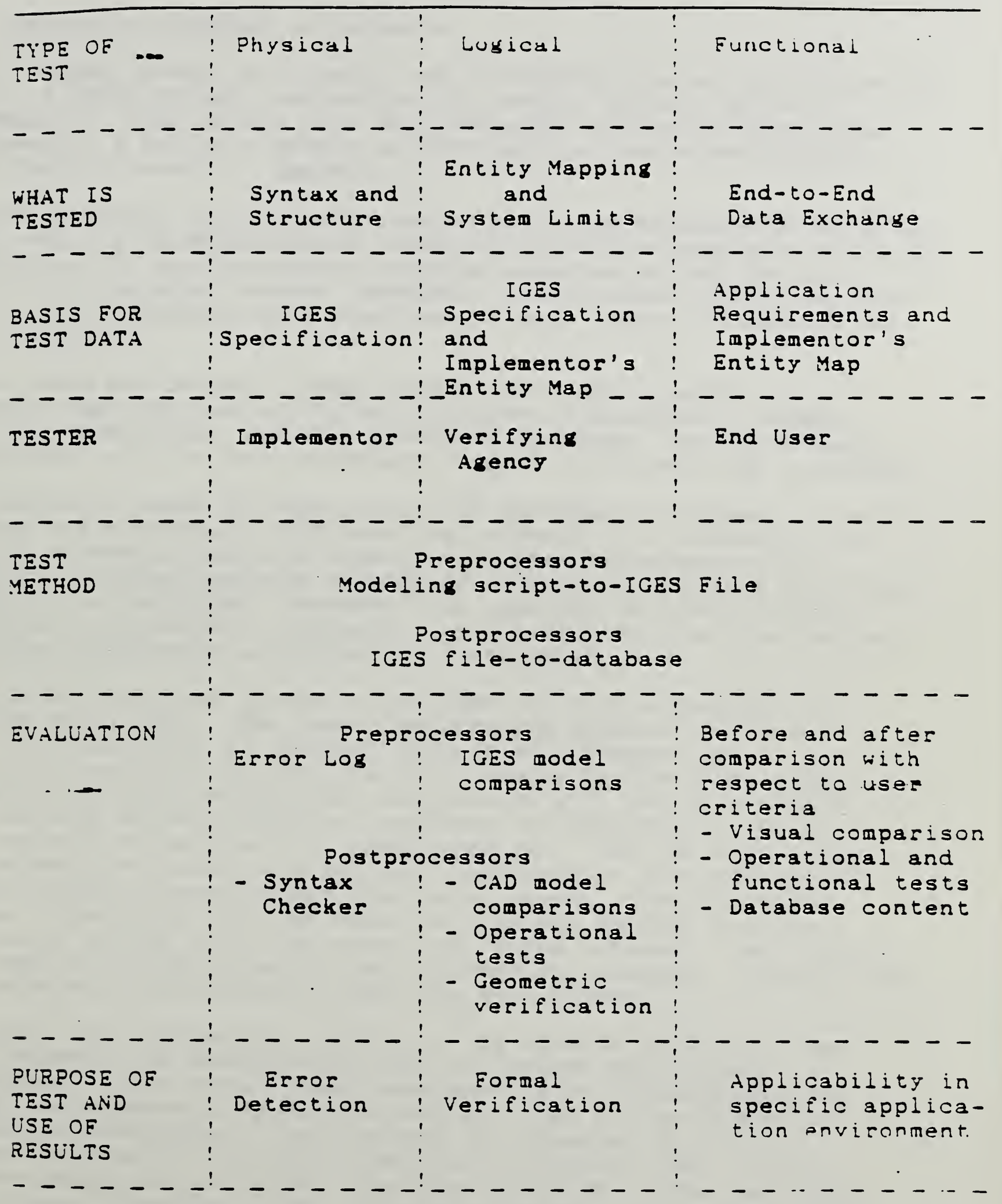





\subsection{POLICY CONSIDERATIONS}

\subsection{Policy on Purchase of Datasets}

DOD's stated intent is to begin use of digital product data files by 1990. A draft Policy Instruction for product data is given in Appendix A. This refers to a draft MIL-STD on Product data given in Appendix $B$ and to a series of IGES application subsets given by a draft MIL-SPEC in Appendix $C$.

Service elements have already started prototype exchange as early as 1985, and a 1984 NAVSEA Policy Instruction states that IGES is to be invoked on all new contracts involving transfer of CAD/CAM data. But in dealing with dataset transfers in a contract situation, the problem is compounded with questions of data rights, liability and dual authority.

While there may be many issues raised as to data rights, it is believed that the use of digital transfers introduces no change over the traditional use of engineering drawings. But invariably contractors will be more reluctant to part with their CAD databases.

The liability issue is seen not in the purchase of datasets as much as when the government furnishes the datasets to a contractor as part of a contractual relationship. If the data exchange is perfect, it seems there is no more of a liability problem than. When a drawing is furnished. However, the question of liability for wrongful or incomplete information as a result of less than perfect software translators is difficult to prejudge.

Intriguing questions abound on the issue of dual authority drawing or dataset. The formal engineering drawing of today is still the authority for product definition. Steeped in tradition, codified by ANSI standard, tested in the courts and cited by MIL-SPEC and MIL-STD, the drawing will remain a useful tool so long as man wishes to interpret the geometry, topology, tolerances and features of a product design. Yet few will argue that someday we will place far more imortance on the exchange of digital product descriptions than we do paper. Drawings will become a by-product derived from the received dataset for the purpose of aiding human understanding of the dataset. The drawing will not be a primary method for information exchange. However, no one is able to cite exactly when this will happen.

The term "dual authority" alludes to the interim period of time when datasets and drawings are both in typical use in data exchanges. Which should take precedence if an inconsistency is found? Experience is that this happens often enough to require serious consideration. One instance was reported in which digital information in IGES format was in typical use. A last -minute change to a critical dimension was made to the text note of a linear dimension in the CAD system rather than by modifying the part geometry being dimensioned. Since the part was made from the received geometry rather than from a model created from the received CAD generated drawing, the part was wrong. 


\subsection{Acceptance Testing of Datasets}

Acceptance testing of datasets by the government must be complete enough to ascertain that the datasets are of sufficient quality to meet the contract specifications for payment. Acceptance testing represents the attempt on the part of receiving agencies to guarantee that all of the information in the sending system can be correctly interpreted by the target system.

At this time the typical testing method for IGES transfer is the visual comparison of a drawing from both the sending and the receiving system. This will not verify that the functionality associated with entities remains intact. The limitation is serious because the need to transfer functionality unambigiously is the primary reason for the existence of application subsets. Fortunately, software tools are beginning to be developed to meet this challenge. These are already in the prototype stage. priority should be given to supporting their creation.

\subsection{Verification of Source Preparation Systems}

Procedures are needed by those who will be producing IGES application subset files as contract deliverables to verify the ability of their systems to conform. A first step is to require SAE application subset validation as a part of each new system purchase. But this does not address all those systems in the installed base. Certainly the same procedures used by SAE could be followed, but the skilled personnel resources may not be available to the smaller firms. 


\subsection{ACTION REQUIRED TO IMPLEMENT}

A formal strategy is needed to effectively implement digital exchange of technical data within the DOD. A draft policy instruction on the subject is given in Appendix A.

Technical data can be divided into unstructured text, technical documentation and product data. Unstructured text is outside the scope of this report. The exchange of technical documentation in digital form is addressed by MIL-STD 1840 which already exists and is in final stages of coordination. Product data exchange is the subject of this report. It is thought that this can best be addressed by creating a DOD-wide MIL-STD similar to 1840 but which addresses the entire range of digital product data applications, not just technical documentation. This is given in draft form in Appendix B. This document represents a major rewrite of 1840 .

To fill the need for a complete and precise specification on IGES application subsets, a new Military specification is proposed. This is given in draft form in Appendix C. It contains subsets for technical illustrations, 2-D engineering drawings and electronic printed wiring boards. These three subsets are only the start of several which will form the completed MIL-SPEC.

A number of actions are necessary to provide implementation of this strategy for application subsets throughout the DOD. A list is given here for consideration by the CALS office:

The draft DOD Policy Instruction for Digital Product Data Exchange given in Appendix $A$ should be reviewed by the CALS office and circulated for adoption by all commands.

The draft Military Standard for Digital Product Data Exchange given in Appendix $B$ should be reviewed by the CALS office and circulated for adoption. This MIL-STD references the MIL-SPEC on IGES application subsets in Appendix $C$.

The draft Military Specification on IGES Application Subsets given in Appendix $C$ should be reviewed by the CALS office and circulated for adoption.

The DOD community should be polled for additional engineering disiplines requiring IGES application subsets including a request for priority ranking of needs. This can best be done through the NSIA CALS committees, the DOD Manufacturing Technology Advisory Group, inhouse program managers from all service components concerned with each application, CALS service contacts and members of the IGES organization who are in the DOD or affected companies. 


\section{REFERENCES}

\section{Glossary}

Acceptance Testing - The testing performed by a user to determine the suitability of a translator for a specific environment.

Application Validation - The testing which is aimed at ensuring that application subsets of IGES are treated in a manner consistent with the application on the system under test. See also Conformance Testing.

CAD Model - The representation of a product definition model in a CAD system's native form. See also IGES Model.

Certify - To guarantee the quality or worth of; to vouch for. Webster's New World Dictionary-1972U

Conformance Testing - The testing which is aimed at ensuring that the processing of individual entities and data items accurately reflects IGES specification.

Entity - The basic unit of information in an IGES file. This term applies to single items which may be individual elements of geometry, collections of annotation to form dimensions, or collections of entities to form structured entities.

Entity Mapping - The change of entity definition during conversion between data formats. This conversion may result in a change of mathematical definition but maintains the same information content.

Evaluation Criteria - The set of items in the test results which are to be examined, along with the means of measuring how these items indicate the performance of the processor under test. These criteria will typically be defined on a test-by-test basis and will describe the features of the test that are of interest. For example, the Evaluation Criteria for a line might be its position in the model and its length. Here, a comparison of the expected position with the resulting position would be defined for the test. See also Validation Criteria.

Functionality - The ability to edit, move, scale or otherwise manipulate a postprocessed entity as if it were created originally on the receiving system.

IGES Model - The representation of a product definition model in IGES format. This is usually in the form of an IGES file. See also CAD Model.

Standard Reference Model - The representation of a product definition model prior to being processed by an IGES

translator. See also Test Results Model. 
Test Data Library - The collection of data sets, along with the documentation for the data sets, which are to be used in the testing of processors. Data sets in the Test Library exercise specific features of the standard and include both correct and incorrect data. A given data set may take part in more than one Test script.

Test Methodology - A high level definition of testing philosophy, practices, issues and general procedures. It contains the rationale of test procedures, the kind of testing that is necessary, and, in general terms, how to conduct tests.

Test Procedures - Descriptions of the various tests that are necessary to test a particular aspect of implementations of the standard. These procedures identify the test data and the processes that are to be used in testing. This will generally contain reference to a set of specific Test Scripts.

Test Result Model - The representation of a product definition model after being processed by an IGES translator. See also Standard Reference Model.

Test scripts - The detailed, step-by-step instructions which describe how to conduct a test. Scripts will contain references to specific data sets in the Test library which are to be used. A log for documenting each test should also be provided. Discussion of specific Evaluation criteria will also be included.

Validation Criteria - The specifications that a test analyst will use to determine the applicability of a piece of software for a specific application. These are based on the results of applying the Evaluation Criteria (q.v.) and usually identify a minimum acceptable level of performance. For example, if the Evaluation Criterion for a line is its position, then the validation Criterion for the test might be that the position may not vary by more than .001 inches, or perhaps by more than $1 \%$ of the coordinate value.

Verify - To test or check the accuracy or correctness of, as by investigation, comparison with a standard or reference to the facts. Webster's New World Dictionary-1972U.

Verification Criteria - The specific criteria that a verifying body will use to assign functionality ratings to a processor. These criteria will be defined by the Testing Methodology Committee. 
BRAD85

BRIG85

DOWN8 6

ELEC8 6

FLOW86

GRAB8 4

HANS 85

MILST86

MYER79

NSEA 84

PIPE86
Bradford, J. "IGES Translator Analysis for Autofact '85", Detroit, MI: Society of Manufacturing Engineers, 1985. Available from the National Technical Information Service.

Briggs, D. "Subsets of IGES." Washington, D.C.: National Bureau of Standards. Published in Minutes of IGES Test, Evaluate, and Support Committee Meeting, 29APR85-3MAY85, Atlanta, GA, 1985. Available from the Chairman.

Downer, Ronald G., "Hughes/EDSG IGES

Requirements Specification", Hughes Aircraft Company, Electro-optical and Data systems Group. Available from the publisher.

Electrical Application Guide, IGES Version 3.0 (Preliminary). Published by the IGES

Electrical Applications Committee (EAC). Available from the Chairman.

Plant Flow Sheet Product Representation, IGES Version 3.0, Appendix C, Apr 86.

Grabowski, H. and Glatz R. "Test and Validation of IGES Processors." Karlsruhe, West Germany: Institute fur Rechneranwendung in Planning and Konstruktion. University of Karlsruhe, 1984, Available from the Chairman.

Hansen, D.I. Correspondence, Cincinnati, OH: Applicon, March 4, 1985. Available from the Chairman

Military Standard MIL-STD-1840, "Automated Interchange of Technical Information", HQ AFLC/SITA, Wright-Patterson AFB, Ohio 45433.

Myers, G. J. "The Art of Software Testing." New York, NY: John Wiley \& Sons, 1979. Available from the publisher

NAVSEA INSTRUCTION 5230, Department of the Navy, Naval Sea Systems Command, Washington, D. C. 20362. Subject: Transferring Technical Data Among Navy and Contractors' CAD/CAM Systems, 23 Aug 84 .

Piping Model Example, IGES Version 4.0 Engineering Change Order 430, NBS, Nov 86. 
TECH8 6

TOPS87
Technical Publications Application Guide, IGES Version 3.0 (Preliminary). Published by the IGES Technical Publications committee. Available from the Chairman.

Testing Methodology of IGES Translators, Draft 0.03 , 19 sept 86, Testing Methodology Committee, Available from the Chairman.

TOP 3.0 Specification for Digital Product Data, Preliminary Draft, Feb 87, Boeing Computer Services, TOP Chairman, PO Box 24346, MS 7c-16, Seattle, WA 98124-0346. 

SCOPE :

This instruction addresses the specification, purchase and acceptance testing of product data in digital form throughout the DoD. It promulgates mechanisms for incorporating the exchange of digital product data into the normal procurement and business operations of the DOD. Requirements are given for the specification, purchase and acceptance testing of product data in digital form. Use of application subsets of the Initial Graphics Exchange specification (IGES) Version $4.0,1987$ is directed by citations to appropriate MII-STD's and MIL-SPEC's.

\section{OBJECTIVE :}

The objective of the Computer Aided Logistics program in digital product data is the effective exchange of data throughout the life cycle of weapons systems development and deployment through the use of computer-readable datasets describing the systems, their individual piece parts and their product support data. $A$ central issue here is the technology of digital representation of product data in its many forms of illustrations, drawings, 3-D wire frame models, surfaced models, solids models and complete product models.

\section{BACKGROUND :}

The CALS Program in product data exchange addresses the exchange, archiving and future use by DOD of digital product data. Major thrusts are:

Development of a comprehensive program of testing and evaluation

Identification and solution of problems encountered in intersystem data exchange

Research into the unique requirements for long term archiving

Development of software tools to assist users in making routine production use of digital product data

Continued development of new applications capability

Validation of new applications areas

Developmental work on methods for complete product model data representation 
Throughout the DOD and its partners in industry, an increasingly larger number of computer aided design systems are being used in all phases of design, analysis, manufacture and test of weapons products.. Over a hundred vendors offer these CAD systems. And it is natural that different DOD activities or different companies would choose different vendor systems to meet their varying needs. Hence, there is a requirement in the normal course of business to be able to exchange the digital part models that are developed on one system to be used on another system.

It is essential for CAIs to be able to fully utilize these automation resources both at contractor and subcontractor facilities as well as inhouse for design review, second sourcing, overhaul planning and spare part production. Digital product data exchange plays a key role in each of these areas.

\section{DIGITAL PRODUCT DATA:}

Two terms will be used; product definition data and product data. Product Definition Data denotes the totality of data elements to completely define the product. Product definition data includes the geometry, topology, relationships, tolerances, attributes and features necessary to completely define a component part or an assembly of parts for the purposes of design, analysis, manufacture, test, inspection. Very little, if any, process data is included, with the exception being reference to a process standard or reference to a procedure which results in a product condition that is not easily specified, e.g., heat treating for 1 hour at 320 degrees. The product definition is expected to be sufficiently complete to enable the generation of all downstream process data.

Product Data is more broadly defined than Product Definition Data. Product data includes all of the product definition data plus a larger class of data elements necessary to fully support the product for all applications over its expected life cycle.

\section{LIFE CYCLE USE:}

Indicative of this larger class of product data are engineering analysis models or results and illustrations of the product to be used in documentation regarding operation, maintenance and engineering change control. Product data spans the entire range of disiplines from conceptual design and engineering analysis to manufacturing planning, production, test, inspection and deployment. Data packages are expected to go through repeated exchanges between primes, subs, government project managers, test labs and consultants. 


\section{EXTENT OF USE:}

The CALS Program requires the ability to deal with digital product data for four generic applications:

Internal transfer of product data among DOD components

The acquisition of new manufactured parts/systems

Data transfer fom Design systems to Product Support systems

Archival storage of parts/assembly information

Numerous internal transfers of product models are found in $R \& D$, prototype design, overhaul and retrofit planning, and each is a candidate for digital exchange in the immediate future.

\section{ECONOMIC BENEFITS:}

Digital product data is becoming an important consideration in DOD's contractual relationship for purchase of manufactured parts, assemblies or whole systems.

DOD has significant investments in data archives necessary to support its deployed forces. Presently this data consists of millions of drawings stored in data repositories, but many agencies are beginning to address the problem of long-term archiving of digital product data.

The economic significance of digital product data is easily seen from these examples. Efficiency, accuracy and leadtime improvements are all substantialiy enhanced through the use of CAD and CAM technology made possible by the sharing of product data.

\section{APPLICATION SUBSETS :}

Each application of CAD/CAM has different requirements for the data describe the product model. The Initial Graphics Exchange Specification provides a mechanism for representing product data in a neutral public domain format. Subsets of IGES entities will be used as required to support the information exchange needs of different design, engineering, manufacturing and product support areas.

An application subset of IGES is defined as a set of specific IGES entity types which are used to completely and unambiguously represent the information requirements of the product for the named application purpose. 


\section{APPLICABLE MILITARY STANDARDS:}

MIL-STD 1840 defines the digital representation of technical documentation with associated drawings. MIL-STD $184 \mathrm{x}$ addresses the exchange of digital product data. Both MIL-STD's make reference to IGES application subsets given in MIL-SPEC nnnn.

\section{POLICY :}

Application Subsets of IGES Version 4.0 as expressed by implementing Military specifications and Standards shall be used for exchanging product data.

ACTION :

MIL-STD Application Subsets will be invoked on all contracts calling for exchange of digital product data.

All offices, activities and detachments shall ensure that all sollicitations, proposals and contracts for new construction, conversion, modification, modernization and overhaul require delivery of any generated digital product data in the appropriate MIL-STD format.

Renegotiation of existing contractural agreements is encouraged where cost effective and feasible.

All DOD repositories of technical information on product definition including engineering drawings shall formulate plans and implement mechanisms for accepting, archiving and furnishing as necessary digital product datasets in MIL-STD format.

Where digital product data along with appropriate engineering drawings is made available to a contractor by a DOD component as government furnished equipment, it shall be marked for reference purposes only with the drawing made prime authority.

In those situations where spare parts are purchased from an inhouse facility or from a contract source, extra incentives should be offered to develop and capture the digital product data in MIL-STD format for future logistics use.

\section{EXCEPTIONS :}

In situations where both sender and receiver possess the same hardware and software, native CAD system database files should be requested in addition to the IGES MIL-STD Application subsets. The native data will satisfy the present need while the IGES will serve longer range or unforeseen future needs. 
NOTE: This draft, dated 23 February 87 prepared by Div 732 National Bureau of standards, has not been approved and is subject to modification. DO NOT USE FOR ACQUISITION PURPOSES. Project NBS CALS Product Data.

MILITARY STANDARD

EXCHANGE OF DIGITAL PRODUCT DATA

Beneficial comments (recommendations, additions deletions) and any pertinent data which may be of use in improving this document should be addressed to Bradford Smith, Bldg. 220 , Rm A353, Bureau of Standards, Gaithersburg, MD 20899 by using the self-addressed Standardization Document Improvement Proposal (DD Form 1426) appearing at the end of this document or by letter. 
FOREWORD

The CALS Program in product data exchange addresses the exchange, archiving and future use by DOD of digital product data. Major thrusts are:

Development of a comprehensive program of testing and evaluation

Identification and solution of problems encountered in intersystem data exchange

Research into the unique requirements for long term archiving

Development of software tools to assist users in making routine production use of digital product data

Continued development of new applications capability

Validation of new applications areas

Developmental work on methods for complete product model data representation

Throughout the DOD and its partners in industry, an increasingly larger number of computer aided design systems are being used in all phases of design, analysis, manufacture and test of weapons products. Over a hundred vendors offer these CAD systems. And it is natural that different DOD activities or different companies would choose different vendor systems to meet their varying needs. Hence, there is a requirement in the normal course of business to be able to exchange the digital part models that are developed on one system to be used on another system.

It is essential for CALS to be able to fully utilize these automation resources both at contractor and subcontractor facilities as well as inhouse for design review, second sourcing, overhaul planning and spare part production. Digital product data exchange plays a key role in each of these areas. 


$$
\text { MIL-STD-184x }
$$

1. SCOPE

1.1 scope. This standard addresses the specification, purchase and acceptance testing of product data in digital form throughout the DOD. It promulgates mechanisms which shall be used when digital product data is to be exchanged in normal procurement and business operations.

1.2 Purpose. The purpose of this standard is to specify the representation of digital product data to facilitate the effective exchange of this information throughout the life cycle of weapons systems development and deployment. This is accomplished through the exchange of computer readable datasets describing the systems, their individual piece parts and their product support data. A central issue here is the technology of digital representation of product data in its many forms of illustrations, drawings, 3-D wire frame models, surfaced models, solids models and complete product models. 


\section{APPLICABLE DOCUMENTS}

\subsection{Government documents.}

2.1.1 Specifications, standards, and handbooks. The following specifications, standards, and handbooks form a part of this specification to the extent specified herein. Unless otherwise specified, the issues of these documents shall be those listed in the issue of the Department of Defense Index of specifications and standards (DODISS) and supplement thereto, cited in the solicitation.
a. MIL-STD-100 Engineering Drawing Practices
b. MIL-STD-D-1000 Engineering Drawings and Associated Lists
c. MIL-STD-804B Formats and Coding of Aperature Cards

2.1.2 Other Government documents, drawings, and publications. The following other government documents, drawings, and publications form a part of this specification to the extent specified herein. Unless otherwise specified, the issues of these documents shall be those in effect on the date of the solicitation.

2.2 Other Publications. The following documents form a part of this standard to the extent specified herein. Unless otherwise indicated, the issue in effect on the date of invitation for bids or request for proposal shall apply, or as otherwise specified in the contract.

a. Initial Graphics Exchange Specification, Version 3.0, NBSIR 86-3359, April 1986, U.S. Department of Commerce, National Bureau of Standards.

(Application for documents should be addressed to National Technical Information Service, 5285 Port Royal Road, springfield, VA 22161, Document Number 86-199-759)

2.3 Order of precedence. In the event of a conflict between the text of this standard and the references cited herein, the text of this standard shall take precedence. 


\section{MIL-STD-184X \\ 3. DEFINITIONS}

3.1 Acronyms used in this text. The acronyms used in this text are defined as follows:
a. IGES - Initial Graphics Exchange Specification
b. ASCII - American Standard Code for Information Interchange
c. EDIF - Electronic Design Interchange Format
d. VHSIC - Very High Speed Integrated circuit

3.2 Application Subset. An application subset of IGES is defined as a set of specific IGES entity types which are used to completely and unambiguously represent the information requirements of the product for the named application purpose.

3.3 Initial Graphics Exchange Specification. IGES provides a mechanism for representing digital product data in a neutral public domain format. Information is represented as geometry, annotation and structural relationships among the entities.

3.4 Product Data. Includes all of the product definition data plus a larger class of data elements necessary to fully support the product for all applications over its expected life cycle.

3.5 Product Definition Data. The totality of data elements in a digital dataset necessary to completely define the product. Product definition data includes the geometry, topology, relationships, tolerances, attributes and features necessary to completely define a component part or an assembly of parts for the purposes of design, analysis, manufacture, test, inspection. Very little if any process data is included, with the exception being reference to a process standard or reference to a procedure which results in a product condition that is not easily specified. 


\section{GENERAL REQUIREMENTS}

4.1 General. Throughout the DOD and its partners in industry, an increasingly larger number of computer aided design systems are being used in all phases of design, analysis, manufacture and test of weapons products. Over a hundred vendors offer these CAD systems. And it is natural that different DOD activities or different companies would choose different vendor systems to meet their varying needs. Hence, there is a requirement in the normal course of business to be able to exchange the digital part models that are developed on one system to be used on another system.

4.2 Digital Product Data. Product Data includes the totality of data elements in a digital dataset necessary to completely define a piece part, an assembly of parts or an entire weapons system. The term includes the geometry, topology, relationships, tolerances, attributes and features necessary to completely define the product and support its lifetime use.

4.2.1 Extent of Use. Product data spans the entire range of disiplines from conceptual design and engineering analysis to manufacturing planning, production, test, inspection and deployment. Data packages are expected to go through repeated exchanges between primes, subs, government project managers and test labs.

4.3 Digital Data Exchange. Product data can be exchanged by way of the neutral data formats. IGES is in widespread use for Mechanical part models and has extensions to technical illustrations, electrical printed wiring boards, architectural engineering, manufacturing and finite element analysis. EDIF and VHSIC are being developed for integrated circuit product designs.

4.4 IGES Data Exchange. In a data exchange with IGES, information is carried as a series of entities describing geometry, annotation and relationships. The sending system places its part model into the IGES entities, and the receiving system extracts the information to construct its part model. Incomplete data exchange results when either system fails to adequately transform its native representation to or from the IGES representation. Since all systems do not, or cannot, support all IGES entities, narrower subsets of entity types are selected to support common data exchange requirements.

4.5 EDIF Product Data Exchange. 《 To Be Developed >

4.6 VHSIC Product Data Exchange. < To Be Developed > 


\section{MIL-STD-184x}

\section{- $\quad 5.0$ DETAILED REQUIREMENTS}

5.1 Exchange of IGES Product Data. Where IGES is used for product data exchange, the detailed requirements of MIL-SPEC-nnn shall be used.

\subsection{Application Subsets. Each engineering application} has different requirements for the data needed to describe the product model. The first step in specifying how an applications area can exchange its product description as a digital dataset is to carefully define the information content to be transmitted. The second step is to specify how this information is mapped unambiguously into each IGES entity. The resulting list of IGES entities and their meaning in the context of the application forms what is termed the application subset. An application subset of IGES can then be defined as a set of specific IGES entity types which are used to completely and unambiguously represent the information requirements of the product for the named application purpose.

5.2.1 Restrictive Nature of Subsets. For each application subset, no IGES entities shall be used which are not enumerated in the defined subset. Systems generating IGES data conforming to these subsets shall not generate IGES entities outside the specified subset. Systems designed to interpret these subsets shall be able to handle all IGES entities within the specified subset.

5.2.2 Requirements on Subsets. All IGES application subsets shall comply with the IGES Specification for entity syntax and file structure. They shall also comply with the detailed specifications of MIL-SPEC-nnnn. IGES files are composed of five sections, Start, Global, Directory Entry, Parameter Data and Terminate. This standard places additional requirements on these sections.

5.2.2.1 Start section. The following information shall be given in the start section of the file:

a. Statement of conformance to the relevant application subset and the revision date of the subset.

b. The identification of the product being described.

c. Date the file was prepared.

d. Performing organization, date and contract number.

e. Data organization method used with contents of each level. 
5.2.2.2 Global section. The following fields in the Global section are required and shall not be defaulted:

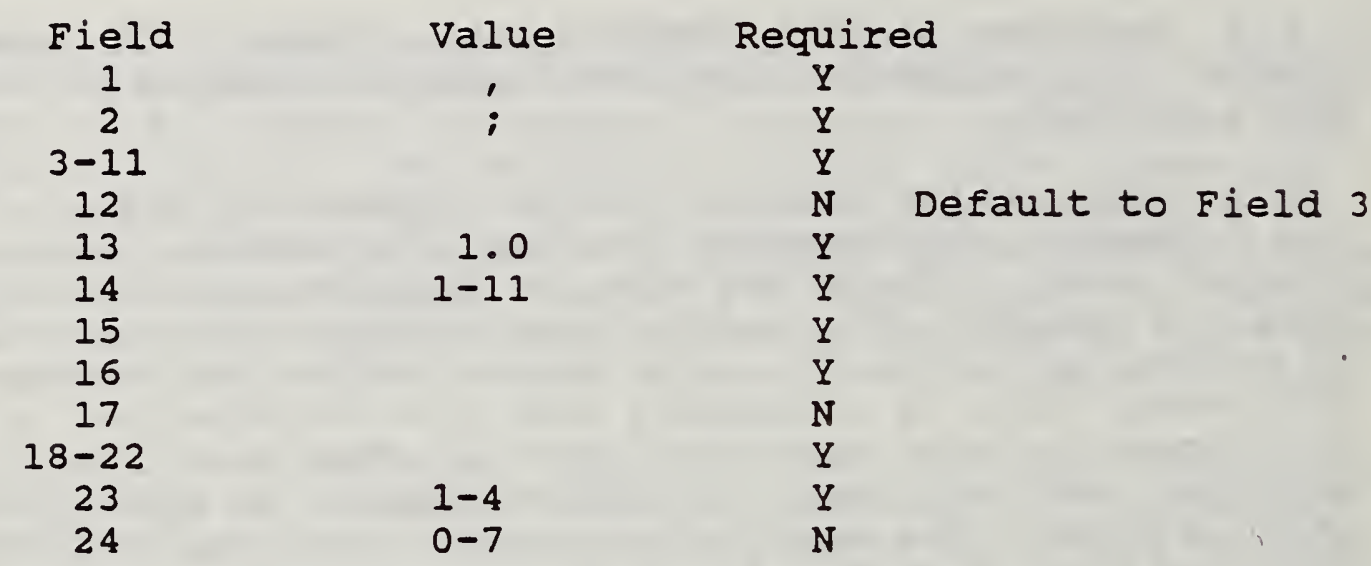

5.2.2.3 Directory Entry Section. The following capabilities shall be provided and shall be supported for all entities:

a. The Level Number Field. All values shall be positive except where necessary to maintain the truest meaning of the referenced entity.

b. The Logical and Physical Subordinate Entity Switch.

c. The Entity Use Flag.

d. The Hierarchical status Flag.

e. The Line Weight Number.

f. The Color Number.

5.2.2.5 Parameter Data Section. No restrictions of a general nature are placed on the parameters in the Parameter Data section.

5.2.2.6 Terminate section. No restrictions of a general nature are placed on the parameters in the Terminate section.

5.3 Testing Requirements. Start, Global, Directory Entry, Parameter Data and Terminate sections shall each be analyzed for conformance to the IGES Specification with an appropriate software utility. The start section and the Global section shall be printed out and checked visually with requirements of the applicable MIL-SPEC-nnn application subset. 
MIL-SPEC-nnnn

5.4 EDIF Product Data Exchange. $<$ To Be Developed $>$

5.5 VHSIC Product Data Exchange. $<$ To Be Developed $>$ 

NOTE: This draft, dated 27 February 87 prepared by Div 732 National Bureau of Standards, has not been approved and is subject to modification. DO NOT USE FOR ACQUISITION PURPOSES. Project NBS CALS Product Data.

\section{MILITARY SPECIFICATION}

IGES APPLICATION SUBSETS

Beneficial comments (recommendations, additions deletions) and any pertinent data which may be of use in improving this document should be addressed to Bradford Smith, Bldg. 220, Rm A353, Bureau of Standards, Gaithersburg, MD 20899 by using the self-addressed Standardization Document Improvement Proposal (DD Form 1426) appearing at the end of this document or by letter.

DISTRIBUTION STATEMENT A. Approved for public release; distribution is unlimited. 
The Appendix C submitced in February 1987 was accepted as the base document for a new military specification. The approved document, . MIL - D - 28000, was approved on 22 December 1987. 


\begin{tabular}{|l|l|l|}
\hline $\begin{array}{c}\text { NBS-114A (REV. 2-80) } \\
\text { U.S. DEPT. OF COMM. } \\
\text { BIBLIOGRAPHIC DATA } \\
\text { SHEET (See instructions) }\end{array}$ & $\begin{array}{l}\text { 1. PUBLICATION OR } \\
\text { REPORT NO. } \\
\text { NBSIR 88-3729 }\end{array}$ & 2. Performing Organ. Report Noj 3. Publication Date \\
\hline
\end{tabular}

4. TITLE AND SUBTITLE

A Collection of Technical Studies Completed for the Computer-aided Acquisition \& Logistic Support (CALS) Program - Fiscal Year 1987 (Vol. 4 of 4 )

5. AUTHOR(S)

Edited by Thomas Wright

6. PERFORMING ORGANIZATION (If joint or other thon NBS, see instructions)

7. Contrace Grant No.

\section{NATIONAL BUREAU OF STANDARDS U.S. DEPARTMENT OF COMMERCE GATTHERSBURG, MD 20899}

8. Type of Report \& period Covered NBSIR, $10 / 86$ through $9 / 87$

9. SPONSORING ORGANIZATION NAME AND COMPLETE ADDRESS (Street, City, State, ZIP)

Office of Assistant Secretary of Defense (A\&P)/WSIG

Department of Defense, Pentagon

Washington, DC 20301-8000

10. SUPPLEMENTARY NOTES

Document describes a computer program; SF-185, FIPS Software Summary, is attached.

11. ABSTRACT (A 200-word or less factual summery of most significant information. If document includes a significant bibliography or literature survey. mention it here)

The overall objective of the Department of Defense Computer-aided Acquisition \& Logistic Support (CALS) Program is to integrate the design, manufacturing, and logistic functions through the efficient application of computer technology. The National Bureau of Standards has been funded since spring 1986 to recommend a suite of industry standards for system integration and digital data transfer, and to accelerate their implementation. A major FY87 thrust was the completion of initial documentation of the high-priority standards required in the CALS environment. This volume is one of four providing a collection of the final reports presented to the CALS Policy office. Major topics contained within this product data volume include: the acceleration of testing methodology for IGES, the development of the IGES application subset concept, and the acceleration of PDES deliverables. The other three volumes include reports on text, data management, media, raster compression, graphics, and a conformance testing strategy.

12. KEY WORDS (Six to twelve entries; alphabetical order; capitalize only proper names; and separate key words by semicolons) CADCAM; CAIS; conformance; DOD; IGES; PDES; testing; verification

13. AVAILABILITY

X Unlimited

— For Official Distribution. Do Not Release to NTIS

$\square$ Order From Superintendent of Documents, U.S. Government Printing Office, Washington, D.C. 20402.

¿X Order From National Technical Information Service (NTIS), Springfield, VA. 22161
14. NO. OF PRINTED PAGES 155

15. Price

$\$ 18.95$ 

